ACCA Think Ahead

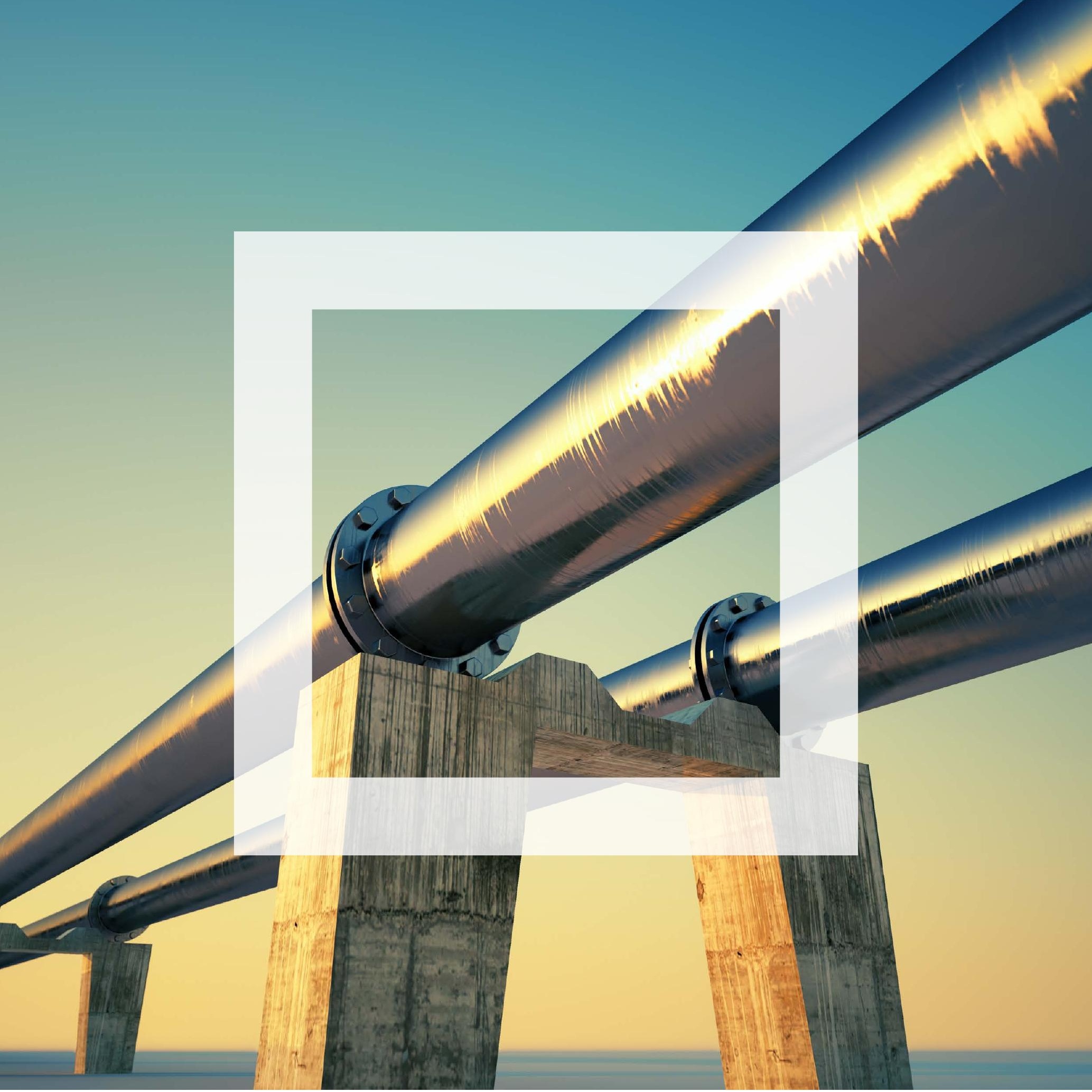

THE CAPITALISATION OF INTANGIBLES DEBATE: ACCOUNTING FOR EXPLORATION AND EVALUATION EXPENDITURE IN EXTRACTIVE ACTIVITIES 


\section{About ACCA}

ACCA is the Association of Chartered Certified Accountants. We're a thriving global community of 227,000 members and 544,000 future members based in 176 countries that upholds the highest professional and ethical values.

We believe that accountancy is a cornerstone profession of society that supports both public and private sectors. That's why we're committed to the development of a strong global accountancy profession and the many benefits that this brings to society and individuals.

Since 1904 being a force for public good has been embedded in our purpose. And because we're a not-for-profit organisation, we build a sustainable global profession by re-investing our surplus to deliver member value and develop the profession for the next generation.

Through our world leading ACCA Qualification, we offer everyone everywhere the opportunity to experience a rewarding career in accountancy, finance and management. And using our respected research, we lead the profession by answering today's questions and preparing us for tomorrow.

Find out more about us at www.accaglobal.com

\section{About the Adam Smith Business School}

The University of Glasgow includes among its alumni, the father of economics, Adam Smith. The Adam Smith Business School is named in his honour. We aim to follow his legacy by developing enlightened, engaged and enterprising graduates, who are internationally recognised and make a positive impact on culture and society. Our business is about creating inspiring leaders, researchers and professionals whose research and relations with industry have real impact, influencing organisations as they develop and grow globally.

The Adam Smith Business School has the triple crown of accreditation as it is accredited by the Association to Advance Collegiate Schools of Business (AACSB International), the European Quality Improvement System (EQUIS) and the Association of MBAs (AMBA) for its MBA programme.

The School is home to research, of international and national excellence, that contributes to theoretical advancement and is relevant to practice. Two more recent examples reflecting this are the School's contribution to the Productivity Institute and the Adam Smith Observatory of Corporate Reporting Practices. The Productivity Institute will directly inform government policy to improve UK productivity. The Observatory is comprised of an international network of researchers in accounting with practice-based experience. It aims at providing accounting standard setters and regulators across the world with evidence-based inputs, such as this report, when the evidence is timely and directly relevant to the issues they tackle.

Find out more about us at www.gla.ac.uk/schools/business/aboutus/ 


\section{THE CAPITALISATION OF INTANGIBLES DEBATE: ACCOUNTING FOR EXPLORATION AND EVALUATION EXPENDITURE IN EXTRACTIVE ACTIVITIES}

ACCA AND ADAM SMITH BUSINESS SCHOOL RESEARCH REPORT

Anna-Fani Constantatos (Deree - The American College of Greece)

Dionysia Dionysiou (University of Stirling)

Richard Slack (Durham University)

loannis Tsalavoutas (University of Glasgow)

Fanis Tsoligkas (University of Bath)

For further information, please contact:

Richard Martin, Head of Corporate Reporting, ACCA

richard.martin@accaglobal.com

Ioannis Tsalavoutas, Professor of Accounting, Adam Smith

Business School, ioannis.tsalavoutas@glasgow.ac.uk 


\section{Contents}

$\begin{array}{ll}\text { Executive summary } & \mathbf{6}\end{array}$

Background and objectives $\quad 6$

Method $\quad 6$

$\begin{array}{ll}\text { Main findings } & 7\end{array}$

$\begin{array}{ll}\text { Conclusions and policy recommendations } & 7\end{array}$

$\begin{array}{ll}\text { 1. Introduction } & 10\end{array}$

$\begin{array}{ll}1.1 \text { Aims } & 10\end{array}$

1.2 Objectives 10

$\begin{array}{ll}1.3 \text { Report outline } & 10\end{array}$

2. Development of IFRS 6 and current stage of the relevant IASB project 12

2.1 Development of IFRS $6 \quad 12$

2.2 Attempts to revise IFRS 6 and the current stage of the IASB project 13

3. Literature review 15

3.1 Diversity of accounting treatment of E\&E costs. 15

3.2 Value relevance of accounting for exploration and evaluation costs 16

3.3 Lobbying, standard setting and IFRS $6 \quad 17$

4. Research approach 19

4.1 Sample selection $\quad 19$

4.2 Descriptive analysis of the accounting policies followed 21

4.3 Econometric analysis $\quad 21$

4.3.1 Determinants of decision to capitalise E\&E costs,

E\&E costs capitalised and E\&E costs' level of intensity 21

4.3.2 Determinants of accounting policy followed 23

4.3.3 Determinants of occurrence of impairment and E\&E costs impaired 23

5. Findings and discussion $\quad 25$

5.1 Accounting policies followed 25

5.2 Descriptive statistics of book values of E\&E expenditure capitalised,
impaired and amortised

5.2.1 Capitalised and expensed E\&E

5.2.2 Impairment and amortisation of E\&E expenditure capitalised 31

5.3 Multivariate analysis 36

5.3.1 Determinants of decision of E\&E capitalisation and amounts capitalised 36

5.3.2 Determinants of accounting policy choice 37

5.3.3 Determinants of impairment recognition and amounts impaired 39 
6. Conclusion

6.1 Conclusions and recommendations 44

6.2 Limitations and directions for future research $\quad 45$

$\begin{array}{ll}\text { About the authors } & 47\end{array}$

$\begin{array}{ll}\text { References } & 48\end{array}$

Appendix A: Brief description of accounting policies for E\&E expenditure as defined in various accounting standards $\quad \mathbf{5 0}$

Appendix B: Variable definition $\quad 53$

Appendix C: Descriptive statistics after categorising our sample firms into total assets terciles (ie what we name as junior explorers, developers and producers)

Appendix D: Examples of companies' disclosures

\section{Acknowledgements:}

The authors would like to thank ACCA and the Adam Smith Observatory of Corporate Reporting Practices for providing the funding for this project. We are grateful to Richard Martin (ACCA) for his valuable suggestions, support and advice during the project.

We thank the participants who attended the roundtable discussion hosted by ACCA on 15 October 2020 and for providing feedback on the preliminary findings of this research. The participants reflected views from relevant constituencies, including auditors, investors, international accounting bodies and corporate preparers. We thank Boglarka Dely, Dimitris Kanakis and Evangelos Seretis for their excellent research assistance with the data collection. 


\section{Executive summary}

\section{Background and objectives}

There are concerns that financial statements no longer reflect the underpinning drivers of value in modern business (Bernanke 2011; Haskel and Westlake 2017; Lev and Gu 2016). Such concerns are particularly relevant to accounting for internally generated intangible assets and intangibles in general. International Accounting Standard (IAS) 38 Intangible Assets, which governs the treatment of the capitalisation of development costs, has been characterised as a standard reflecting prudence and conservatism with a corresponding prevalence of expensing (Mazzi et al. 2019a). Nonetheless, there is significant lack of evidence about the extent to which companies capitalise other internally generated intangible assets, especially those that fall outside the scope of IAS 38.

In this research, we complement the study by Mazzi et al. (2019a) and focus on the accounting treatment of Exploration and Evaluation expenditure (hereafter E\&E) by companies in the extractive industry (hereafter El). E\&E expenses include: the acquisition of rights to explore; topographical, geological, geochemical and geophysical studies; exploratory drilling; trenching; sampling; and activities that relate to evaluating the technical feasibility and commercial viability of extracting a mineral resource. In essence, the accounting for E\&E costs can be viewed as an extension of the debate on the recognition of intangible assets versus the level of accounting conservatism.

While there is scant literature on El firms, and in relation to E\&E expenditure in International Financial Reporting Standards (IFRS) reporting regimes, this research concentrates on the accounting policies used for the treatment of these expenditures. To the best of the authors' knowledge, however, research on the amounts involved and hence recognised, expensed and impaired is not available. Furthermore, there is an absence of evidence on the characteristics of firms that capitalise and impair such expenditure. The overall objective of this research is to shed light on these areas.

\section{Method}

This research project was conducted in three key stages.

First, we identified a sample of firms in general mining, and oil and gas industry groups for 2018. These firms are listed in eight countries with significant constituents in the El. From potentially 1,646 firms, the final sample used consisted of 1,096 firms that have an annual report available in English and perform direct exploration activities. Using this sample, we first categorised the firms' accounting policy choices for E\&E expenditure into four types, which ranged from more aggressive to more conservative reporting, namely: Full Cost, Area of Interest, Successful Efforts and Expense All. Subsequently, we categorised the firms on the basis of their policy choice and of their country of origin, industry, and company development stage.

Second, we collected the net book values of E\&E amounts, E\&E costs capitalised internally and externally and E\&E costs impaired in the year. We then performed univariate statistical descriptive analysis, considering the different policy choices, country of origin, industry, and company development stage.

In the third and final stage, we performed multivariate regression analysis. This stage addressed three main research aims: i) identifying the factors influencing the decision of companies to capitalise; and identifying the factors affecting the magnitude of E\&E expenditure capitalised in the year; ii) investigating companies' decision to choose a certain accounting policy; and iii) identifying the factors driving the likelihood that companies would impair and provide the determinants of the impairment amounts. 


\section{Main findings}

Overall, we find a general tendency of companies to capitalise and recognise significant amounts of internally generated E\&E expenditure. Specifically, around $75 \%$ of the sample firms had a non-zero net book value of E\&E assets on the balance sheet and $66 \%$ capitalised internally generated E\&E assets in 2018. These, on average, accounted for $35 \%$ and $8 \%$ of companies' total assets, respectively. We also find that impairments are significant and commonly occur (ie $36.6 \%$ recognised an impairment of $E \& E$ assets in 2018), with the mean value of E\&E costs impairment accounting for a large proportion of the previous year's non-current assets (mean 33.5\%).

We have identified very different policies applied, resulting in capitalisation with materially different outcomes and a consequent lack of comparability. The Successful Efforts policy is the most common accounting method used and it is most common among Canadian and UK firms in the sample. The Area of Interest method is the second most common accounting method, being most common among Australian firms (where it is mandated under Australian Accounting Standards Board (AASB) 6 Exploration for and evaluation of mineral resources) (AASB 2004). The third most common method we identify is the so-called Expense All. This method is the most closely related to what is prescribed in IAS 38 with respect to other intangible assets. The Full Cost method is the least used (only $2.5 \%$ firms in the sample use it).

When we analyse these choices across industry groups, we find that mining firms appear to be more heterogeneous than oil and gas firms, with an almost equal split across the Successful Efforts, Area of Interest and Expense All methods. The application of the Area of Interest method is largely driven by the high number of Australian mining firms, highlighting a country effect. Oil and gas firms mostly follow the Successful Efforts method (70\%) and 22\% follow the Area of Interest method. This finding is what we would intuitively expect, given that only $20 \%$ of firms in this industry are from Australia.

When delving more into the characteristics of our sample firms, we identify the following.

Consistent with the classification of the Area of Interest method as a less conservative approach, we find that firms that follow this method report higher values of total E\&E capitalised and internally generated E\&E asset capitalised than firms following the Successful Efforts method. Nevertheless, the impairment in relation to $E \& E$ assets is of similar magnitude among firms using these two methods. The latter is attributed to the fact that, although companies choosing the Area of Interest method follow more aggressive reporting when capitalising costs that may relate to unsuccessful projects, they do not necessarily differ significantly with the firms following the Successful Efforts method in their choice of the unit of account for impairment testing.

Mining firms report higher values of total E\&E capitalised, internally and externally generated E\&E assets capitalised and E\&E intensity. Even so, the likelihood of recognising an impairment is lower for mining firms and the magnitude of E\&E assets impaired is not significantly different across mining and oil and gas firms.

Finally, we classified our sample firms into three categories: junior explorers, developers and producers, on the basis of the distribution of values of revenue. For example, junior explorers have zero revenue. We find that junior explorers have higher net-book value of capitalised E\&E to total assets, and are overall more E\&E intense. These values decrease monotonically as revenues increase. Further, more companies in the mining sector are junior explorers or developers while oil and gas involve more producers (who correspondingly have larger asset bases). Moreover, the mean (median) value of impairment relative to noncurrent assets at the end of the previous year for junior explorers is significantly larger than that for the developers and producers. Nonetheless, impairment recognition for E\&E assets is not necessarily more frequent in smaller firms (junior explorers) than in developers or producers.

\section{Conclusions and policy recommendations}

The findings of this research are very timely. The International Accounting Standards Board (IASB) is collecting information to help it make a decision on whether to start a project to replace or amend International Financial Reporting Standards (IFRS) 6 Exploration for and Evaluation of Mineral Resources. It is also timely because IASB technical staff presented a paper to the Board in October 2020 on the accounting policy diversity when applying IFRS 6 (IASB 2020b). The evidence provided herein about the amounts companies capitalise, impair and expense complements the IASB staff paper (IASB 2020b) and provides a more holistic view of the significance of the amounts involved and the complexities facing users of the financial statements. The present report aims at supplying insights that would assist the IASB in its decisions on the replacement or amendment of IFRS 6 in the future. The key recommendations arising from our findings are summarised as follows. 
i. Our findings suggest that the basic capitalisation and impairment model seems to be working in the El. This is contrasted to the relative lack of capitalisation of development costs of new products and processes under IAS 38. In fact, previous literature and evidence from users suggests that E\&E amounts capitalised and impaired are value relevant. Thus if, as has been suggested, the IASB proceeds by withdrawing IFRS 6 and including extractive activities in a broader project on intangible assets, a more conservative treatment of E\&E expenditure that would result from the current approach in IAS 38 is not supported.

ii. The standard could be more specific in outlining and defining alternative methods from which companies could choose instead of leaving so much freedom, which results in the application of diverse policies, including the continued application of policies permitted or required in pre-IFRS national standards. If that were the case, there would be no need for separate standards for oil and gas and mining, as was voiced in the responses to the 2010 IASB Discussion Paper (IASB Staff paper 2019b, para 11: 5). ${ }^{1}$

iii. Given that only a small proportion of firms use the Full Cost method, this may not be among the methods proposed by the revised standard.

iv. Providing specific definitions of the various methods that a firm could apply would also result in a more comparable reporting among firms that claim to be using the two most common methods (Successful Efforts or Area of Interest) but there is vagueness as to how they operationalise the unit of account for testing E\&E capitalised for impairment. v. In contrast to other accounting standards, IFRS 6 lacks mandatory disclosure requirements. This raises wider concerns about the lack of internal consistency among IFRSs. Importantly, the comparability of El companies' practices is hindered by the lack of transparency. For example, and reflective of our findings, companies should be required to explain clearly what unit of account they use for impairment testing purposes. Additionally, companies should provide an explicit statement as to whether they amortise the capitalised E\&E of a specific useful life and where in the income statement such amounts are included. Finally, companies should be explicitly required to provide the disclosures mandated by IAS 36 in relation to other information about the impairment testing of E\&E assets.

vi. Companies capitalise significant amounts of E\&E assets, in contrast to internally generated intangible assets governed by IAS 38. This may reflect companies' policy traditions and users' expectations in the sectors concerned. Nevertheless, this not only begs the question of the suitability of IAS 38 for nonEl companies in today's economies but also reveals a potential lack of internal consistency between IFRSs, which deal with similar issues pertaining to the recognition of intangible assets. Hence, if the IASB does not revise IAS 38, one of the potential alternatives within a revised IFRS 6 could be a method similar to what we label as 'Expense All'. This would be only on the grounds of increasing consistency with the policies companies have to follow under IAS 38. 


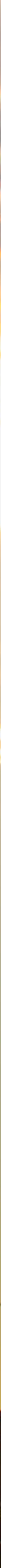




\section{Introduction}

\section{Despite the continuous adoption of IFRS, or convergence of national accounting standards with IFRS across the world, there remain concerns and debates about the levels of accounting comparability between companies.}

Significant aspects of these concerns relate to the level of assets recognised in financial statements, and the accompanying disclosures as mandated by the standards. Arguably, this is in part because of the principles-based nature of IFRS, the application of which allows for managerial discretion.

\subsection{Aims}

Previous literature has demonstrated variation in the accounting policies followed by companies, although there is lack of evidence on the amounts of E\&E expenditure companies capitalise, expense and impair and the factors that influence the recognition of these amounts. Further, it is not known to what extent the specific accounting policies chosen are related to these amounts. We manually captured the accounting policies followed by companies and the related amounts recognised in companies' financial statements and then conducted univariate and econometric analyses that reflected three main research aims:

- to understand the factors that are associated with the decision to capitalise E\&E expenditure and the corresponding amounts capitalised

- to identify the factors that are associated with the accounting policy chosen by firms, and

- to investigate factors that are associated with an impairment of E\&E capitalised expenditure and the corresponding amounts of impairment recognised.

\subsection{Objectives}

Against this backdrop, while hand-collecting data for a sample of 1,096 E\&E firms from eight countries, the objectives of the study are to:

- explore the accounting policies companies follow for the treatment of E\&E expenditures

- capture and analyse the amounts of E\&E expenditure companies capitalise, expense and impair

- explore the factors that are associated with the decision to capitalise E\&E expenditure and the corresponding amounts capitalised

- explore the factors that are associated with the accounting policies chosen by firms

- explore the factors that are associated with the recognition of an impairment of E\&E assets, and

- explore the factors that are associated with the magnitude of E\&E assets' impairment.

\subsection{Report outline}

The next chapter describes the development of IFRS 6 and the current stage of a pertinent IASB project. Chapter 3 reviews the relevant academic and practice literature. The research design is outlined in Chapter 4. We then present and discuss our results in Chapter 5. Conclusions are set out in Chapter 6. 

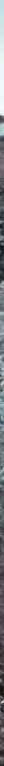

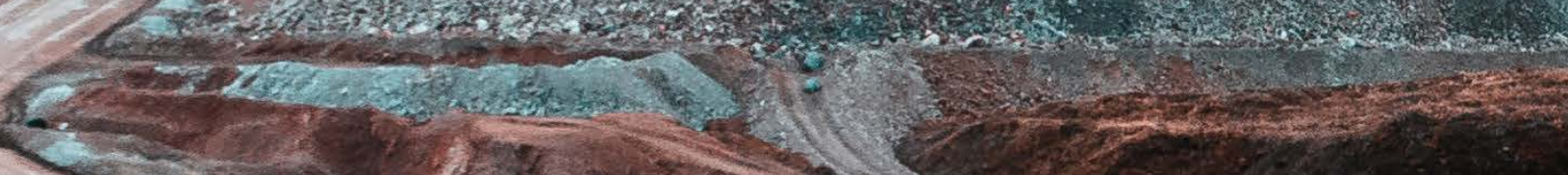

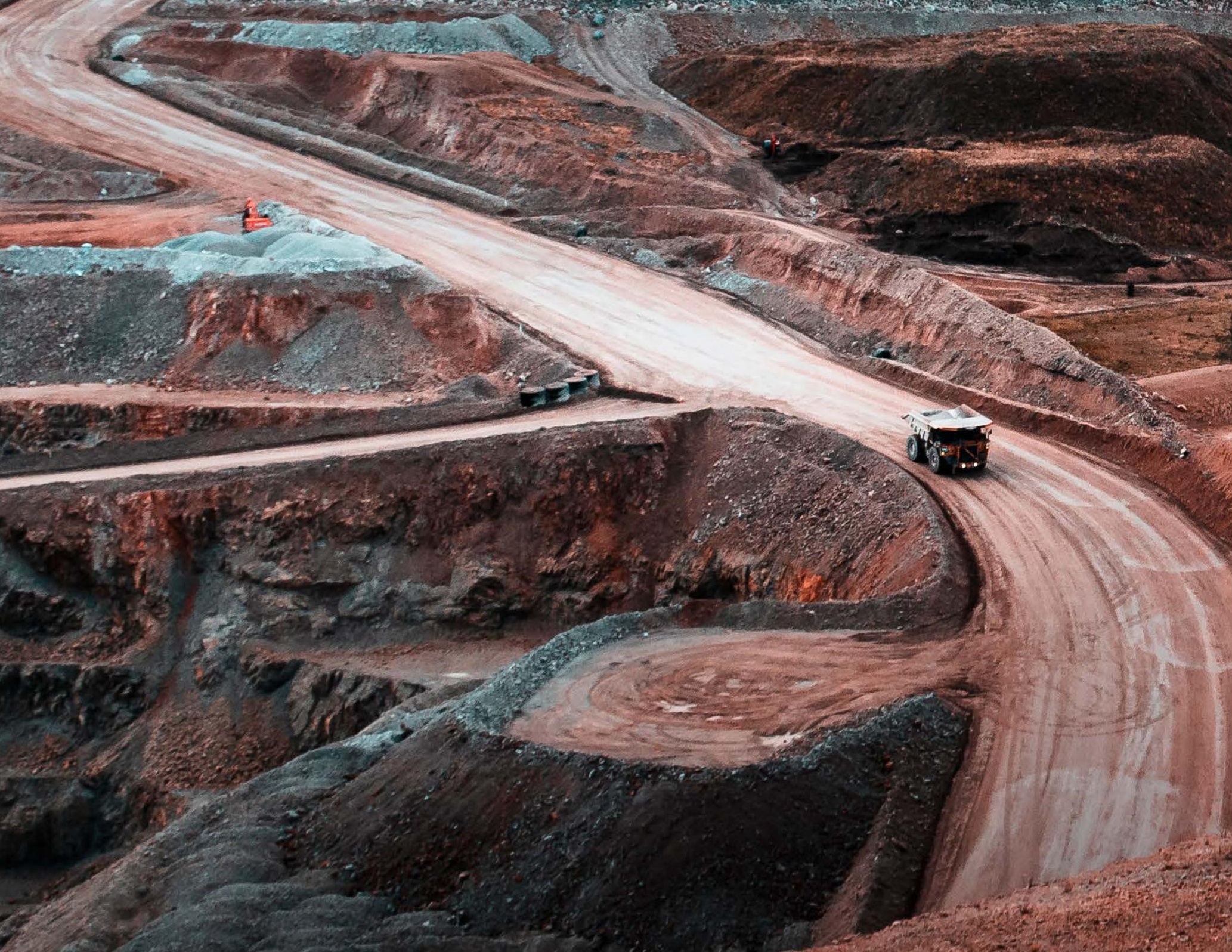

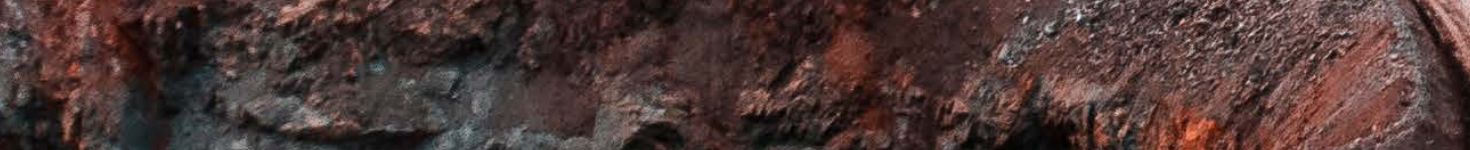

4. 


\section{Development of IFRS 6 and current stage of the relevant IASB project}

This chapter sets out the development of IFRS 6, subsequent proposals for change and the current status of deliberations for potential revisions of the standard.

While IFRS 6 makes no specific requirement, there are four prevalent accounting methods that are generally applied to E\&E costs. These have been broadly defined and grouped in practice and academic literature as follows, from most aggressive to conservative: Full Cost; Area of Interest; Successful Efforts; and Expense All. In Appendix A and section 4.2, we provide details of these methods. In this chapter, we concentrate on how IFRS 6 has been developed and explore the current stage of a relevant IASB project, providing the context for the present study.

\subsection{Development of IFRS 6}

Owing to a historic variation in accounting practices under respective national accounting standards, in 1998, the IASB's predecessor, The International Accounting Standards Committee (IASC), established a steering committee to examine the accounting and financial reporting by entities engaged in $\mathrm{El}$ and consider the potential methods for inclusion in an IAS. In November 2000, the steering committee published an Issues Paper, Extractive Industries. This noted that owing to the variety of accounting methods, it was 'difficult for users to compare financial statements issued by mining and petroleum enterprises in different countries, or by such enterprises and other enterprises in the same country' (IASC 2000: 4).

The steering committee tentatively proposed not allowing the full capitalisation of E\&E expenditure, with non-viable expenditure being amortised against revenue from successful areas (Full Cost), and requiring companies to capitalise all expenditure and writing off expenditure related to unsuccessful projects either as incurred or once that assessment was made (Successful Efforts) (IASC 2000; Cortese et al. 2009; 2010). In practice, with the approaching implementation of IFRS in many countries in 2005, it was not feasible to complete the detailed analysis required, gather appropriate input from constituents and undertake the Board's normal due process in time to implement changes, from respective existing national generally accepted accounting principles (GAAP). Further, Cortese et al. $(2009 ; 2010)$ contend that any change away from national standards and policies applied by entities would have been subject to resistance from a number of factors such as national standard boards and industry lobbying. Thus, an agreement would be unlikely to have been reached on a single accounting policy.

THERE ARE FOUR PREVALENT ACCOUNTING METHODS THAT ARE GENERALLY APPLIED TO E\&E COSTS. THESE HAVE BEEN BROADLY DEFINED AND GROUPED IN PRACTICE AND ACADEMIC LITERATURE AS FOLLOWS, FROM MOST AGGRESSIVE TO CONSERVATIVE: FULL COST; AREA OF INTEREST; SUCCESSFUL EFFORTS; AND EXPENSE ALL. 
Nonetheless, in April 2004, the IASB approved a research project addressing accounting for extractive activities. This was undertaken by staff from the national standard-setters in Australia, Canada, Norway and South Africa, being four countries with significant national interest in the El sector. The research project team was assisted by an advisory panel, consisting of firms from El, accounting firms, users, and securities regulators from around the world.

As part of the wide adoption of IFRS by countries, IFRS 6 was issued in June 2004, as an interim standard with limited scope (IASB 2004a). Hence, IFRS 6 was intended to be a temporary standard until 'the Board completes its comprehensive review of accounting for extractive activities' (IASB 2004b: BC2). IFRS 6 was effective for annual periods beginning on or after 1 January 2006.

Regarding the accounting treatment required, the standard explicitly states 'an entity adopting IFRS 6 may continue to use the accounting policies applied immediately before adopting the IFRS. This includes continuing to use recognition and measurement practices that are part of those accounting policies' (IASB 2004a: para IN 5: A233) (emphasis added). No definitions of methods or accounting policies were included in IFRS 6 (and see Nobes and Stadler 2020). Indeed, in its Basis for Conclusions of IFRS 6, the IASB (2004b: BC 17: B576) recognised that 'a variety of accounting practices are followed by entities engaged in the exploration for and evaluation of mineral resources. These practices range from deferring on the balance sheet nearly all exploration and evaluation expenditure to recognising all such expenditure in profit or loss as incurred. The IFRS permits these various accounting practices to continue'. It is noted that beyond the lack of specific definitions of accounting methods that companies could use, the standard includes no mandatory disclosures on the subject matter - which is in contrast to the majority of other IFRSs.

In the documents published to accompany IFRS 6, four IASB members dissented because they would not permit entities the alternative of continuing their existing accounting treatment for E\&E costs, which may result in the inappropriate recognition of assets (IFRS 2006: s. DO 2). Their concerns were heightened by the absence from the Board's main agenda of a project on accounting for exploration for and evaluation of mineral resources generally.

\subsection{Attempts to revise IFRS 6 and the current stage of the IASB project}

A Discussion Paper with findings from the research project that had been established in 2004 was published in April 2010 (IASB 2010). The IASB noted that the Discussion Paper 'is the first step towards a possible IFRS for extractive activities that would address those concerns and replace IFRS 6 (IASB 2010: para P2: 12). Further, 'the Preface to International Financial Reporting Standards explains that the IASB does not intend to permit choice in accounting treatments, and so this choice is not being proposed for minerals or oil and gas properties' (IASB 2010: para 4.7: 72). The Discussion Paper proposed the so-called 'area of interest method' that the Australian standard requires (see later) as the unit of account and a model for asset recognition based on the acquisition of legal rights of exploration. Subsequently, 'costs of exploration and evaluation and development would be capitalised as "enhancements of the legal rights" as they do not represent separate assets but are necessary in order to obtain future economic benefits' (IASB, 2010: 53) Gray et al. (2019: 51) note that 'an important rationale for this reasoning appears to be the "costs attach" logic'. This is because determining the unit of account relating to extractive activities can have a significant effect on the size of capitalised expenditure.

Responses to the Discussion Paper were invited and together these would help inform IASB over the next steps for IFRS 6. A main theme from the responses to the Discussion Paper was that either the IASB should develop a separate standard for El or it should include El in a broader project, reconsidering the accounting for intangible assets. If the IASB was to opt for the former, the suggestion was 'that separate standards should be developed for minerals and for oil and gas extractive activities because of the differences that exist between each industry' (IASB staff paper 2019b, para 11: 5). The IASB assigned a low priority to the project, although the IFRS 2011-12 Agenda Consultation had highlighted broader concerns about the accounting for R\&D activity and the recognition and measurement of intangible assets (IASB 2016a: paras 5-6: 2). Further, the IFRS Agenda Consultation in 2016 concluded that, 'the arguments made in respect of both the extractive activities part of the project, and the intangible assets / R\&D part of the project lead us to conclude that there is not an urgency to address the issues identified' (IASB 2016c para 35: 8). 
In July 2016, this was classified by the IASB as a 'Research Pipeline Project' that was initially inactive but was likely to start in the forecasted period 2017-2021 (IASB 2016b). The research project focusing on extractive industries commenced in 2018 and national standard setters that contributed to the 2010 Discussion Paper and other stakeholders were asked to inform the IASB of any significant changes in extractive activities, especially in view of oil and gas markets' volatility (IASB 2019a). The feedback was presented at the IASB's March 2019 meeting. Subsequently, it was discussed in September 2019 (IASB 2019b: 6), when mixed views were expressed on the scope of the project, with suggestions ranging from:

a. improving the existing recognition, measurement and disclosure requirements of IFRS Standards to improve consistency and comparability in financial reporting, to

b. withdrawing IFRS 6 and including extractive activities in a broader project on intangible assets, to

c. doing nothing and maintaining IFRS 6 .
It was also reported that most preparers thought that IFRS 6 was working well. Further, the Capital Markets Advisory Committee members acknowledged that standardisation could be difficult but suggested that the Board could consider additional disclosure requirements to help users more fully understand the accounting for E\&E expenditure (IASB 2019b; Nobes and Stadler 2020). Thus, at present, IFRS 6 remains in force with a continued 'diversity in practice in the accounting policies developed by entities with extractive activities' (EFRAG 2020: 1). Studies on this diversity of accounting are discussed in Chapter 3.

Most recently, in advance of the October 2020 IASB meeting, a comprehensive review of the accounting practices relating to $E \& E$ expenditure was carried out by the IASB staff (IASB 2020b). The analysis was carried out using 1,531 entities across 177 jurisdictions. The results show that firms apply a range of accounting policies while many fail to disclose explicitly the accounting policy applied. The IASB will then be asked to decide whether to commence a project to replace or amend IFRS 6 at a future meeting (IASB 2020b).

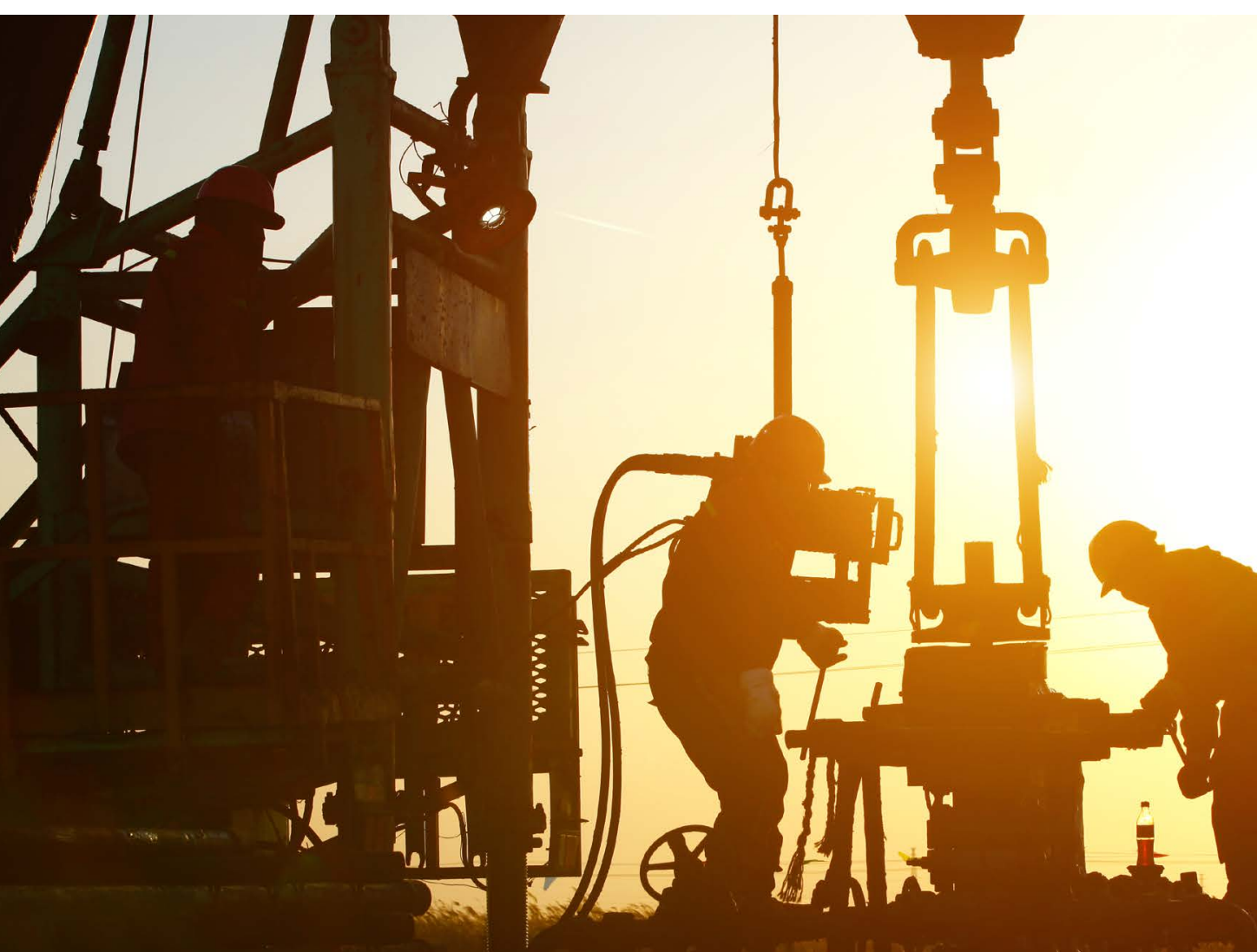




\section{Literature review}

\section{This literature review reflects on previous academic and practice-based literature and addresses three main areas relevant to E\&E costs in EI.}

These studies can be summarised across the following three themes: the diversity of the accounting treatment of E\&E expenditures; the value relevance of such accounting numbers to investors; and standard setting and the influence of lobbying. The review identifies a surprising sparsity of literature in these areas (and see Gray et al. 2019; IASB 2020a; Stadler and Nobes 2020). This is also encapsulated by Gray et al. (2019:80), who note that 'the literature comprising international comparative studies on accounting practices across El firms is very limited'. With particular relevance to this project, it becomes apparent that the majority of the studies in this limited strand of the literature focus on the accounting methods companies apply for E\&E expenditure and there is dearth of evidence on the magnitude and frequency of amounts capitalised as internally or externally generated, expensed and impaired by El firms. There is also dearth of evidence about the factors that influence the recognition and impairment of these amounts.

\subsection{Diversity of accounting treatment of E\&E costs}

Within El, diversity of accounting practice is not a new phenomenon. This is well illustrated by a historical perspective in a much-cited quote of Curle (1905: 29) who notes: 'I hope that the time is approaching when the system of standardisation will be extended to mining costs and mining accounts. There must be some one method, in accounts especially, which is best of all' (see also Luther 1996; Smith and Venter, 2020; Vent and Milne, 1989).

From a pre-IFRS era, Luther (1996) qualitatively reviews the accounting treatment applied in five countries associated with El: Australia, Canada, South Africa, UK and USA. He concludes that 'there is significant diversity in accounting by El companies in the countries considered' (Luther 1996: 84) and notes that the absence of a mandatory accounting standard allows for considerable latitude.

Of the studies that have examined diversity in accounting under IFRS 6 (notably, Abdo 2016; IASB 2020b; Power et al. 2017; Stadler and Nobes 2020), common findings have been in relation to country, sector and entity size as factors influencing the accounting treatment followed. These studies have predominantly focused on one or all of the three countries with the largest representation of El firms: Australia, Canada and the UK, and principally covered oil and gas and/or mining (minerals) sectors. Most of these studies apply the classifications based on generic methods of accounting referred to in earlier literature, although none of these methods are defined in IFRS 6 (ie Full Cost; Area of Interest; Successful Efforts and Expense All, see also Appendix A and section 4.2 below).

More specifically, Power et al. (2017) is a single country study and focuses on any reported in-sector diversity in the accounting for E\&E costs. Power et al. (2017) analyse UK listed extractive companies over the period 2006-2012. This analysis is limited to three accounting methods (Full Cost, Successful Efforts and Expense All) and thus does not explicitly consider Area of Interest. For 84 oil and gas companies, they find that $71 \%$ used the Successful Efforts method with $29 \%$ using Full Cost. ${ }^{2}$ Further analysis shows that larger companies tended to use Successful Efforts whereas smaller, AIM-listed, companies favoured the Full Cost method. In contrast to oil and gas, of the 110 mining companies, $75 \%$ used the Successful Efforts method and

2 Descriptive statistics indicate that median values of book value E\&E assets capitalised represent $24 \%$ and $46 \%$ of total assets, respectively. 
23\% used the most conservative Expense All method. ${ }^{3}$ Reflecting on the differences, within and between sectors, Power et al. (2017: 558) conclude: 'the analysis of the accounting policy descriptions provided by LSE-listed extractive firms...shows that firms exploit the latitude provided by IFRS 6 to use a diversity of accounting policies for exploration expenditure'. This is indeed consistent with other recent cross-country studies examined below.

Abdo (2016) analyses 118 companies' annual reports in the oil and gas industry for the period 2006-14 from six countries. In fact, the study could be characterised as a single country (UK) one owing to the dominance of UKlisted companies in the sample. The research attempts to examine whether IFRS has harmonised accounting practices by extractive industries post IFRS 6. ${ }^{4}$ The results show a predominance of Successful Efforts (55 companies, 47\%) and Full Cost (33 companies, 28\%). A further 11 companies (9\%) are classified as using Area of Interest; of these six are based in Australia (where Area of Interest is mandated under AASB 6), while the remainder (19 companies, 16\%) do not state a clear policy. Despite this variety of practice, Abdo (2016: 356) concludes that 'IFRS 6 has made a positive impact on harmonising accounting practices by extractive industries', with greater comparability of reported information in relation to the wide application of Successful Efforts and Full Cost generic methods. This, however, may be disputed if the applied methods are examined in greater granularity, as set out by Stadler and Nobes (2020).

Such an observation is consistent with the significant variations found in two more recent cross-country studies, Stadler and Nobes (2020) and IASB (2020b). In their review of varied accounting practice for El firms, Stadler and Nobes (2020) examined 311 firms from 10 countries for the financial year 2017. The main focus was naturally on Australia (81 companies, 26\%), Canada (84 companies, 27\%) and UK (90 companies, 29\%), across two main sectors: oil and gas, and mining. They highlight the diversity in accounting methods applied and identify nine classifications, ordered by levels of conservatism, being a finer-grained resolution of the more generic methods referred to in the earlier literature. This highlights the considerable variation in practice and the need for greater definitional clarity in any revisions to the standard (and see Nobes and Stadler 2020). The results show that accounting varies by country, sector and firm size. From a country perspective, Area of Interest was most frequently applied, as expected, in Australia, and Australian companies are characterised as less conservative than those in the UK. At a sector level, mining firms tend to apply more conservative methods than are applied in oil and gas. Additionally, larger firms tend to apply more conservative methods than smaller firms (consistent with the UK evidence of Power et al. (2017), albeit they do not explore the use of the Area of Interest method).

IASB (2020b) also provide a cross-country study examining 1,513 annual reports from 2018, comprising North America, including Canada (32\%), Oceania, including Australia (48\%), and Europe, including the UK (12\%). The two sectors reported on were minerals, and oil and gas (representing, $76 \%$ and $20 \%$ of the sample, respectively). The research again highlights the variation in accounting by region and sector with, as previously found at a sector level, the minerals sector being characterised as more conservative than oil and gas. The report highlights that 'the Board has received feedback that accounting policies developed by entities in the extractives industry that apply IFRS 6 Exploration for and Evaluation of Mineral Resources lack consistency and comparability both between jurisdictions and within jurisdictions' (IASB 2020b:1). This also reflects earlier comments from international bodies such as EFRAG (2020) and IASC (2000).

An issue arising from such accounting diversity is the impact on investors and the value relevance of accounting information to them, in the El.

\subsection{Value relevance of accounting for exploration and evaluation costs.}

El firms operate in inherently uncertain environments owing to the nature of exploration, compounded by the volatility of mineral and oil and gas market prices (Gray et al. 2019; IASB 2019a). Indeed, Cortese et al. (2009: 28) highlight that 'the exploration and evaluation phase is arguably the most risky given the high proportion of dry holes relative to successful projects (Katz, 1985; Wise and Spear, 2002). Companies may spend millions of dollars on an exploration effort only to find that variables such as development and production risk, changing technology, time horizons, market risk, and the legal and political environment render the project uneconomical'. This uncertainty, potentially compounded by a diversity of accounting treatments, leads to information asymmetry between extractive companies and investors (Gray et al. 2019; IASB 2020a). A small number of studies have considered the value relevance of the diverse accounting,

3 Descriptive statistics indicate that median values of book value E\&E assets capitalised represent $17 \%$ and $49 \%$ of total assets, respectively

4 Abdo (2016: 347) states that 'IFRS 6 allows the use of two alternative accounting methods: the successful efforts (SE) and full costing (FC) methods'. But this does not recognise the permitted use of any chosen accounting treatment and the resultant method diversity, which may clearly impair harmonisation. 
measured as the association of E\&E costs with stock prices and returns. These studies provide some evidence on, for instance, the signalling of capitalisation and whether accounting diversity matters to capital market users.

In their Australian-based study (1993 to 2013, on $131 \mathrm{El}$ companies), Chen et al. (2018) examined whether the intensity of E\&E has an impact on analysts' efforts to acquire private information and on their forecast accuracy. ${ }^{5}$ They find that analysts produced more accurate forecasts for those El firms with a higher intensity of E\&E activities. Furthermore, they find a signalling effect of capitalisation, enabling 'managers to better communicate information about the probable future benefits of these exploration projects, and this assists analysts to develop more useful private information and improves the accuracy of their forecasts' (Chen et al. 2018: 78). Thus, they conclude that capitalisation sends a value-relevant signal to equity market users. While also focusing on Australia, Zhou et al. (2015), use a two-period study, comprising 116 firm-years from 2003 and 2004 and 324 firm-years between 2006 and 2009. ${ }^{6}$ They find that capitalised E\&E expenditures across both periods are positively associated with the share prices of El firms and hence are value relevant, while the writtenoff exploration and evaluation expenditures are negatively associated with the share price of extractive firms.

Power et al. (2017), focusing on the UK, show that capitalised E\&E assets are positively associated with market prices. This indicates that they are relevant to investors, albeit only for oil and gas firms listed in the main market. In contrast, for mining companies, capitalised expenditures were, on average, not value relevant.

Outside IFRS, Berry and Wright (2001) show that capitalised exploration costs under US GAAP are value relevant while Bryant (2003) shows that accounting numbers (earnings and book value of equity (BVE)) under the Full Cost Capitalisation are more value relevant than under the Successful Efforts method of capitalisation. The only dissenting study to the foregoing evidence is that by Misund (2017). Using US10K Securities and Exchange Commission (SEC) filings, he examines the relative importance of cash flow versus earnings for investors for oil and gas firms in relation to 1,627 Full Cost firmyears and 1,890 Successful Efforts firm-years. He finds that cash flow measures, not earnings, are significantly associated with oil company returns. Hence, he concludes that 'investors prefer cash flows in the oil and gas sector because of accounting method confusion' (Misund, 2017: 12). Misund (2017) also cites the adverse effects of politicised processes and lobbying on the continued diversity in accounting for extractive industries, which we consider in section 3.3 below.

Interestingly, the findings by Zhou et al. (2015) and Berry and Wright (2001) and in particular Power et al. (2017) and Bryant (2003) reflect the comments by capital markets users in a 2018 EFRAG meeting. They indicated that users cope with the diversity of accounting policies followed by having some analysts who focus solely on oil and gas and not on other extractive industries. The latter in turn are split into a mining aggregates category and a base metal category (EFRAG TEG-CFSS meeting, 2020).

\subsection{Lobbying, standard setting and IFRS 6}

A key aspect of the use of diverse accounting methods has been the debate on the continued application of the Full Cost method, especially in the oil and gas sector, against the more conservative Area of Interest, Successful Efforts, or Expense All methods.

Both the FASB (1977) and IASC (2000) had advocated that the Full Cost method should be discontinued, with the more conservative Successful Efforts method being used to account for exploration expenditure. The Full Cost method was more extensively used by smaller firms in the oil and gas sector, which strongly opposed any change and lobbied extensively against such recommendations. The Full Cost method enables smaller companies to shield from earnings volatility more effectively, owing to potentially large expense costs that would depress earnings relating to unsuccessful exploration activities under the Successful Efforts method (Abdo 2016; Karapinar et al. 2012). This latter method may also impair their ability to raise capital and consequently may result in a reduction in exploration activity.

Within the US context, the SEC faced lobbying pressure and, within the context of the international oil crisis, it overruled the recommendations made by the FASB, viewing them as too prudent and contrary to the public interest (Cortese et al. 2009; 2010; Luther 1996; Power et al. 2017). In relation to the IASC proposal, similar lobbying in support of the continuation of the Full Cost method is reported by Cortese et al. (2010). While the IASC recommendation received support from a majority

\footnotetext{
5 For their sample, annual E\&E expenditures (ie capitalised E\&E expenditures plus E\&E expense) represent, on average, $5.4 \%$ (2.6\%, median) of last year's total assets.

6 Descriptive statistics indicate that mean (median) values of book value E\&E assets capitalised in a given year represent $5.6 \%(2.3 \%)$ and $5.1 \%(2.2 \%)$ of total number of shares outstanding for each of the two periods.
} 
of responders to the consultation, the non-supportive responses came from El lobby groups whose membership included smaller oil and gas companies following the Full Cost method. Furthermore, owing to the opposition faced by the FASB in its earlier attempt to reform accounting in this area, and the harmonisation process of the IASB and FASB (for instance The Norwalk Agreement signed in 2002), the Full Cost and Successful Efforts policies were effectively retained. Consequently, IFRS 6 issued in 2004 enabled the continuation of existing national policies and the diversity of accounting.
Reflecting this lobbying and the implications for any change in accounting policy, Luther (1996: 67) had foreseen that 'the cost of regulation and standardization would not be justified.... This review shows that the debate is likely to be more related to politics than accounting'. More recently, Cortese et al. (2010) highlight user preference, sector norms and size effect, evidenced through the role of lobbying, which have helped maintain the status quo of existing national GAAP reporting. Thus, any calls for reform of IFRS 6 may face the same industry-political obstacles that have effectively served to resist change recommendations made by global accounting bodies.

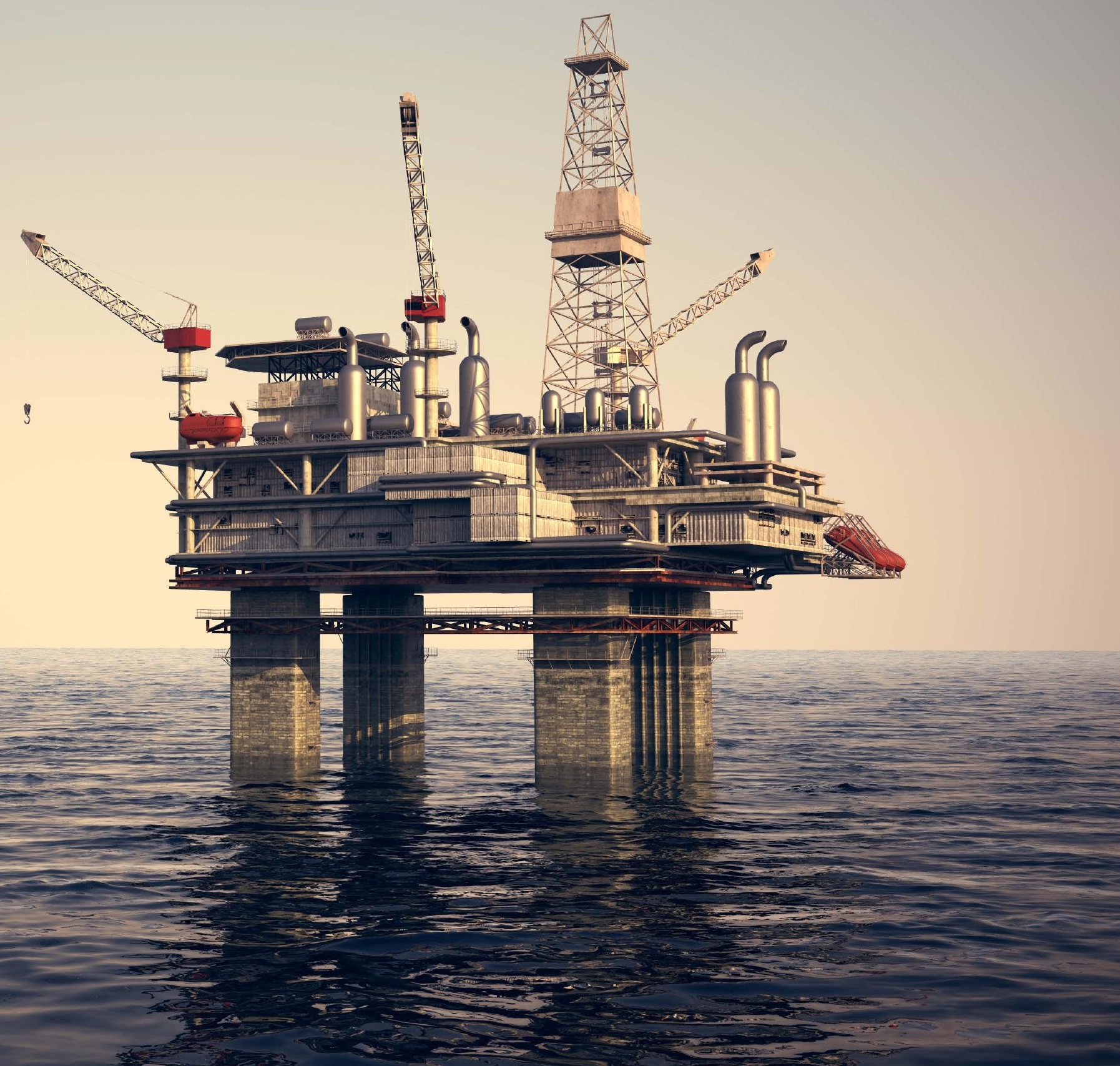




\section{Research approach}

\subsection{Sample selection}

The sample selection started by identifying countries that, as of 2018, had adopted IFRS or had their accounting standards converged to IFRS, and had a large number of listed firms operating in the El, including both mining and oil and gas firms in their corresponding stock markets. ${ }^{7}$ These include Australia, Canada, India, South Korea and the UK. We supplement this list with countries participating in the 2010 IFRS Discussion Paper that meet the same criteria, namely Norway and South Africa. Finally, we also include Russia, for which listed firms have now adopted IFRS, given that there are some large organisations that focus on, or have interests in, extractive activities.

Overall, we considered the following eight countries: Australia, Canada, India, South Korea, Norway, Russia, South Africa and the UK. For each country, we obtained data from Worldscope/Datastream. We included all firms in the research lists constructed by Worldscope, excluding instruments not classified as equity. For large firms that are cross-listed, we considered their primary listings only. To identify companies that might be relevant for our analysis, we concentrated on the following subsectors of Industry Classification Benchmark (ICB): alternative fuels; aluminium; coal; diamonds and gemstones; oil: crude producers; general mining; gold mining; integrated oil and gas; iron and steel; platinum and precious metals; offshore drilling and services; copper.

We selected these subsectors because firms therein are more likely to be associated with extractive activities. For the financial year 2018, 2,588 firms operated in these 12 subsectors across the eight countries in our sample. Subsequently, we excluded 103 firms with accounting periods longer than 380 days or shorter than 350 days, and 808 firms with insufficient accounting data for the subsequent analysis. Given the aims of the project, we also excluded 30 firms that did not report under IFRS. ${ }^{8}$ This process yielded a sample of 1,647 firms that could be engaged with extractive activities.

We searched on the website of each of these firms to find the annual report. If the corresponding annual report was not available there, we searched via Google or the Perfect Information or Thomson Eikon databases. With this step, we eliminated 194 firms because we were unable to locate the annual report or their report was not available in English. This resulted in 1,483 annual reports that we manually examined and identified whether these firms were involved in extractive activities. Consequently, we further excluded 355 firms that were not extractive firms after all (for instance, being service providers or producers of metal pipes and similar products), and two firms with vague information not allowing us to identify with certainty whether they were involved in extractive activities or not. Table 4.1 details this sample selection process.

OVERALL, WE CONSIDERED THE FOLLOWING EIGHT COUNTRIES: AUSTRALIA, CANADA, INDIA, SOUTH KOREA, NORWAY, RUSSIA, SOUTH AFRICA AND THE UK.

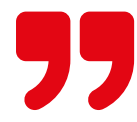

\footnotetext{
7 We consulted the guide published by the IFRS Foundation on the use of IFRS by jurisdiction available here: <https://www.ifrs.org/use-around-the-world/use-of-ifrsstandards-by-jurisdiction/>.

8 In order to identify companies' reporting standards, we use the Worldscope item 'accounting standards followed' (WC07536).
} 
TABLE 4.1: Sample selection

We focused on all companies belonging in ICB Level 5 sector for each of the eight countries in our sample

Excluding firms that have their financial year end changed

Excluding firms with missing firm-specific data

Excluding firms not reporting under IFRS

Excluding firms for which we could not locate the annual report

Excluding firms not involved in extractive activities

FINAL SAMPLE

TABLE 4.2: Sample of firms included in the analysis

\begin{tabular}{|c|c|c|c|c|c|c|c|c|c|}
\hline $\begin{array}{l}\text { INDUSTRY } \\
\text { SUBSECTORS }\end{array}$ & AUSTRALIA & CANADA & INDIA & $\begin{array}{l}\text { SOUTH } \\
\text { KOREA }\end{array}$ & NORWAY & RUSSIA & $\begin{array}{l}\text { SOUTH } \\
\text { AFRICA }\end{array}$ & UK & TOTAL \\
\hline Alternative fuels & 0 & 1 & 0 & 0 & 0 & 0 & 0 & 0 & 1 \\
\hline Aluminium & 1 & 0 & 0 & 0 & 1 & 0 & 0 & 0 & 2 \\
\hline Coal & 25 & 5 & 1 & 0 & 0 & 2 & 1 & 1 & 35 \\
\hline Copper & 4 & 10 & 0 & 0 & 0 & 0 & 0 & 3 & 17 \\
\hline $\begin{array}{l}\text { Diamonds and } \\
\text { gemstones }\end{array}$ & 4 & 14 & 0 & 0 & 0 & 0 & 1 & 4 & 23 \\
\hline General mining & 158 & 270 & 0 & 0 & 2 & 0 & 2 & 37 & 469 \\
\hline Gold mining & 67 & 133 & 1 & 0 & 0 & 1 & 3 & 15 & 220 \\
\hline $\begin{array}{l}\text { Integrated oil } \\
\text { and gas }\end{array}$ & 0 & 3 & 0 & 0 & 1 & 6 & 1 & 2 & 13 \\
\hline Iron and steel & 10 & 3 & 4 & 1 & 0 & 2 & 0 & 6 & 26 \\
\hline $\begin{array}{l}\text { Offshore drilling } \\
\text { and services }\end{array}$ & 5 & 0 & 0 & 0 & 0 & 0 & 0 & 2 & 7 \\
\hline $\begin{array}{l}\text { Oil: crude } \\
\text { producers }\end{array}$ & 48 & 132 & 2 & 0 & 8 & 1 & 0 & 53 & 244 \\
\hline $\begin{array}{l}\text { Platinum and } \\
\text { precious metals }\end{array}$ & 2 & 30 & 0 & 0 & 0 & 0 & 4 & 3 & 39 \\
\hline TOTAL & 324 & 601 & 8 & 1 & 12 & 12 & 12 & 126 & 1,096 \\
\hline
\end{tabular}


Table 4.2 shows the sample composition by country and subsector. The table indicates that our sample consists of a large proportion of Canadian firms (601 observations), Australian firms (324 observations) and UK firms (126 observations). The weight of the remaining countries is much smaller on an individual basis. It is noted that the firms in our sample from the remaining countries are mostly among the largest firms by market capitalisation in their respective countries. For example, all Indian firms have a market capitalisation above the median market capitalisation and only $17 \%$ of the Russian firms have a market capitalisation below the median market capitalisation. Finally, about $60 \%$ of our sample firms from Norway and South Africa have a market capitalisation above the median market capitalisation.

As regards industry representation, the sample consists primarily of firms in the 'general mining' (469 firm-year observations), 'oil: crude producers' (244 firm-observations), and 'gold mining' (220 firm-year observations) industry subsectors. The weight of the remaining subsectors is much smaller.

\subsection{Descriptive analysis of the accounting policies followed}

To inform our main analysis, we first attempted to identify the accounting treatment of E\&E costs in our sample firms. Following previous academic and practice literature, we adopted four categories of accounting policy with which to classify firms. The four categories depict decreasing levels of conservatism, ranging from Full Cost, Area of Interest, Successful Efforts, and what we label as 'Expense All'. We categorised Area of Interest as somewhat less conservative than Successful Efforts (consistent with Deloitte Touche Tohmatsu (2001) and Stadler and Nobes (2020)). As a framework for doing so, we mainly followed as closely as possible the definitions provided in Power et al. (2017). To assist our interpretations of these definitions and the companies' descriptions of their methods, irrespective of the labels they may have used, we frequently consulted the technical guide: IFRS in Practice: An Overview of IFRS 6 Exploration for and Evaluation of Mineral Resources (BDO 2013). Table 4.3 below reproduces the descriptions of the definitions we used from both these sources. With regard to the Area of Interest method, we also reflected its description as per AASB 6 (see Appendix A).

Notwithstanding the above, we acknowledge that there were cases in which we necessarily exercised judgement when allocating a firm's method to a particular category.
First, the labels that companies use would lead to a different classification because in many cases their definitions would not fit those of various accounting standards (see Appendix A) or 'any authoritative literature' (Stadler and Nobes 2020: 3). Second, it was common for companies to use various definitions of what constitutes 'an area'. Given that Area of Interest is a form of the Successful Efforts method, which suggests a wider impairment pool, we needed to discuss how to classify firms in either category. Indicative of the judgement that can be involved is that the IASB staff paper (IASB 2020b) study classified $22 \%$ of firms under the label 'capitalised - unknown'.

\subsection{Econometric analysis}

\subsubsection{Determinants of decision to capitalise} E\&E costs, E\&E costs capitalised and E\&E costs' level of intensity

With regard to factors influencing the decision to capitalise internally generated E\&E expenditure in the year we examined, we used multivariate Probit analysis with the dependent variable being an indicator variable (Capitalis). This equals one (1) when a company capitalises E\&E expenditure internally and zero (0) otherwise. To examine factors that are associated with the magnitude (amounts) of internally capitalised E\&E, we used Ordinary Least Squares (OLS) multivariate analysis, with the dependent variable being the amount of internal E\&E capitalised, scaled by total assets (AmountCapitalis). Further, we examined the factors that might affect a firm's E\&E intensity (E\&Eintensity ie the sum of E\&E internally and externally generated plus any amounts expensed).

In identifying possible factors to explain internally generated E\&E capitalisation choice and magnitude as well as overall E\&E intensity, we drew on existing literature that examines the factors associated with the decision to capitalise and the magnitude of development costs (eg, Cazavan-Jeny et al. 2011; Dinh et al. 2016; Mazzi et al. 2019a; Mazzi et al. 2019b). We also considered the characteristics of firms in this particular industry (Stadler and Nobes, 2020).

The factors we considered in our analysis are: firm size (FirmSize), the ratio of return on assets (Profitability), leverage (Leverage), a categorical variable ranging from one (1) to three (3) to reflect the tercile in which the firm is classified in our sample on the basis of their revenue (RevenueT), firm age (Age), a binary variable that equals one (1) if the annual report is audited by a Big Four firm and zero (0) otherwise (Big4) and binary variable that equals one (1) if a firm capitalised E\&E in the year before and zero (0) otherwise (Capitalis Lag). ${ }^{9}$ 
TABLE 4.3: Definitions of exploration and evaluation policies used in our analysis

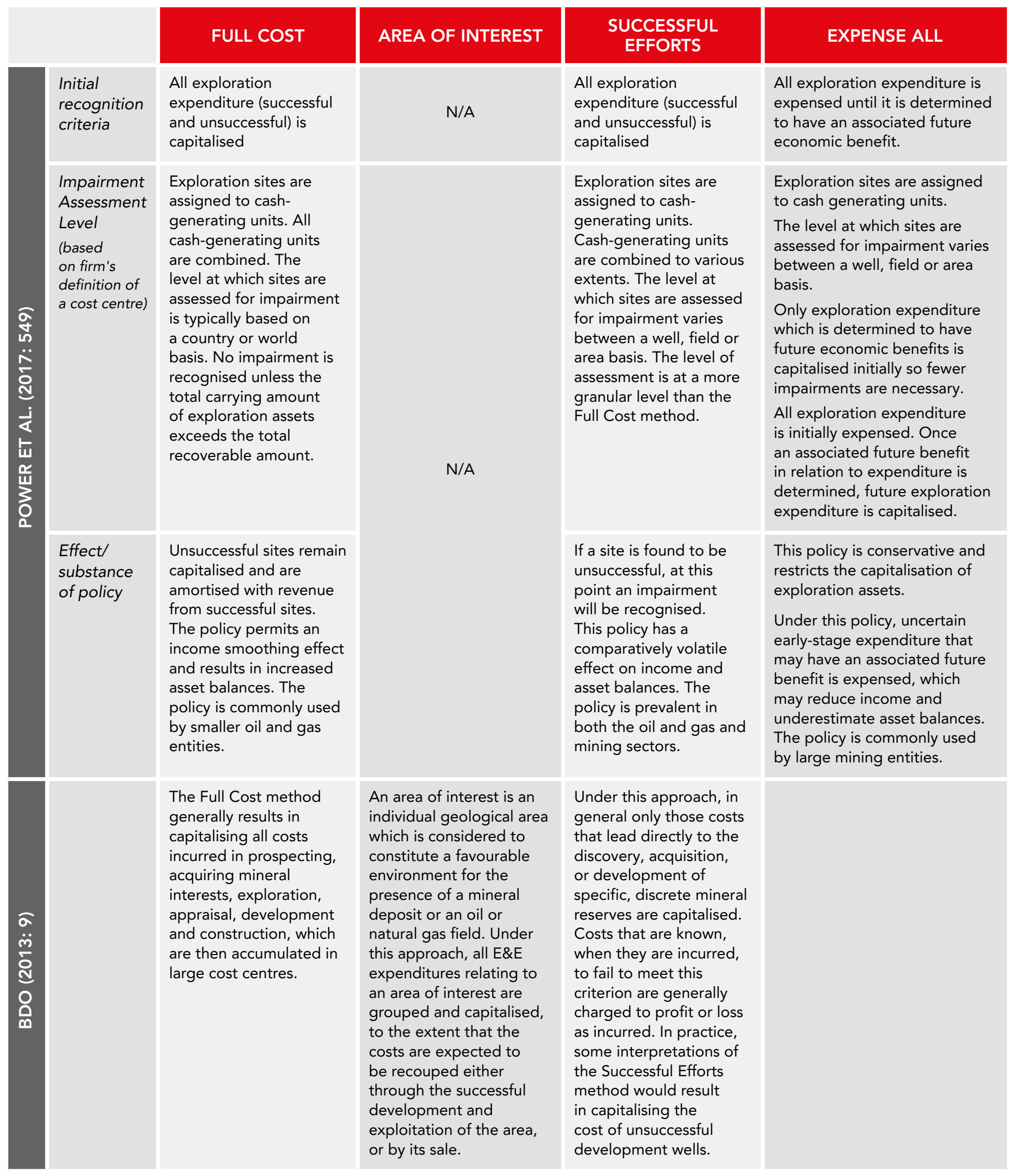


We also controlled for institutional influences in the country of domicile with the following variables: enforcement (Enforcement), corruption (Corruption), investor protection (InvProtect) and an indicator variable reflecting whether a country is classified as having a civil or common law (CivicLaw) system.

To control for industry effects, we included an indicator variable (MiningVsOil) that takes the value of one (1) for mining firms (ie firms in the aluminium, coal, copper, diamonds and gemstones, general mining, and gold subsectors) and zero (0) for the remaining firms. These operate in the oil and gas subsectors (ie alternative fuels; integrated oil and gas; offshore drilling and services; oil: crude producers). Finally, we included an indicator variable for Australian firms (Australia), an indicator variable for Canadian firms (Canada) and an indicator variable for UK firms (UK). Detailed variable definitions are presented in Appendix $\mathrm{B}^{10}$ and a generic representation of the models we applied is expressed in Equation 4.1.

\subsubsection{Determinants of accounting policy followed}

To identify factors that determine the accounting policy that a given firm chooses, we used multivariate ordered logit analysis with the dependent variable being a categorical variable (AccPolicyOrder) that equals one (1) for companies using the Full Cost method, two (2) for companies using Area of Interest, three (3) for companies using Successful Efforts and four (4) for those companies using the Expense All method. Using the same independent variables as in Equation 4.1, the factors that affect a firm's choice of accounting policy can be expressed in Equation 4.2.

\subsubsection{Determinants of occurrence of impairment and E\&E costs impaired}

Finally, we investigated the factors that determine the occurrence of an impairment of a previously E\&E capitalised expenditure and the magnitude of the amount impaired. With regard to the former, we used multivariate Probit analysis with the dependent variable being an indicator variable (Impair) that equals one (1) when a company impairs E\&E expenditure, and zero (0) otherwise. With regard to the latter, we used multivariate OLS analysis, with the dependent variable being the amount of E\&E impaired, scaled by non-current assets at the end of the previous year (ImpairAmount).

In addition to the factors considered in Equations 4.1 and 4.2 , for this analysis we included three indicator variables to capture the effect of the accounting policy used by firms. Specifically, we added an indicator variable which is equal to one (1) for firms that use the Expense All method (DExpenseAll) and zero (0) otherwise; an indicator variable which is equal to one (1) for firms which use the Successful Efforts method (SuccessEffort) and zero (0) otherwise and an indicator variable which is equal to one (1) for firms which use the Area of Interest method (Arealnterest) and zero (0) otherwise. The factors that determine an impairment of E\&E capitalised expenditure and the amount impaired can be expressed in Equation 4.3. ${ }^{11}$

\section{EQUATION 4.1:}

Capitalis or AmountCapitalis or E\&Eintensity $=f($ FirmSize,Profitability, Leverage,RevenueT,Age,Big4,CapitalisLag, Enforcement,Corruption,InvProtect,CivicLaw,MiningVsOil,Australia,Canada,UK)

\section{EQUATION 4.2:}

AccPolicyOrder = f(FirmSize,Profitability,Leverage,RevenueT,Age,Big4,CapitalisLag,Enforcement, Corruption,InvProtect, CivicLaw,MiningVsOil,Australia,Canada,UK)

\section{EQUATION 4.3:}

Impair or Impair Amount = f (FirmSize,Profitability,Leverage,RevenueT,Age,Big4,CapitalisLag,Enforcement,Corruption, InvProtect,CivicLaw,MiningVsOil,Australia,Canada,UK,DExpenseAll, SuccessEffort,AreaInterest)

10 All continuous variables in all descriptive statistics presented and in the regressions (including lag amounts) are winzorised in the \pm 1 percentile.

11 For the regressions where the dependent variable is the amount of E\&E impairment (Impair Amount), the variable Capitalis Lag is substituted by the total amount capitalised the year before (AmountTotalCapitalis Lag). 


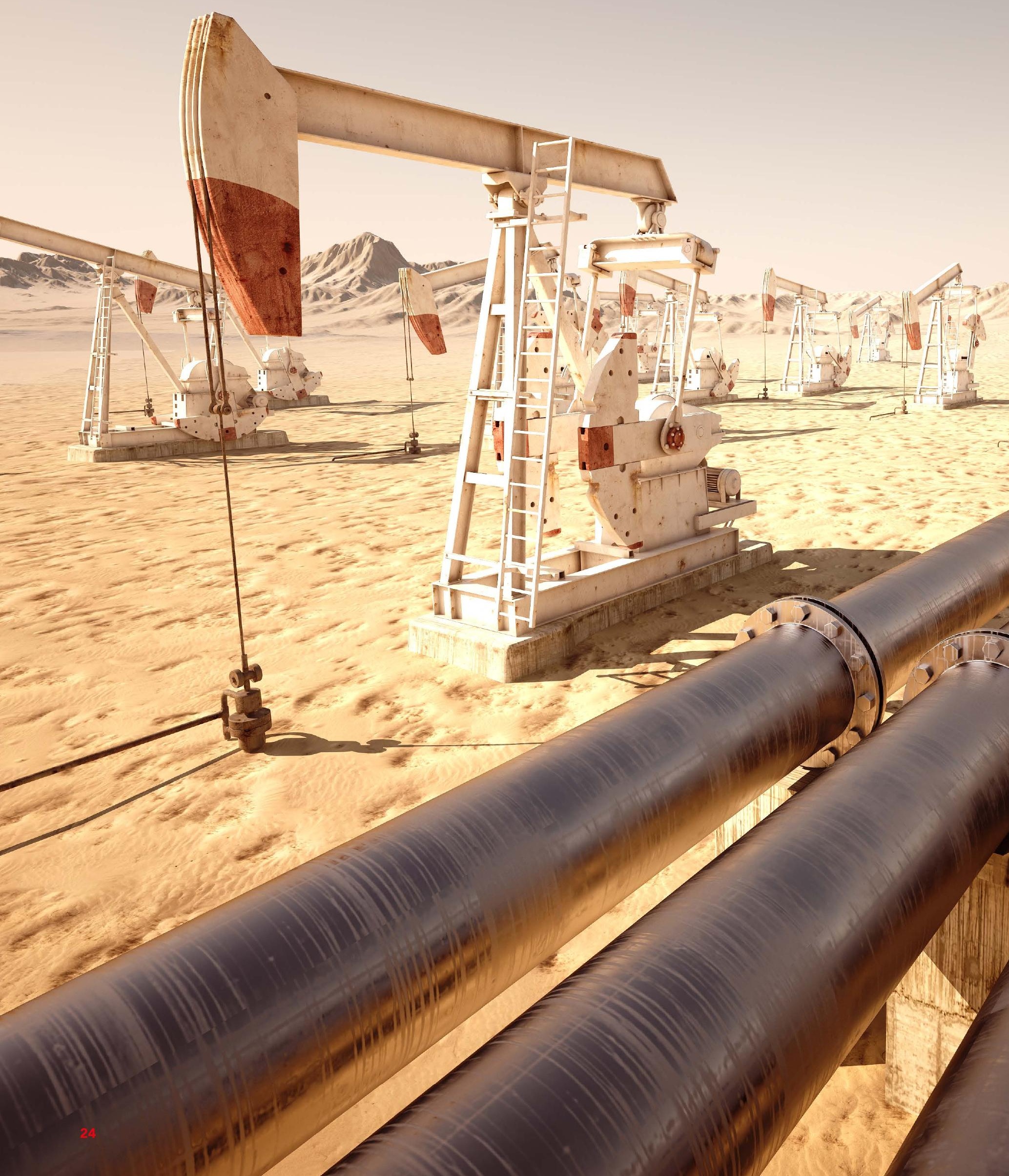




\section{Findings and discussion}

\subsection{Accounting policies followed}

Table 5.1 (Panel A) presents the methods that companies follow across countries. ${ }^{12}$ We find that Successful Efforts is the most commonly used accounting method (497 firms, 45.3\%). Indeed, this is the most popular method among Canadian and UK firms (369 firms, 61.4\% and 86 firms, $68.3 \%$, respectively) and it is the method followed almost exclusively by our sample firms in India, Norway and Russia (seven firms, 87.5\%; nine firms, 75\%; and ten firms, 83.3\%, respectively). ${ }^{13}$ The second most popular method is the Area of Interest (356 firms, 32.5\%). Given that it is mandated under AASB 6, it is by far the most commonly applied by Australian firms (280 firms, 86.4\%). ${ }^{14}$ It is also followed by 57 Canadian (9.5\%) and 16 UK (12.7\%) firms. The third most prominent accounting method is Expense All (215 firms, 19.6\%). This method is predominantly followed by firms in South Africa (nine firms, 75\%) and is the second most commonly applied method among Canadian firms (158 firms, 26.3\%). The least common method is Full Cost, adopted by 28 firms, 10 of which are in the UK (8\%) and 17 in Canada (2.8\%). ${ }^{15}$ The finding of the very low frequency of the Full Cost method is consistent with the findings of the recent IASB staff survey (IASB 2020b), which indicates that $1 \%$ of the 1,531 firms examined, for the same period as we used, follow this method. In untabulated tests, we find that the mean value of market values and total assets is lower for firms using the more aggressive accounting methods (Full Cost and Area of Interest) and higher for those using the less aggressive accounting methods (Successful Efforts and Expense All).

Panel B of Table 5.1 presents the accounting method for E\&E expenditure selected by our sample firms across each subsector. Focusing on the three subsectors that dominate the sample, most firms in general mining (185 firms, 39.4\%) apply the Successful Efforts method with a slightly smaller proportion applying the Area of Interest (174 firms, 37.1\%). The Expense All method is followed by 98 firms (20.9\%). The Successful Efforts method is also the most common method among gold mining firms (78 firms, 35.5\%), followed by the Area of Interest method (73 firms, 33.2\%) and then by the Expense All method (67 firms, 30.5\%). Oil: crude producers choose mainly the Successful Efforts accounting method (170 firms, 68.3\%) as do all 13 firms in the integrated oil and gas subsector (100\%). These findings can largely be explained by the country in which firms in these subsectors are based (see Table 4.2) and the findings discussed above, with reference to Panel A in Table 5.1.

Given the large weights of these subsectors in our sample, for the remaining of our analysis, we merged all subsectors into two industry groups, namely oil and gas (265 firms) and mining (831 firms). 'Oil and gas' include all the observations in the alternative fuels, integrated oil and gas, offshore drilling and services, and oil: crude producers subsectors. The remaining subsectors are categorised as mining.

Panel C of Table 5.1 shows the methods followed by companies across the two large industry groups (oil and gas, and mining) and countries. Given the constituent firms in these two industries, the methods followed reflect the patterns discussed for Panels A and B. The majority of oil and gas firms choose the Successful Efforts method (185 firms, 69.8\%) with the Area of Interest being the second most popular but with significantly less prominence (58 firms, $21.9 \%$ ). This can be explained by the fact that only 53 of the Australian firms in the sample (16.4\%) are in the

\footnotetext{
12 We note that only 11 firms in our sample switched method from 2017 to 2018.

13 The finding for the UK is in line with the findings of Power et al. (2017) and Abdo (2016).

14 We note that, even though Area of Interest is mandated under AASB 6, we have classified some Australian firms as following the Successful Efforts or Area of Interest (14 firms, 4.3\% and 30 firms, 9.3\%, respectively). This finding is in line with the findings of Stadler and Nobes (2020), who identify 55 Australian firms in their sample following the Area of Interest method and 11 firms, which, although stating that they follow this method, are effectively following the Successful Efforts method. Stadler and Nobes (2020) also classify 12 and 3 firms as following the Expense All or an Other method, respectively (Table 1 in Stadler and Nobes (2020).

$15 \mathrm{~A} \chi^{2}$ test of independence shows that the policies are significantly different between the countries $\left(\chi^{2}\right.$ test statistic $=631.24, p$-value $\left.=0.000\right)$.
} 
oil and gas industry. Nonetheless, considering that many mining firms are in Australia (271 firms of which 236 apply Area of Interest), we observe greater heterogeneity of accounting methods used among mining firms. While the Successful Efforts method is the most popular among such firms (312 firms, 37.5\%), the Area of Interest follows very closely (298 firms, 35.9\%). Moreover, about $25 \%$ of mining firms follow the Expense All method. ${ }^{16}$ Finally, across the two industries, 17 firms (60.7\%) in the mining industry and 11 firms (39.3\%) in the oil and gas industry use the less frequently adopted Full Cost method. ${ }^{17}$
This analysis allows us to conclude that the accounting policy choice in relation to $E \& E$ expenditure is primarily driven by the country in which a company is listed (Successful Efforts most applied in Canada and UK, and Area of Interest in Australia). While the majority of firms in the El follow the Successful Efforts method, largely independently of the industry/subsector in which they operate, firms in Australia are bounded by tradition and local accounting standards' requirements and follow the Area of Interest method.

TABLE 5.1: Accounting method for E\&E recognition

\begin{tabular}{|c|c|c|c|c|c|}
\hline PANEL A: COUNTRY & FULL COST & $\begin{array}{l}\text { AREA OF } \\
\text { INTEREST }\end{array}$ & $\begin{array}{l}\text { SUCCESSFUL } \\
\text { EFFORTS }\end{array}$ & EXPENSE ALL & TOTAL \\
\hline Australia & 0 & 280 & 14 & 30 & 324 \\
\hline Canada & 17 & 57 & 369 & 158 & 601 \\
\hline India & 1 & 0 & 7 & 0 & 8 \\
\hline South Korea & 0 & 0 & 1 & 0 & 1 \\
\hline Norway & 0 & 0 & 9 & 3 & 12 \\
\hline Russia & 0 & 1 & 10 & 1 & 12 \\
\hline South Africa & 0 & 2 & 1 & 9 & 12 \\
\hline UK & 10 & 16 & 86 & 14 & 126 \\
\hline TOTAL & 28 & 356 & 497 & 215 & 1,096 \\
\hline PANEL B: IND. SUBSECTORS & FULL COST & $\begin{array}{l}\text { AREA OF } \\
\text { INTEREST }\end{array}$ & $\begin{array}{l}\text { SUCCESSFUL } \\
\text { EFFORTS }\end{array}$ & EXPENSE ALL & TOTAL \\
\hline Alternative fuels & 0 & 0 & 0 & 1 & 1 \\
\hline Aluminium & 0 & 1 & 0 & 1 & 2 \\
\hline Coal & 0 & 23 & 7 & 5 & 35 \\
\hline Copper & 1 & 5 & 6 & 5 & 17 \\
\hline Diamonds and gemstones & 0 & 6 & 6 & 11 & 23 \\
\hline General mining & 12 & 174 & 185 & 98 & 469 \\
\hline Gold mining & 2 & 73 & 78 & 67 & 220 \\
\hline Integrated oil and gas & 0 & 0 & 13 & 0 & 13 \\
\hline Iron and steel & 1 & 10 & 11 & 4 & 26 \\
\hline Offshore drilling and services & 0 & 0 & 2 & 0 & 2 \\
\hline Oil: crude producers & 11 & 58 & 170 & 10 & 249 \\
\hline Platinum and precious metals & 1 & 6 & 19 & 13 & 39 \\
\hline TOTAL & 28 & 356 & 497 & 215 & 1,096 \\
\hline
\end{tabular}

\footnotetext{
16 This is consistent with the IASB staff survey (IASB 2020b), which notes that 'minerals entities (24\%) are more likely to adopt an accounting policy of expensing all exploration and evaluation expenditure, or only capitalising the acquisition of minerals or oil and gas properties, than oil and gas entities $(5 \%)^{\prime}$.

$17 \mathrm{~A} \chi^{2}$ test of independence shows that the policies followed by companies in the various subsectors are significantly different $\left(\chi^{2}\right.$ test statistic $=91.45$, $\mathrm{p}$-value $=$ 0.000 ).
} 


\begin{tabular}{|c|c|c|c|c|c|c|c|c|c|}
\hline \begin{tabular}{l} 
PANEL C: \\
IND.GROUP \} $\\
{\text { COUNTRY }}$ & AUSTRALIA & CANADA & INDIA & $\begin{array}{l}\text { SOUTH } \\
\text { KOREA }\end{array}$ & NORWAY & RUSSIA & $\begin{array}{l}\text { SOUTH } \\
\text { AFRICA }\end{array}$ & UK & TOTAL \\
\hline $\begin{array}{l}\text { FULL COST } \\
\text { Oil and gas } \\
\text { Mining }\end{array}$ & $\begin{array}{l}0 \\
0\end{array}$ & $\begin{array}{c}4 \\
13\end{array}$ & $\begin{array}{l}0 \\
1\end{array}$ & $\begin{array}{l}0 \\
0\end{array}$ & $\begin{array}{l}0 \\
0\end{array}$ & $\begin{array}{l}0 \\
0\end{array}$ & $\begin{array}{l}0 \\
0\end{array}$ & $\begin{array}{l}7 \\
3\end{array}$ & $\begin{array}{l}11 \\
17\end{array}$ \\
\hline $\begin{array}{l}\text { AREA OF } \\
\text { INTEREST } \\
\text { Oil and gas } \\
\text { Mining }\end{array}$ & $\begin{array}{c}44 \\
236\end{array}$ & $\begin{array}{l}10 \\
47\end{array}$ & $\begin{array}{l}0 \\
0\end{array}$ & $\begin{array}{l}0 \\
0\end{array}$ & $\begin{array}{l}0 \\
0\end{array}$ & $\begin{array}{l}0 \\
1\end{array}$ & $\begin{array}{l}0 \\
2\end{array}$ & $\begin{array}{c}4 \\
12\end{array}$ & $\begin{array}{c}58 \\
298\end{array}$ \\
\hline $\begin{array}{l}\text { SUCCESSFUL } \\
\text { EFFORTS } \\
\text { Oil and gas } \\
\text { Mining }\end{array}$ & $\begin{array}{l}5 \\
9\end{array}$ & $\begin{array}{l}118 \\
251\end{array}$ & $\begin{array}{l}2 \\
5\end{array}$ & $\begin{array}{l}0 \\
1\end{array}$ & $\begin{array}{l}8 \\
1\end{array}$ & $\begin{array}{l}7 \\
3\end{array}$ & $\begin{array}{l}1 \\
0\end{array}$ & $\begin{array}{l}44 \\
42\end{array}$ & $\begin{array}{l}185 \\
312\end{array}$ \\
\hline $\begin{array}{l}\text { EXPENSE ALL } \\
\text { Oil and gas } \\
\text { Mining }\end{array}$ & $\begin{array}{c}4 \\
26\end{array}$ & $\begin{array}{c}4 \\
154\end{array}$ & $\begin{array}{l}0 \\
0\end{array}$ & $\begin{array}{l}0 \\
0\end{array}$ & $\begin{array}{l}1 \\
2\end{array}$ & $\begin{array}{l}0 \\
1\end{array}$ & $\begin{array}{l}0 \\
9\end{array}$ & $\begin{array}{c}2 \\
12\end{array}$ & $\begin{array}{c}11 \\
204\end{array}$ \\
\hline TOTAL & 324 & 601 & 8 & 1 & 12 & 12 & 12 & 126 & 1,096 \\
\hline
\end{tabular}
\end{tabular}

\subsection{Descriptive statistics of book values of E\&E expenditure capitalised, impaired and amortised}

\subsubsection{Capitalised and expensed E\&E}

Table 5.2 (Panel A) presents the descriptive statistics for the E\&E expenditure variables that we have extracted manually from companies' financial statements. Of the 1,096 sampled firms, 1,002 reported separately an amount of capitalised E\&E assets on their balance sheets. For 764 of these firms, the amount is non-zero for 2018. The mean (median) net book value of all capitalised E\&E represents 35.4\% (16.0\%) of companies' total assets at the year-end. Further, we find that, in 2018 alone, $66 \%$ of firms capitalised an E\&E internally generated asset. On average this comprises $7.8 \%$ of year-end total assets. Additionally, we identify that 241 firms (24.3\%) also capitalised, on average, an E\&E externally generated asset that comprises $3.1 \%$ of yearend total assets. Having also captured the corresponding amounts for the previous year (2017), we observe that companies appear to capitalise with similar frequency and similar amounts across the two years (see columns: E\&E Iner. Capitalis. Lag and E\&E Exter. Capitalis Lag).

Collectively, these figures indicate that the vast majority of El companies (c75\% in our sample) capitalise, frequently and arguably consistently, significant amounts of internally generated E\&E expenditure. This finding is in direct contrast to evidence concerning the lack of capitalisation of development costs under IAS 38, which imposes six conditions (see Mazzi et al. 2019a, for example). This evidence contributes to the wider debate on the recognition of intangible assets on companies' balance sheets (Haskel and Westlake 2017; Lev, 2018; Lev and Gu 2016). This finding suggests that, when the accounting standard offers companies the option and flexibility for capitalising internally generated intangible assets, companies do so, even though this may lead to a high frequency of impairment, often of a large magnitude (see relevant findings in sub-section 5.2.2 below). We acknowledge that there is heterogeneity and lack of comparability as to the exact method companies follow for the capitalisation of E\&E assets. Nonetheless, the substance is that such assets find their way onto the balance sheet.

Table 5.2 also reports the mean (median) value of E\&E expensed in the income statement (scaled by the lag of non-current assets). We identify 357 firms reporting a non-zero value for expensed E\&E, which suggests the following. Not only firms that we have classified as following the Expense All method (ie similar to the approach in IAS 38 for the capitalisation of internally generated development costs, which results in a high frequency of expensing), but also some firms that follow the Successful Efforts or Area of Interest methods report a related expense in the income statement (in combination with Table 5.1). The mean for this variable is $123.5 \%$ and indicates that, for some firms, such expenditure constitutes an extremely large proportion of prior year non-current assets. Given this, we cap the E\&E expenses to $100 \%$ (results shown under E\&E Expense Max column). From the latter, we can observe that firms expense a large proportion of $E \& E$ in the income statement relative to the previous year's non-current assets (mean $=9.8 \%$ ). 
The last column in Table 5.2 reports companies' intensity in E\&E (the sum of both internally and externally generated E\&E assets in the year and E\&E expensed in the income statement, scaled by total assets). The mean (median) value is $84 \%$ (6.2\%). This indicates that the amounts involved for the majority of firms in El worldwide are material, yet their accounting treatment is arguably left to companies' discretion.

Anecdotal evidence and discussions with standard setters indicate that companies in the El can be classified into three categories: 'junior explorers', 'developers' and 'producers'. Effectively, the firms in the first category are small, with low value of assets and revenues. As these firms then grow and it is confirmed that their sites are indeed capable of generating economic benefits, they are either acquired by developers and/or producers or they become developers/producers themselves. As such, the smaller the firm in El may be, the higher its intensity might be. Higher E\&E intensity and low value of other assets could encourage managers in these firms to capitalise larger amounts of internally and/or externally generated E\&E expenditure by adopting less conservative accounting policies. We explore this conjecture in Panel B of Table 5.2.

Panel B of Table 5.2 presents the descriptive statistics for the E\&E variables after categorising our sample firms into revenue terciles (ie, what we name as 'junior explorers', 'developers' and 'producers'). ${ }^{18}$ Overall, the results show that the mean and median values of the E\&E variables decrease monotonically as revenue increases. Specifically, the mean (median) net-book value of capitalised E\&E to total assets for the junior explorers is $48.2 \%$ (58.8\%), and for the developers is $39.0 \%$ (33.6\%), while for the producers it is $8.5 \%$ (3.2\%). E\&E net book value differences in means and medians among each group are statistically significant at the $1 \%$ level. Effectively, this decrease captures the increase in the denominator value (ie total assets) as companies grow. We note a similar monotonic decrease in the internally capitalised E\&E and externally acquired E\&E as revenue increases for the year examined. ${ }^{19}$ Similarly, the mean E\&E expensed Max is $15.9 \%$ for the junior explorers, while that for the developers is $9.2 \%$ and for the producers is $1 \%$. These trends are also reflected on the overall E\&E intensity. This also decreases as revenue increases: junior explorers showing a mean (median) value of $131.8 \%$ (12.7\%), developers showing a mean (median) value of $39.4 \%$ (9.2\%) and the producers showing a mean (median) value of $60.9 \%(1 \%) .{ }^{20} \mathrm{~A}$ similar pattern is observed when we create terciles with total assets (firm size) (see Appendix C). Overall, this suggests that over the years, companies accumulate significant amounts of E\&E capitalised on their balance sheets, with this being significantly more acute in smaller firms, which are significantly more intensive in E\&E expenditure.

As a final note, for 2018, we observe that the percentage of firms that capitalise internally generated $E \& E$, relative to their total assets, across the three groups are $61 \%, 70 \%$ and $68 \%$, respectively. Hence, there is no clear indication that, in 2018 specifically, smaller firms capitalised internally generated E\&E proportionately more frequently.

\section{OVER THE YEARS, COMPANIES ACCUMULATE SIGNIFICANT AMOUNTS OF E\&E CAPITALISED ON THEIR BALANCE SHEETS, WITH THIS BEING SIGNIFICANTLY MORE ACUTE IN SMALLER FIRMS, WHICH ARE SIGNIFICANTLY MORE INTENSIVE IN E\&E EXPENDITURE.}

18 The groups are split on the basis of distribution of values of revenue, not on the basis of an equal split of the number of observations. The distributions are skewed to the left, ie a large number of firms are small and all small firms go into the first group. Specifically, all 430 firms characterised as 'junior explorers' have zero revenue and hence all report losses. Also, the median age is 13 years and median market value is c. $\mathrm{f} 6 \mathrm{~m}$. For comparison, the firms characterised as 'producers' report a median value or revenue (market value) of c. $£ 206 \mathrm{~m}$ ( $\mathrm{f303 \textrm {m }}$ ) and median age of 17 years.

19 Although differences in means and medians are not statistically significant between the junior explorers and the developers, they are significantly different between junior explorers and producers and developers and producers.

20 The latter mean is inflated by outliers in the E\&E expense variable. When using the E\&E Expense Max the mean is significantly smaller. 
TABLE 5.2: E\&E capitalised, expensed and E\&E intensity

\begin{tabular}{|c|c|c|c|c|c|c|c|c|c|}
\hline & $\begin{array}{l}\text { E\&E } \\
\text { NBV }\end{array}$ & $\begin{array}{c}\text { E\&E } \\
\text { NBV Lag }\end{array}$ & $\begin{array}{c}\text { E\&E } \\
\text { Inter. } \\
\text { Capitalis }\end{array}$ & $\begin{array}{c}\text { E\&E Inter. } \\
\text { Capitalis } \\
\text { Lag }\end{array}$ & $\begin{array}{c}\text { E\&E } \\
\text { Exter. } \\
\text { Capitalis }\end{array}$ & $\begin{array}{c}\text { E\&E Exter. } \\
\text { Capitalis } \\
\text { Lag }\end{array}$ & $\begin{array}{c}\text { E\&E } \\
\text { Expense }\end{array}$ & $\begin{array}{c}\text { E\&E } \\
\text { Expense } \\
\text { Max }\end{array}$ & $\begin{array}{c}\text { E\&E } \\
\text { Intensity }\end{array}$ \\
\hline \multicolumn{10}{|c|}{ PANEL A: FULL SAMPLE } \\
\hline$N$ & 1002 & 1002 & 1002 & 1002 & 993 & 993 & 944 & 944 & 1002 \\
\hline $\mathrm{N}$-no zeros & 764 & 779 & 657 & 659 & 241 & 221 & 357 & 357 & 901 \\
\hline Mean & 0.354 & 0.365 & 0.078 & 0.074 & 0.031 & 0.040 & 1.235 & 0.098 & 0.844 \\
\hline Median & 0.160 & 0.211 & 0.010 & 0.009 & 0.000 & 0.000 & 0.000 & 0.000 & 0.062 \\
\hline StDev & 0.372 & 0.369 & 0.170 & 0.149 & 0.104 & 0.149 & 7.385 & 0.266 & 5.235 \\
\hline Min & 0.000 & 0.000 & 0.000 & 0.000 & 0.000 & 0.000 & 0.000 & 0.000 & 0.000 \\
\hline Max & 0.991 & 0.996 & 1.184 & 0.852 & 0.611 & 0.933 & 58.434 & 1.000 & 48.570 \\
\hline \multicolumn{10}{|c|}{ PANEL B: TERCILES BY REVENUE } \\
\hline \multicolumn{10}{|c|}{ JUNIOR EXPLORERS } \\
\hline$N$ & 430 & 430 & 430 & 430 & 427 & 427 & 389 & 389 & 430 \\
\hline $\mathrm{N}$-no zeros & 318 & 330 & 261 & 265 & 141 & 128 & 139 & 139 & 384 \\
\hline Mean & 0.482 & 0.495 & 0.100 & 0.096 & 0.045 & 0.063 & 1.762 & 0.159 & 1.318 \\
\hline Median & 0.588 & 0.583 & 0.016 & 0.016 & 0.000 & 0.000 & 0.000 & 0.000 & 0.127 \\
\hline StDev & 0.398 & 0.385 & 0.201 & 0.177 & 0.123 & 0.190 & 8.727 & 0.333 & 6.447 \\
\hline Min & 0.000 & 0.000 & 0.000 & 0.000 & 0.000 & 0.000 & 0.000 & 0.000 & 0.000 \\
\hline Max & 0.991 & 0.996 & 1.184 & 0.852 & 0.611 & 0.933 & 58.434 & 1.000 & 48.570 \\
\hline \multicolumn{10}{|c|}{ DEVELOPERS } \\
\hline$N$ & 323 & 323 & 323 & 323 & 320 & 320 & 309 & 309 & 323 \\
\hline $\mathrm{N}$-no zeros & 125 & 252 & 226 & 227 & 60 & 52 & 100 & 100 & 290 \\
\hline Mean & 0.390 & 0.399 & 0.099 & 0.091 & 0.035 & 0.036 & 1.548 & 0.092 & 0.394 \\
\hline Median & 0.336 & 0.355 & 0.027 & 0.028 & 0.000 & 0.000 & 0.000 & 0.000 & 0.092 \\
\hline StDev & 0.359 & 0.364 & 0.175 & 0.148 & 0.110 & 0.135 & 8.330 & 0.257 & 2.751 \\
\hline Min & 0.000 & 0.000 & 0.000 & 0.000 & 0.000 & 0.000 & 0.000 & 0.000 & 0.000 \\
\hline Max & 0.991 & 0.996 & 1.184 & 0.852 & 0.611 & 0.933 & 58.434 & 1.000 & 48.570 \\
\hline \multicolumn{10}{|c|}{ PRODUCERS } \\
\hline$N$ & 249 & 249 & 249 & 249 & 246 & 246 & 246 & 246 & 249 \\
\hline $\mathrm{N}$-no zeros & 195 & 197 & 170 & 167 & 40 & 41 & 118 & 118 & 227 \\
\hline Mean & 0.085 & 0.096 & 0.015 & 0.015 & 0.003 & 0.007 & 0.010 & 0.010 & 0.609 \\
\hline Median & 0.032 & 0.038 & 0.002 & 0.002 & 0.000 & 0.000 & 0.000 & 0.000 & 0.010 \\
\hline StDev & 0.124 & 0.137 & 0.032 & 0.046 & 0.017 & 0.031 & 0.028 & 0.028 & 5.307 \\
\hline Min & 0.000 & 0.000 & 0.000 & 0.000 & 0.000 & 0.000 & 0.000 & 0.000 & 0.000 \\
\hline Max & 0.653 & 0.718 & 0.210 & 0.622 & 0.163 & 0.278 & 0.301 & 0.301 & 48.570 \\
\hline
\end{tabular}


TABLE 5.3: E\&E capitalised, expensed and E\&E intensity, by accounting policy used

\begin{tabular}{|c|c|c|c|c|c|c|c|c|c|}
\hline & $\begin{array}{l}\text { E\&E } \\
\text { NBV }\end{array}$ & $\begin{array}{c}\text { E\&E } \\
\text { NBV Lag }\end{array}$ & $\begin{array}{c}\text { E\&E } \\
\text { Inter. } \\
\text { Capitalis }\end{array}$ & $\begin{array}{c}\text { E\&E Inter. } \\
\text { Capitalis } \\
\text { Lag }\end{array}$ & $\begin{array}{c}\text { E\&E } \\
\text { Exter. } \\
\text { Capitalis }\end{array}$ & $\begin{array}{c}\text { E\&E Exter. } \\
\text { Capitalis } \\
\text { Lag }\end{array}$ & $\begin{array}{c}\text { E\&E } \\
\text { Expense }\end{array}$ & $\begin{array}{c}\text { E\&E } \\
\text { Expense } \\
\text { Max }\end{array}$ & $\begin{array}{c}\text { E\&E } \\
\text { Intensity }\end{array}$ \\
\hline \multicolumn{10}{|l|}{ FULL COST } \\
\hline$N$ & 24 & 24 & 24 & 24 & 23 & 23 & 23 & 23 & 24 \\
\hline $\mathrm{N}$-no zeros & 18 & 23 & 18 & 19 & 2 & 1 & 3 & 3 & 18 \\
\hline Mean & 0.367 & 0.425 & 0.040 & 0.039 & 0.001 & 0.012 & 0.013 & 0.013 & 0.048 \\
\hline Median & 0.236 & 0.377 & 0.015 & 0.007 & 0.000 & 0.000 & 0.000 & 0.000 & 0.019 \\
\hline StDev & 0.381 & 0.349 & 0.063 & 0.081 & 0.002 & 0.058 & 0.060 & 0.060 & 0.067 \\
\hline Min & 0.000 & 0.000 & 0.000 & 0.000 & 0.000 & 0.000 & 0.000 & 0.000 & 0.000 \\
\hline Max & 0.989 & 0.984 & 0.222 & 0.369 & 0.009 & 0.278 & 0.288 & 0.288 & 0.222 \\
\hline \multicolumn{10}{|c|}{ AREA OF INTEREST } \\
\hline $\mathrm{N}$ & 339 & 339 & 339 & 339 & 336 & 336 & 325 & 325 & 339 \\
\hline $\mathrm{N}$-no zeros & 287 & 292 & 269 & 269 & 82 & 65 & 95 & 95 & 314 \\
\hline Mean & 0.439 & 0.455 & 0.107 & 0.088 & 0.034 & 0.039 & 0.432 & 0.054 & 0.501 \\
\hline Median & 0.444 & 0.460 & 0.038 & 0.031 & 0.000 & 0.000 & 0.000 & 0.000 & 0.078 \\
\hline StDev & 0.368 & 0.370 & 0.190 & 0.139 & 0.105 & 0.146 & 3.893 & 0.193 & 3.758 \\
\hline Min & 0.000 & 0.000 & 0.000 & 0.000 & 0.000 & 0.000 & 0.000 & 0.000 & 0.000 \\
\hline Max & 0.991 & 0.996 & 1.184 & 0.852 & 0.611 & 0.933 & 58.434 & 1.000 & 48.570 \\
\hline \multicolumn{10}{|c|}{ SUCCESSFUL EFFORTS } \\
\hline$N$ & 445 & 445 & 445 & 445 & 442 & 442 & 422 & 422 & 445 \\
\hline $\mathrm{N}$-no zeros & 383 & 391 & 346 & 351 & 129 & 128 & 102 & 102 & 387 \\
\hline Mean & 0.375 & 0.393 & 0.089 & 0.095 & 0.035 & 0.045 & 0.396 & 0.035 & 0.818 \\
\hline Median & 0.198 & 0.280 & 0.019 & 0.019 & 0.000 & 0.000 & 0.000 & 0.000 & 0.043 \\
\hline StDev & 0.374 & 0.366 & 0.176 & 0.177 & 0.110 & 0.155 & 4.317 & 0.162 & 5.381 \\
\hline Min & 0.000 & 0.000 & 0.000 & 0.000 & 0.000 & 0.000 & 0.000 & 0.000 & 0.000 \\
\hline Max & 0.991 & 0.996 & 1.184 & 0.852 & 0.611 & 0.933 & 58.434 & 1.000 & 48.570 \\
\hline \multicolumn{10}{|c|}{ EXPENSE ALL } \\
\hline$N$ & 194 & 194 & 194 & 194 & 192 & 192 & 174 & 174 & 194 \\
\hline $\mathrm{N}$-no zeros & 76 & 73 & 24 & 20 & 28 & 27 & 157 & 157 & 182 \\
\hline Mean & 0.152 & 0.134 & 0.011 & 0.008 & 0.021 & 0.036 & 4.934 & 0.344 & 1.600 \\
\hline Median & 0.000 & 0.000 & 0.000 & 0.000 & 0.000 & 0.000 & 0.097 & 0.097 & 0.106 \\
\hline StDev & 0.296 & 0.273 & 0.088 & 0.048 & 0.089 & 0.145 & 14.376 & 0.420 & 7.066 \\
\hline Min & 0.000 & 0.000 & 0.000 & 0.000 & 0.000 & 0.000 & 0.000 & 0.000 & 0.000 \\
\hline Max & 0.991 & 0.978 & 1.184 & 0.488 & 0.611 & 0.933 & 58.434 & 1.000 & 48.570 \\
\hline
\end{tabular}


Table 5.3 reports descriptive statistics for the same E\&E expenditure-related variables, albeit across the four subsamples of firms, on the basis of the accounting method selected for the treatment of such expenditure. Even though Area of Interest is the second most popular method among our sample firms, we note that firms that choose this method report higher values of total E\&E capitalised relative to total assets than do companies that follow the Successful Efforts method (mean: $43.9 \%$ vs $37.5 \%$, significant at the $5 \%$; median: $44.4 \%$ vs $19.8 \%$, significant at the $10 \%$, respectively). Additionally, the median value of the internally generated E\&E asset capitalised in 2018 is significantly higher for firms following the Area of Interest method than for those following the Successful Efforts method ( $3.8 \%$ vs $1.9 \%$, significant at the $5 \%$ level). This is consistent with the classification of the Area of Interest method as being less conservative than Successful Efforts and can be explained by the tradition of accounting policy applied in Australia, flowing through to reporting under Australian IFRS. ${ }^{21}$ As Cortese et al. (2009) explain, in the period pre-IFRS era in Australia, pre-production costs were 'to be capitalised if the stage of the project prohibited an assessment of the viability of the area-of-interest' (Australian Accounting Standards Board 1989: 8). Hence, companies could capitalise some costs related to unsuccessful projects and this is also permitted under current AASB 6 (see Appendix A). This is also why Deloitte Touche Tohmatsu (2001: 17, Figure 10) indicated that, under Successful Efforts, pre-acquisition prospecting and exploration costs are 'generally expensed' while those under the Area of Interest are 'either capitalised or expensed'. ${ }^{22}$ As a consequence, capitalisation of such expenditure could subsequently result in higher frequency of recognition of E\&E impairments under the Area of Interest method than under Successful Efforts (and see further discussion on this around the findings presented in Table 5.7 on impairments).

As a final note, as expected, companies that follow the Expense All method report the lowest total and internally generated E\&E asset capitalised (means: $15.2 \%$ and 1.1\%, respectively). These are significantly lower at the $1 \%$ level than the corresponding amounts reported by firms following both the Successful Efforts and Area of Interest methods.

Table 5.4 reports descriptive statistics for the same E\&E expenditure-related variables, albeit across the two sub-samples of the oil and gas, and mining industries. The table shows that the mean (median) of the ratio of total E\&E asset value to total assets is significantly larger in mining firms (38.9\% (25.4\%) vs $23.9 \%$ (7.6\%), both differences being statistically significant at the $1 \%$ level). The same pattern is observed for internally $(8.2 \%(1 \%)$ versus $6.6 \%(1 \%))$ and externally $(3.6 \%(0 \%)$ versus $1.6 \%$ $(0 \%))$ generated E\&E capitalised in the year, respectively. Consistent with these figures, E\&E intensity is also higher among mining firms (mean: $89.7 \%$ vs $67 \%$; median: $8.1 \%$ vs $2.2 \%$ ). These findings can be interpreted by considering the underlying characteristics of the constituent firms of the two industry groups and results presented in previous tables. Untabulated descriptive statistics reveal that firms in the oil and gas industry report significantly larger amounts of total assets and revenues, are older and have significantly larger market values. Hence, more companies in the mining sector are junior explorers or developers while oil and gas firms include more producers (which correspondingly have larger asset bases). Further, we have already observed that oil and gas firms tend to use the Successful Efforts method while mining firms are more heterogeneous, with many of them being in Australia and hence following the Area of Interest method, which results in capitalisation of larger amounts of E\&E assets.

\subsubsection{Impairment and amortisation of E\&E expenditure capitalised}

Table 5.5 presents the descriptive statistics for the amounts of E\&E impairments, impairment reversals and E\&E-related amortisation recognised in the year. Of the 1,002 firms that report an E\&E asset on the balance sheet, 944 report separately whether they incurred a related impairment in the year, with 346 having recognised an E\&E related impairment. Specifically, we find that among those firms that report a non-zero impairment, the mean value of the impairment recognised relative to non-current assets at the end of the previous year is $33.5 \%$. We note that this is highly left skewed, as indicated by the lower median (4.6\%) and the high standard deviation (0.722). Nevertheless, the amounts of impairment recognised cannot be considered negligible. They equate to around $5 \%$ of non-current assets at the end of the previous period and, in many instances, exceed this by a very large amount. Impairment reversal is found in only 13 firms in our sample and the reversal relative to total assets at the end of the previous period is very low in magnitude (mean: -0.001; median: -0.002). Further, we find that amortisation of E\&E asset is not very common, as only 23 firms report a non-zero amount and this is low in magnitude (mean: 0.002; median: 0.003 ) relative to total assets.

21 The potential for such an aggressive reporting could be exacerbated among smaller firms, which have an incentive to capitalise large amounts of E\&E expenditure In line with this argument, Nobes (2006) notes that national accounting traditions are likely to continue under IFRS, at least partially, because of 'a company's conscious desire to disrupt its accounting as little as possible' (Nobes 2006: 235).

22 We believe that this is why BDO (2013: 9) state that 'however, some interpretations of the successful efforts method would result in capitalising the cost of unsuccessful development wells'. 
TABLE 5.4: E\&E capitalised, expensed and E\&E intensity, by industry group

\begin{tabular}{|c|c|c|c|c|c|c|c|c|c|}
\hline & $\begin{array}{l}\text { E\&E } \\
\text { NBV }\end{array}$ & $\begin{array}{c}\text { E\&E } \\
\text { NBV Lag }\end{array}$ & $\begin{array}{c}\text { E\&E } \\
\text { Inter. } \\
\text { Capitalis }\end{array}$ & $\begin{array}{c}\text { E\&E Inter. } \\
\text { Capitalis } \\
\text { Lag }\end{array}$ & $\begin{array}{c}\text { E\&E } \\
\text { Exter. } \\
\text { Capitalis }\end{array}$ & $\begin{array}{c}\text { E\&E Exter. } \\
\text { Capitalis } \\
\text { Lag }\end{array}$ & $\begin{array}{c}\text { E\&E } \\
\text { Expense }\end{array}$ & $\begin{array}{c}\text { E\&E } \\
\text { Expense } \\
\text { Max }\end{array}$ & $\begin{array}{c}\text { E\&E } \\
\text { Intensity }\end{array}$ \\
\hline \multicolumn{10}{|c|}{ OIL AND GAS } \\
\hline$N$ & 234 & 234 & 234 & 234 & 230 & 230 & 227 & 227 & 234 \\
\hline $\mathrm{N}$-no zeros & 195 & 201 & 180 & 182 & 40 & 37 & 74 & 74 & 206 \\
\hline Mean & 0.239 & 0.268 & 0.066 & 0.068 & 0.016 & 0.023 & 0.555 & 0.033 & 0.670 \\
\hline Median & 0.076 & 0.124 & 0.010 & 0.009 & 0.000 & 0.000 & 0.000 & 0.000 & 0.022 \\
\hline StDev & 0.307 & 0.301 & 0.165 & 0.148 & 0.070 & 0.114 & 5.477 & 0.155 & 4.941 \\
\hline Min & 0.000 & 0.000 & 0.000 & 0.000 & 0.000 & 0.000 & 0.000 & 0.000 & 0.000 \\
\hline Max & 0.991 & 0.996 & 1.184 & 0.852 & 0.611 & 0.933 & 58.434 & 1.000 & 48.570 \\
\hline \multicolumn{10}{|l|}{ MINING } \\
\hline$N$ & 768 & 768 & 768 & 768 & 763 & 763 & 717 & 717 & 768 \\
\hline $\mathrm{N}$-no zeros & 569 & 578 & 477 & 477 & 201 & 184 & 283 & 283 & 695 \\
\hline Mean & 0.389 & 0.394 & 0.082 & 0.076 & 0.036 & 0.046 & 1.451 & 0.119 & 0.897 \\
\hline Median & 0.254 & 0.281 & 0.010 & 0.009 & 0.000 & 0.000 & 0.000 & 0.000 & 0.081 \\
\hline StDev & 0.383 & 0.383 & 0.171 & 0.149 & 0.111 & 0.157 & 7.884 & 0.290 & 5.323 \\
\hline Min & 0.000 & 0.000 & 0.000 & 0.000 & 0.000 & 0.000 & 0.000 & 0.000 & 0.000 \\
\hline Max & 0.991 & 0.996 & 1.184 & 0.852 & 0.611 & 0.933 & 58.434 & 1.000 & 48.570 \\
\hline
\end{tabular}

TABLE 5.5: E\&E Impairment, impairment reversal \& E\&E amortisation

\begin{tabular}{|l|c|c|c|c|}
\hline & E\&E IMPAIR & E\&E IMPAIR MAX & IMPAIRMENT REVERSAL & AMORTISATION \\
\hline FULL SAMPLE & & & & 1002 \\
\hline N & 944 & 944 & 1002 & 23 \\
\hline N-no zeros & 346 & 346 & 13 & 0.002 \\
\hline Mean & 0.335 & 0.231 & -0.001 & 0.003 \\
\hline Median & 0.046 & 0.046 & -0.002 & 0.002 \\
\hline StDev & 0.722 & 0.337 & 0.000 & 0.000 \\
\hline Min & 0.000 & 0.000 & -0.002 & 0.004 \\
\hline Max & 3.838 & 1.000 & 0.000 & \\
\hline
\end{tabular}

Note: Descriptive statistics excluding zeros. 
TABLE 5.6: E\&E impairment across junior explorers, developers, and producers

\begin{tabular}{|c|c|c|c|c|c|c|}
\hline & \multicolumn{2}{|c|}{ JUNIOR EXPLORERS } & \multicolumn{2}{|c|}{ DEVELOPERS } & \multicolumn{2}{|c|}{ PRODUCERS } \\
\hline & $\begin{array}{l}\text { E\&E } \\
\text { IMPAIR }\end{array}$ & $\begin{array}{c}\text { E\&E } \\
\text { IMPAIR MAX }\end{array}$ & $\begin{array}{c}\text { E\&E } \\
\text { IMPAIR }\end{array}$ & $\begin{array}{c}\text { E\&E } \\
\text { IMPAIR MAX }\end{array}$ & $\begin{array}{l}\text { E\&E } \\
\text { IMPAIR }\end{array}$ & $\begin{array}{c}\text { E\&E } \\
\text { IMPAIR MAX }\end{array}$ \\
\hline $\mathrm{N}$ & 389 & 389 & 309 & 309 & 246 & 246 \\
\hline $\mathrm{N}$-no zeros & 129 & 129 & 137 & 137 & 80 & 80 \\
\hline Mean & 0.468 & 0.343 & 0.388 & 0.245 & 0.029 & 0.029 \\
\hline Median & 0.150 & 0.150 & 0.068 & 0.068 & 0.008 & 0.008 \\
\hline StDev & 0.777 & 0.387 & 0.823 & 0.332 & 0.055 & 0.055 \\
\hline Min & 0.000 & 0.000 & 0.000 & 0.000 & 0.000 & 0.000 \\
\hline Max & 3.838 & 1.000 & 3.838 & 1.000 & 0.337 & 0.337 \\
\hline
\end{tabular}

Note: Descriptive statistics excluding zeros.

Having demonstrated that net-book values of E\&E assets and the values of internally generated E\&E assets capitalised in the year are larger in magnitude for smaller firms (see Table 5.1), Table 5.6 presents the descriptive statistics in relation to E\&E assets' impairment after categorising our sample firms into revenue terciles (ie junior explorers; developers; and producers). The results show that the magnitude of impairment relative to noncurrent assets at the end of the previous year decreases as revenue increases. Specifically, the mean (median) value of impairment for junior explorers is $46.8 \%(15 \%)$, while that for the developers and producers is $38.8 \%(6.8 \%)$ and $2.9 \%(1 \%)$, respectively. ${ }^{23}$ We also note that the same pattern does not apply for the frequency of impairments. Specifically, while the magnitude of the impairments recognised is larger for smaller firms, impairment recognition for E\&E assets is not necessarily more frequent in smaller firms (junior explorers: $33.2 \%$, developers: $44.3 \%$, producers: $32.5 \%$ ).

Table 5.7 presents the descriptive statistics in relation to E\&E assets' impairment, impairment reversal and amortisation, albeit across the four sub-samples of firms on the basis of the accounting method selected for the treatment of E\&E expenditure. Perhaps somewhat surprising, given that firms following the Area of Interest method tend to have larger E\&E assets on the balance sheet (see Table 5.3), Table 5.7 shows that impairments in relation to E\&E assets are of similar magnitude among firms using this method (mean: 34.6\%; median: $4.2 \%$ ) and the Successful Efforts method (mean: 33.4\%; median: $5.5 \%$ ). These differences are not statistically significantly different. Even so, we do find that a significantly larger proportion of firms recognise an impairment under the Area of Interest method $(164 / 325=50 \%)$ than those following the Successful Efforts method (152/422=36\%). This is consistent with the underlying premise that firms following the Area of Interest method may capitalise some costs related to unsuccessful projects (see discussion of the figures reported in Table 5.3).

Intuitively and in a simplified way, one would expect to find lower percentages of firms recognising an impairment under the Area of Interest method. This could be the case because unsuccessful exploration could be carried forward in an 'area' as long as the overall Area of Interest is eventually a success. In fact, AASB 6 (para 7) argues that 'in most cases, an area of interest will comprise a single mine or deposit or a separate oil or gas field' (IASB 2020b: 7 footnote 3). Further, as explained by Power et al. (2017: 549), under the Successful Efforts method, the level at which sites are assessed for impairment varies between a well, field or area basis (emphasis added). To illustrate the point, Power et al. (2017) cite Trueman (1975), who explains that oil and gas firms (which we also classify as mostly following the Successful Efforts method - see Table 5.1, Panel C) '... have different views on exploration cost centres, with cost centres being defined as either wells, fields, areas, countries or the world' (Trueman 1975: 546). Similarly, with regard to application of the Area of Interest method, Stadler and Nobes (2020: 2) note that: 'little insight about the pooling basis is gained from references to "area of interest" (mainly by Australian firms). A firm might repeat the term many times without offering a clue about whether it means a single mine, a license, a geological area, a reporting segment or the whole E\&E 
TABLE 5.7: E\&E impairment, impairment reversal and E\&E amortisation, by accounting policy used

\section{E\&E IMPAIR}

\section{E\&E IMPAIR MAX}

IMPAIRMENT REVERSAL

AMORTISATION

\section{FULL COST}

\begin{tabular}{|l|r|r|}
\hline N & 23 & 23 \\
\hline N-no zeros & 5 & 5 \\
\hline Mean & 0.073 & 0.073 \\
\hline Median & 0.037 & 0.037 \\
\hline StDev & 0.090 & 0.090 \\
\hline Min & 0.001 & 0.001 \\
\hline Max & 0.210 & 0.210 \\
\hline
\end{tabular}

AREA OF INTEREST

\begin{tabular}{|c|c|c|c|c|}
\hline $\mathrm{N}$ & 325 & 325 & 339 & 339 \\
\hline $\mathrm{N}$-no zeros & 164 & 164 & 4 & 2 \\
\hline Mean & 0.346 & 0.226 & -0.001 & 0.001 \\
\hline Median & 0.042 & 0.042 & -0.002 & 0.001 \\
\hline StDev & 0.768 & 0.326 & 0.001 & 0.001 \\
\hline Min & 0.000 & 0.000 & -0.002 & 0.001 \\
\hline Max & 3.838 & 1.000 & 0.000 & 0.002 \\
\hline \multicolumn{5}{|c|}{ SUCCESSFUL EFFORTS } \\
\hline $\mathrm{N}$ & 422 & 422 & 445 & 445 \\
\hline $\mathrm{N}$-no zeros & 152 & 152 & 7 & 19 \\
\hline Mean & 0.334 & 0.247 & -0.001 & 0.002 \\
\hline Median & 0.055 & 0.055 & -0.002 & 0.004 \\
\hline StDev & 0.673 & 0.356 & 0.000 & 0.002 \\
\hline Min & 0.000 & 0.000 & -0.002 & 0.000 \\
\hline Max & 3.838 & 1.000 & 0.000 & 0.004 \\
\hline \multicolumn{5}{|c|}{ EXPENSE ALL } \\
\hline $\mathrm{N}$ & 174 & 174 & 194 & 194 \\
\hline N-no zeros & 25 & 25 & 2 & 2 \\
\hline Mean & 0.321 & 0.205 & -0.002 & 0.003 \\
\hline Median & 0.025 & 0.025 & -0.002 & 0.003 \\
\hline StDev & 0.788 & 0.329 & 0.000 & 0.002 \\
\hline Min & 0.001 & 0.001 & -0.002 & 0.002 \\
\hline Max & 3.838 & 1.000 & -0.002 & 0.004 \\
\hline
\end{tabular}

Note: Descriptive statistics excluding zeros. 
effort'. On that basis, Stadler and Nobes (2020) indicate that there can be four variations of the Area of Interest method, using the pooling basis (Methods 6-9 in Table 2 of Stadler and Nobes 2020). In fact, in their Table 4, they identify $13 \%$ of the firms they classify as following the Area of Interest method as being very close to those following the Successful Efforts method because they 'impair by project'. Further, they classify $49 \%$ of the firms in their sample as following the Successful Efforts method, which also 'impair by project' (ie, the same method as Area of Interest). Hence, while firms following the Area of Interest method may capitalise costs related to unsuccessful exploration (unlike firms following the Successful Efforts method), they may not be very different in the basis used for impairment testing of these costs capitalised. This can explain the higher proportion of firms recognising an impairment under the Area of Interest method but not recognising significantly different amounts of impairments.

Further, firms using the Expense All method follow firms using the Area of Interest and Successful Efforts methods in the magnitude (mean: $32.1 \%$; median: $2.5 \%$ ) and frequency $(25 / 174=14 \%)$ of impairments. Moreover, among firms using the Full Cost method, impairment frequency is $22 \%$ and mean (median) value is $7.3 \%$ (3.7\%). Finally, the results show that amortisation is most common among firms using the Successful Efforts method and in line with the results presented in Table 5.5, the magnitude of amortisation is generally a small proportion of total assets.

Table 5.8 shows the descriptive statistics in relation to $E \& E$ assets' impairment, impairment reversal and amortisation, albeit across the two sub-samples of the oil and gas, and mining industries. While from the results reported in Table 5.4, we have observed that mining firms report significantly larger amounts of net book value of E\&E assets as well as externally generated E\&E assets, the results in Table 5.8 show that the magnitude of E\&E assets impaired in mining firms appears to be only marginally larger than those impaired by oil and gas firms (mean (median): $37.1 \%$ (4.6\%) in mining vs $24.6 \%$ (4.6\%) in oil and gas). The difference in the mean is statistically significant at the $10 \%$ level and the difference in the median is statistically insignificant. ${ }^{24}$ Given that a large proportion of mining firms follow the Expense All method (see Table 5.1, Panel C), this finding is what we would intuitively expect.

TABLE 5.8: E\&E impairment, impairment reversal \& E\&E amortisation, by industry group

\section{\begin{tabular}{l|l|l|l} 
E\&E IMPAIR & E\&E IMPAIR MAX & IMPAIRMENT REVERSAL & AMORTISATION
\end{tabular}}

\begin{tabular}{|l|r|r|r|r|}
\hline OIL AND GAS & & & & \\
\hline N & 227 & 227 & 234 & 12 \\
\hline N-no zeros & 100 & 100 & 2 & 0.003 \\
\hline Mean & 0.246 & 0.200 & -0.001 & 0.004 \\
\hline Median & 0.046 & 0.046 & -0.001 & 0.002 \\
\hline StDev & 0.509 & 0.305 & 0.001 & 0.000 \\
\hline Min & 0.000 & 0.000 & -0.002 & 0.004 \\
\hline Max & 3.838 & 1.000 & 0.000 & 768 \\
\hline MINING & & & & 11 \\
\hline N & 717 & 717 & 768 & 0.002 \\
\hline N-no zeros & 246 & 246 & 11 & 0.002 \\
\hline Mean & 0.371 & 0.244 & -0.001 & 0.002 \\
\hline Median & 0.046 & 0.046 & -0.002 & 0.000 \\
\hline StDev & 0.790 & 0.350 & 0.000 & 0.004 \\
\hline Min & 0.000 & 0.000 & -0.002 & 0.000 \\
\hline Max & 3.838 & 1.000 & & \\
\hline
\end{tabular}

Note: Descriptive statistics excluding zeros.

24 Further, marginal differences exist between the two industry groups for reversal of impairment (mining: -0.001 ; oil and gas: -0.001 ). Additionally, the magnitude of amortisation represents a very small proportion of total assets across both industry groups. 
Overall and in combination, the findings reported in sections 5.1 and 5.2 indicate that companies capitalise large amounts of E\&E assets, even though the probability of recognising a large impairment in the future is also high.

Finally, to demonstrate the variety in the accounting methods companies follow and how these are described, Appendix D presents extracts from the financial statements of 20 firms that have high E\&E intensity and/or record large impairment.

\subsection{Multivariate analysis}

\subsubsection{Determinants of decision of E\&E} capitalisation and amounts capitalised In this section, we report the results of the multivariate analyses, which explore the determinants of the decision to capitalise internally generated E\&E assets and the magnitude of such assets (see Equation 4.1). Table 5.9 shows the results of a Probit regression, with the dependent variable being one (1) if the company has capitalised internally generated E\&E assets in the year, and zero (0) otherwise. We report the results of three alternative models: a) using the various control variables but excluding the industry dummy MiningVsOil (which classifies firms as either oil and gas or mining) and country dummies, b) excluding the country dummies only, and c) a model which includes all variables.

The results from these tests show that, first, a firm's decision to capitalise depends positively on its size, as the coefficient of firm size is consistently positive across all specifications (a coefficient around $0.09-0.11$ and statistically significant at the $1 \%$ level). This suggests that the larger the company, the higher the likelihood that it will capitalise. Although this finding could be counterintuitive at first glance, it can be explained as follows. Larger companies have a larger pool of projects that can be considered in aggregate. This aggregation increases the probability of success, leading larger firms to capitalise E\&E costs more often, regardless of the accounting policy followed. In contrast, small firms may be dependent upon single sites. Firm age shows a negative and statistically significant coefficient (around -0.2, at the $5 \%$ level), suggesting that the younger the company, or the earlier in its life cycle, the higher the capitalisation likelihood. To some extent, these findings confirm the descriptive analysis discussed in relation to the findings presented in Table 5.2. When discussing those findings, we have indicated that that the percentage of firms that capitalise internally generated E\&E as a proportion of their total assets across junior explorers, developers, and producers are $61 \%, 70 \%$ and $68 \%$, respectively.
TABLE 5.9: Determinants of the decision to capitalise internally generated E\&E assets in the year

\begin{tabular}{|c|c|c|c|}
\hline VARIABLES & $\begin{array}{c}(1) \\
\text { CAPITALIS }\end{array}$ & $\begin{array}{c}(2) \\
\text { CAPITALIS }\end{array}$ & $\begin{array}{c}\text { (3) } \\
\text { CAPITALIS }\end{array}$ \\
\hline \multirow[t]{2}{*}{ FirmSize } & $0.089 * \star \star$ & $0.089 * \star \star$ & $0.107^{\star \star \star \star}$ \\
\hline & (2.891) & (2.901) & (3.369) \\
\hline \multirow[t]{2}{*}{ RevenueT } & -0.009 & -0.019 & -0.103 \\
\hline & $(-0.092)$ & $(-0.187)$ & $(-0.958)$ \\
\hline \multirow[t]{2}{*}{ Profitability } & -0.000 & -0.000 & 0.000 \\
\hline & $(-0.099)$ & $(-0.108)$ & (0.022) \\
\hline \multirow[t]{2}{*}{ Leverage } & -0.006 & -0.006 & -0.009 \\
\hline & $(-0.626)$ & $(-0.645)$ & $(-0.833)$ \\
\hline \multirow[t]{2}{*}{ Age } & $-0.214^{\star \star}$ & $-0.213^{\star \star}$ & $-0.183^{\star \star}$ \\
\hline & $(-2.504)$ & $(-2.491)$ & $(-2.114)$ \\
\hline \multirow[t]{2}{*}{ Big4 } & -0.243 & $-0.258^{*}$ & -0.222 \\
\hline & $(-1.595)$ & $(-1.680)$ & $(-1.411)$ \\
\hline \multirow[t]{2}{*}{ Capitalis Lag } & $2.666^{\star \star \star}$ & $2.657^{\star \star \star}$ & $2.638^{\star \star \star}$ \\
\hline & (22.163) & (22.012) & (21.662) \\
\hline \multirow[t]{2}{*}{ Enforcement } & -0.010 & -0.012 & 0.248 \\
\hline & $(-0.277)$ & $(-0.334)$ & (0.029) \\
\hline \multirow[t]{2}{*}{ Corruption } & 0.009 & 0.009 & -0.063 \\
\hline & (0.494) & $(0.520)$ & $(-0.029)$ \\
\hline \multirow[t]{2}{*}{ InvProtect } & -0.577 & -0.642 & -9.051 \\
\hline & $(-0.934)$ & $(-1.025)$ & $(-0.041)$ \\
\hline \multirow[t]{2}{*}{ CivicLaw } & -0.261 & -0.339 & -4.802 \\
\hline & $(-0.469)$ & $(-0.600)$ & $(-0.031)$ \\
\hline \multirow[t]{2}{*}{ MiningVsOil } & & -0.127 & -0.176 \\
\hline & & $(-0.842)$ & $(-1.149)$ \\
\hline \multirow[t]{2}{*}{ Australia } & & & -2.807 \\
\hline & & & $(-0.021)$ \\
\hline \multirow[t]{2}{*}{ Canada } & & & -4.528 \\
\hline & & & $(-0.026)$ \\
\hline \multirow[t]{2}{*}{ UK } & & & -2.138 \\
\hline & & & $(-0.020)$ \\
\hline \multirow[t]{2}{*}{ Constant } & -1.260 & -1.030 & 1.572 \\
\hline & $(-1.166)$ & $(-0.919)$ & $(0.028)$ \\
\hline Observations & 1,002 & 1,002 & 1,002 \\
\hline Pseudo-R2 & 0.565 & 0.565 & 0.573 \\
\hline
\end{tabular}

z-statistics in parentheses

*** $p<0.01,{ }^{* *} p<0.05,{ }^{*} p<0.1$

Note: The table presents the results of a Probit regression, with

Capitalisation dummy as the dependent variable. Capitalis takes a value of one (1) when there is an internal capitalisation over the year, and zero (0) otherwise. All variables are defined in Appendix B. 
Hence, there is no clear indication that specifically smaller firms more frequently capitalised proportionally their internally generated E\&E in 2018 specifically. Nonetheless, we note from the underlying data that the median age for the firms in the first two groups is 13 years while it is 17 years for the producers. Further, we find that the coefficient of the indicator variable that a firm also capitalised internally generated E\&E assets the year before (Capitalis Lag) is highly positive and statistically significant in all models (around 2.7 and statistically significant at the $1 \%$ level). This documents that a past capitalisation also leads to very high likelihood of capitalisation also in the following year. Finally, it is noted that neither country-related nor industry- related factors appear to influence the decision to capitalise internally generated E\&E assets. This is not surprising when we consider that $66 \%$ of the sample firms capitalise internally generated E\&E assets in the year, by following any of the four different methods.

Table 5.10 also reports results of a multivariate analysis based on Equation 4.1, but this analysis focuses on the factors explaining the magnitude of the E\&E assets capitalised in the year. Hence, an OLS regression is performed with the dependent variable being the amount of internally generated E\&E that was capitalised in the year, scaled by total assets. We report four models. In Models (1) - (3) we use a) the various control variables, excluding the industry dummy MiningVsOil and country dummies, b) the various control variables, excluding the country dummies and c) a full model including all variables. Model (4) includes all independent variables of Equation 4.1 but the dependent variable is the E\&E intensity. This additional test complements the main tests in that it allows us to explore whether the overall intensity in $E \& E$ is influenced by different factors of the amount of E\&E capitalised internally.

Firm size is again statistically significant, however, with a negative coefficient (around -0.10 and statistically significant at the $1 \%$ level). This suggests that the larger the company, the lower the relative amount capitalised, when the likelihood to capitalise is higher (according to Table 5.9). In other words, a large company will capitalise more frequently, but the amounts capitalised are small relative to its total assets. This is consistent with our earlier descriptive findings in Table 5.2, where revenues (and total assets in Appendix C) indicate a monotonic negative relation to the amounts capitalised. This is further supported with the life cycle interpretation discussed earlier. We find a consistently negative coefficient for profitability (a coefficient around -0.001 and statistically significant at the $1 \%$ level). This suggests that the lower the profitability of the firm is, the higher the amount of
E\&E capitalised. This is in line with the descriptive analysis discussed in relation to the findings presented in Table 5.2 and the underlying characteristics of junior explorers discussed in footnote 18. Finally, the coefficient of the amount of internally generated E\&E capitalised the year before is positive and statistically significant at the $1 \%$ level (coefficient around 0.4). Effectively, the amount a company capitalises in one year can be positively correlated with the amount that it will capitalise a year ahead. Reflecting also on the findings reported in Table 5.9 , past practice appears to be a good indicator for future practice in this context.

\subsubsection{Determinants of accounting policy choice}

We now turn to the results of the multivariate analysis relating to our second research aim, to identify the factors associated with the adoption of a certain accounting policy (Equation 4.2). We apply ordered logit regression, with the dependent variable being a categorical variable, AccPolicyOrder, that takes values from 1 to 4 for the four accounting choices (AccPolicyOrder1 = 'Full Cost', AccPolicyOrder2 = 'Area of Interest', AccPolicyOrder3 = 'Successful Efforts' and AccPolicyOrder4 = 'Expense All'). The results of this analysis are presented in Table 5.11. Model (1) includes all control variables except the country dummies, while Model (2) also includes the country dummy variables.

In many respects, the results reported from these tests confirm the evidence based on the descriptive analysis, provided earlier, and in untabulated results (see section 5.1). For example, when focusing on the results relating to Model 1, the following can be observed. The larger the company (ie the greater its total assets), the higher the probability that it will adopt a more conservative method (FirmSize reports a positive and statistically significant coefficient (0.148) at the $1 \%$ level). Further, the lower the revenues of the firm (ie, the lower the revenue tercile that it is in), the higher the probability that it will adopt a less conservative method (ie Full Cost or Area of Interest) (RevenueT reports a negative and statistically significant coefficient (-0.548) at the $1 \%$ level). Moreover, when a company capitalises internally generated E\&E the year before, the higher the probability that it will adopt a less conservative method (ie that it will apply a method that leads to large amounts being capitalised). (Capitalis Lag reports a negative and statistically significant coefficient $(-2.170)$ at the $1 \%$ level).

When focusing on the results relating to Model (2), where three country dummies are included to capture the specific effect of the companies based in Australia, Canada and the UK, we see large negative and statistically significant coefficients for the Australia, and UK country 
TABLE 5.10: Determinants of the amounts capitalised

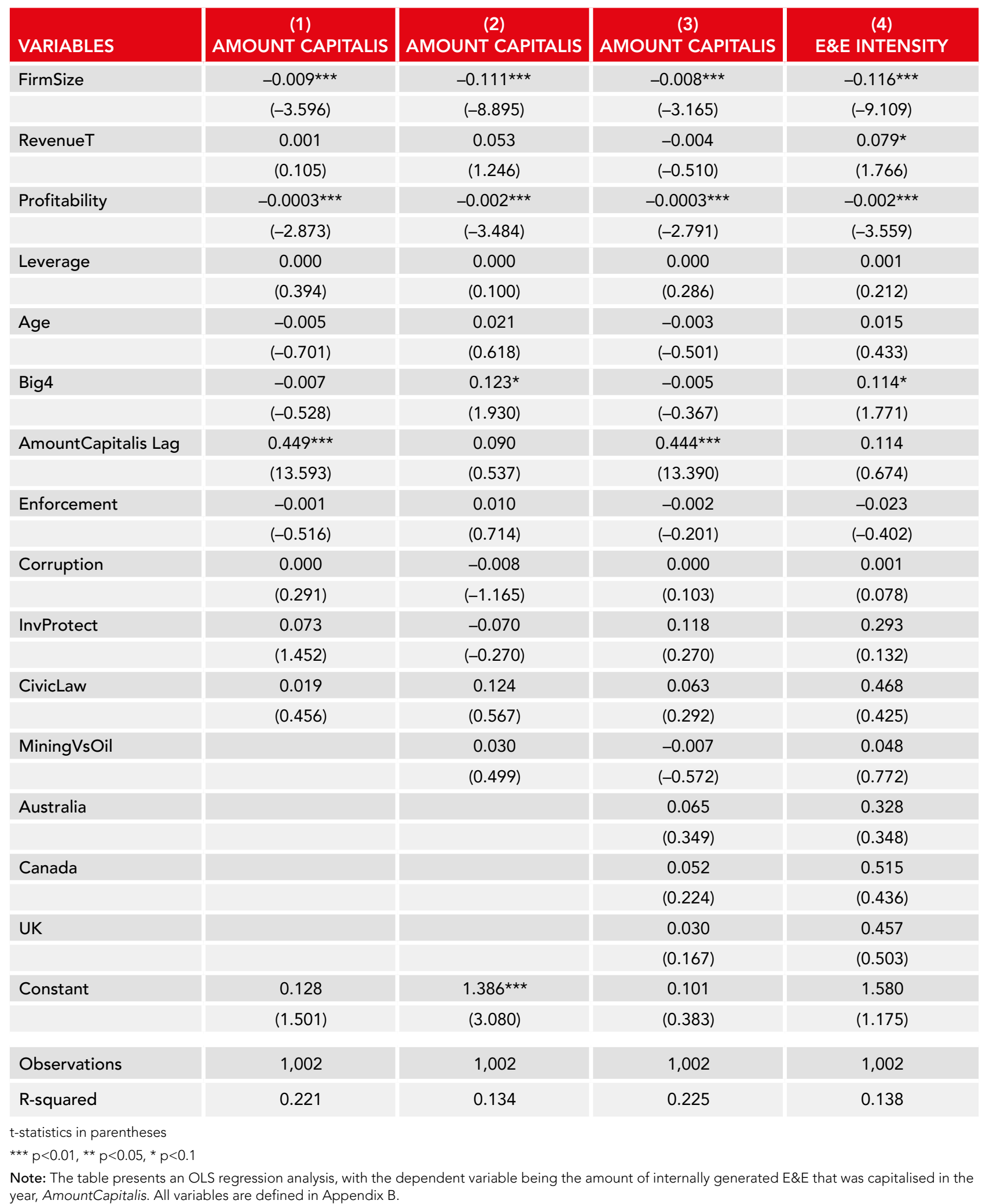


TABLE 5.11: Determinants of policy choice

\begin{tabular}{|c|c|c|}
\hline VARIABLES & $\begin{array}{c}(1) \\
\text { ACCPOLICYORDER }\end{array}$ & $\begin{array}{c}\text { (2) } \\
\text { ACCPOLICYORDER }\end{array}$ \\
\hline \multirow[t]{2}{*}{ FirmSize } & $0.148^{\star \star \star}$ & 0.055 \\
\hline & $(4.476)$ & $(1.541)$ \\
\hline \multirow[t]{2}{*}{ RevenueT } & $-0.548^{\star \star \star}$ & -0.033 \\
\hline & $(-4.925)$ & $(-0.267)$ \\
\hline \multirow[t]{2}{*}{ Profitability } & 0.002 & 0.001 \\
\hline & $(1.418)$ & $(0.718)$ \\
\hline \multirow[t]{2}{*}{ Leverage } & -0.009 & -0.005 \\
\hline & $(-1.596)$ & $(-0.753)$ \\
\hline \multirow[t]{2}{*}{ Age } & 0.120 & -0.022 \\
\hline & (1.345) & $(-0.230)$ \\
\hline \multirow[t]{2}{*}{ Big4 } & $0.367^{\star \star}$ & 0.153 \\
\hline & (2.241) & $(0.862)$ \\
\hline \multirow[t]{2}{*}{ Capitalis Lag } & 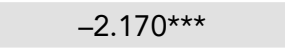 & $-2.094^{\star \star \star}$ \\
\hline & $(-13.830)$ & $(-12.973)$ \\
\hline \multirow[t]{2}{*}{ Enforcement } & $0.124 * \star \star$ & 0.191 \\
\hline & (3.464) & (1.339) \\
\hline \multirow[t]{2}{*}{ Corruption } & $-0.049 * \star \star *$ & -0.036 \\
\hline & $(-2.921)$ & $(-0.967)$ \\
\hline \multirow[t]{2}{*}{ InvProtect } & $-3.981^{\star \star \star}$ & 5.073 \\
\hline & $(-5.890)$ & (0.778) \\
\hline \multirow[t]{2}{*}{ CivicLaw } & -0.608 & -1.763 \\
\hline & $(-1.128)$ & $(-0.645)$ \\
\hline \multirow[t]{2}{*}{ MiningVsOil } & -0.101 & 0.350 ** \\
\hline & $(-0.648)$ & (2.061) \\
\hline \multirow[t]{2}{*}{ Australia } & & $-7.873^{\star \star \star}$ \\
\hline & & $(-3.139)$ \\
\hline \multirow[t]{2}{*}{ Canada } & & -4.444 \\
\hline & & $(-1.502)$ \\
\hline \multirow[t]{2}{*}{ UK } & & $-6.647^{\star \star}$ \\
\hline & & $(-2.404)$ \\
\hline
\end{tabular}

\begin{tabular}{|l|l|l|}
\hline Observations & 1,002 & 1,002 \\
\hline Pseudo-R2 & 0.144 & 0.269 \\
\hline
\end{tabular}

$z$ statistics in parentheses.

${ }^{* * *} p<0.01,{ }^{* *} p<0.05,{ }^{*} p<0.1$

Note: The table presents ordered logit regressions, with categorical variable AccPolicyOrder as the dependent variable. AccPolicyOrder takes values from 1 to 4 for the four accounting choices. AccPolicyOrder1 = 'Full Cost', AccPolicyOrder2 = 'Area of Interest', AccPolicyOrder3 = 'Successful Efforts' and AccPolicyOrder4 = 'Expense All'. All variables are defined in Appendix B. dummies $(-7.873$ and -6.647 , significant at the $1 \%$ and $5 \%$ level, respectively). These negative coefficients suggest that Australian firms are more likely to adopt the Area of Interest method and firms in the UK are more likely to adopt the Successful Efforts method (the coefficient is larger for Australia than that for the UK). This finding confirms the evidence based on the descriptive analysis, provided earlier (section 5.1). In fact, because of the significant weight of these two country variables in this model, the only other two variables that report significant coefficients are Capitalis Lag and MiningVsOil. The former reports a negative and statistically significant coefficient, as in Model (1). MiningVsOil reports a positive and statistically significant coefficient $(0.350$, at the $5 \%$ level). This suggests that mining firms are associated with a higher probability of adopting the Expense All method than are firms in oil and gas. This finding is consistent with the descriptive analysis presented in Table 5.1, Panel C. This shows that, from the 215 firms in the sample that follow the Expense All method, 204 are mining firms. Thus, although the majority of mining firms (75.4\%) adopt one of the other three, more aggressive, methods, there is still a higher probability that mining firms will adopt the Expense All method.

\subsubsection{Determinants of impairment recognition and amounts impaired}

In this section, we present the results of the multivariate analysis relating to the third research aim, to identify which factors are associated with the recognition of an impairment of E\&E assets and the corresponding impairment amounts recognised (Equation 4.3). Table 5.12 reports the findings on the factors associated with the recognition of an impairment of E\&E assets. Model (1) includes all control variables, except for the three country dummies relating to Australia, Canada and the UK. The latter are added in Model (2). Model (3) builds on Model (2) but includes only those firms that report an impairment of E\&E expenditure below the value of the previous year's non-current assets (ie it is restricted to less extreme cases of impairment recognised).

The results in Table 5.12 reveal that firm size is negatively associated with the incidence of impairment across all three models (coefficients: $-0.073,-0.071$ and -0.051 , significant at the $1 \%, 1 \%$ and $5 \%$ levels, respectively). Thus, larger firms are less likely to recognise an impairment of E\&E assets. ${ }^{25}$ Further, the larger the amount of E\&E assets capitalised in the previous year, the higher the probability that the firm will recognise an impairment in the current year (coefficients Total Capitalis Lag: 1.057, 1.069 and 
TABLE 5.12: Determinants of impairment recognition

\begin{tabular}{|c|c|c|c|}
\hline VARIABLES & (1) IMPAIR & (2) IMPAIR & (3) IMPAIR<1 \\
\hline \multirow[t]{2}{*}{ FirmSize } & $-0.073^{\star \star \star}$ & $-0.071 * \star \star$ & $-0.051^{\star \star}$ \\
\hline & $(-3.283)$ & $(-3.150)$ & $(-2.187)$ \\
\hline \multirow[t]{2}{*}{ RevenueT } & -0.110 & -0.114 & -0.084 \\
\hline & $(-0.982)$ & $(-0.961)$ & $(-0.701)$ \\
\hline \multirow[t]{2}{*}{ Profitability } & -0.000 & -0.000 & -0.000 \\
\hline & $(-0.052)$ & $(-0.068)$ & $(-0.075)$ \\
\hline \multirow[t]{2}{*}{ Leverage } & 0.003 & 0.003 & 0.003 \\
\hline & $(0.602)$ & $(0.619)$ & $(0.547)$ \\
\hline \multirow[t]{2}{*}{ Age } & 0.014 & 0.004 & 0.023 \\
\hline & $(0.219)$ & $(0.066)$ & $(0.350)$ \\
\hline \multirow[t]{2}{*}{ Big4 } & 0.092 & 0.061 & 0.058 \\
\hline & (0.798) & $(0.522)$ & $(0.488)$ \\
\hline \multirow[t]{2}{*}{ Total Capitalis Lag } & $1.057^{\star \star \star}$ & $1.069^{\star \star \star}$ & $1.075^{\star \star \star}$ \\
\hline & (7.698) & (7.703) & (7.457) \\
\hline \multirow[t]{2}{*}{ Enforcement } & $-0.047^{\star}$ & -0.359 & -0.359 \\
\hline & $(-1.834)$ & $(-0.049)$ & $(-0.049)$ \\
\hline \multirow[t]{2}{*}{ Corruption } & 0.019 & 0.099 & 0.098 \\
\hline & (1.447) & $(0.053)$ & $(0.053)$ \\
\hline \multirow[t]{2}{*}{ InvProtect } & $1.051^{\star \star}$ & 15.223 & 15.195 \\
\hline & (2.220) & $(0.080)$ & $(0.080)$ \\
\hline \multirow[t]{2}{*}{ CivicLaw } & 0.242 & 7.409 & 7.333 \\
\hline & $(0.613)$ & $(0.057)$ & $(0.056)$ \\
\hline \multirow[t]{2}{*}{ MiningVsOil } & $-0.294^{\star \star}$ & $-0.309 * \star \star$ & $-0.314^{\star \star \star}$ \\
\hline & $(-2.546)$ & $(-2.649)$ & $(-2.670)$ \\
\hline \multirow[t]{2}{*}{ Australia } & & 4.453 & 4.548 \\
\hline & & (0.039) & $(0.041)$ \\
\hline \multirow[t]{2}{*}{ Canada } & & 6.587 & 6.656 \\
\hline & & $(0.045)$ & $(0.046)$ \\
\hline \multirow[t]{2}{*}{ UK } & & 2.284 & 2.351 \\
\hline & & $(0.025)$ & $(0.026)$ \\
\hline \multirow[t]{2}{*}{ DExpenseAll } & 0.430 & 0.396 & 0.364 \\
\hline & (1.240) & (1.133) & (1.031) \\
\hline \multirow[t]{2}{*}{ SuccessEffort } & $0.528^{*}$ & $0.527^{\star}$ & 0.489 \\
\hline & (1.663) & (1.660) & (1.538) \\
\hline \multirow[t]{2}{*}{ Arealnterest } & $0.851^{\star \star \star}$ & $0.855^{\star \star}$ & $0.808^{\star \star}$ \\
\hline & (2.666) & (2.514) & $(2.367)$ \\
\hline \multirow[t]{2}{*}{ Constant } & -0.916 & -7.290 & -7.524 \\
\hline & $(-1.026)$ & $(-0.150)$ & $(-0.155)$ \\
\hline Observations & 944 & 944 & 920 \\
\hline Pseudo-R2 & 0.123 & 0.127 & 0.124 \\
\hline $\begin{array}{l}\text {-statistics in parenthese } \\
{ }^{* \star} p<0.01,{ }^{\star \star} p<0.05 \text {, }{ }^{*}\end{array}$ & & & \\
\hline
\end{tabular}


1.075, significant at the $1 \%$ level). This is what we would intuitively expect because, by definition, recognising an internally generated intangible asset entails the risk of impairment, given the uncertainty around the generation of future benefits. Additionally, firms in the mining industry are less likely to recognise an impairment of E\&E assets than firms in the oil and gas industry (coefficients: -0.294 , -0.309 and -0.314 , significant at the $5 \%, 1 \%$ and $1 \%$ level, respectively). This finding is consistent with the underlying data in Table 5.8 and is primarily driven by the fact that a large proportion of firms in the mining industry (25\%) follow the most conservative method (Expense All, see Table 5.1, Panel C), which reduces the probability that E\&E assets will be impaired. Finally, our results show weak (strong) evidence that firms using the Successful Efforts (Area of Interest) method are more likely to recognise an impairment of E\&E assets (coefficients for SuccessEffort: $0.528,0.527$ and 0.489 , only the first two being significant at the $10 \%$ level; coefficients for Arealnterest: 0.851 , 0.855 and 0.808 , significant at the $1 \%, 5 \%$ and $5 \%$ level, respectively). This finding is supports intuitive expectations and reflects the earlier discussion about the descriptive analysis. Area of Interest is associated with more aggressive reporting (see section 4.2) and leads to higher net-book values of E\&E assets on the balance sheet (see Table 5.3), which, subsequently, results in higher probability of recognising an impairment of such assets. Similarly, given that Successful Efforts is a more aggressive method than Expense All, it is no surprise to identify some weak evidence that firms following this method have a higher probability of recognising an impairment of E\&E assets. In Table 5.7, we also show that a significantly larger proportion of firms recognise an impairment under the Area of Interest method $(164 / 325=50 \%)$ than of firms following the Successful Efforts method (152/422=36\%).
The results of the analysis examining the factors affecting the amount of E\&E impairment recognised are presented in Table 5.13. Similarly to Table 5.12, Model (1) includes all control variables, except for the three country dummies relating to Australia, Canada and the UK. The latter are added in Model (2). Model (3) repeats the analysis presented in Model (2) but replaces the ratio of E\&E impairment to prior year non-current assets with one (1), when the ratio is above one (1). Model (4) includes only those firms that report an impairment of E\&E expenditure below the value of the previous year's non-current assets (ie it is restricted to less extreme cases of impairment recognised). Finally, Model (5) repeats the analysis presented in Model (2) by excluding those firms not recognising an impairment (ie cases where impairment is zero are excluded).

The results show that firm size is negatively associated with the magnitude of E\&E assets impaired (coefficients: -0.042 , $-0.043,-0.028,-0.019$ and -0.106 , statistically significant at the $1 \%$ level, respectively). This result suggests that, relative to previous year's non-current assets, large firms impair smaller amounts of E\&E assets than do small firms. This agrees with what we would intuitively expect since we have identified that, relative to their assets, large firms capitalise lower amounts of E\&E internally generated assets than do small firms (see Table 5.10). Further, we find that the larger the amount of capitalised E\&E in the previous year, the greater is the magnitude of impairment of such assets in the current year (coefficients: 0.281, 0.284, 0.169, 0.084, statistically significant at the $1 \%$ level, respectively). ${ }^{26}$ This agrees with intuitive expectations because, by definition as discussed above, recognising an internally generated intangible asset entails the risk of impairment. Finally, we find that the Arealnterest reports a positive but statistically insignificant coefficient in four out of the five models. ${ }^{27}$ This finding is consistent with the descriptive analysis in Table 5.7, which shows that impairments in relation to E\&E assets are of similar magnitude among firms using this method and the Successful Efforts method. 
TABLE 5.13: Determinants of impairment amount

\begin{tabular}{|c|c|c|c|c|c|}
\hline VARIABLES & $\begin{array}{l}\text { (1) IMPAIR } \\
\text { AMOUNT }\end{array}$ & $\begin{array}{l}\text { (2) IMPAIR } \\
\text { AMOUNT }\end{array}$ & $\begin{array}{c}\text { (3) IMPAIR } \\
\text { AMOUNT_MAX }\end{array}$ & $\begin{array}{c}\text { (4) IMPAIR } \\
\text { AMOUNT<1 }\end{array}$ & $\begin{array}{c}(5) \text { IMPAIR } \\
\text { AMOUNT>0 }\end{array}$ \\
\hline \multirow[t]{2}{*}{ FirmSize } & $-0.042^{\star \star \star}$ & $-0.043^{\star \star \star}$ & $-0.028^{\star \star \star}$ & $-0.019 * \star \star$ & $-0.106^{\star \star \star}$ \\
\hline & $(-5.896)$ & $(-5.934)$ & $(-8.060)$ & $(-6.622)$ & $(-5.771)$ \\
\hline \multirow[t]{2}{*}{ RevenueT } & -0.043 & -0.055 & -0.020 & 0.002 & -0.080 \\
\hline & $(-1.155)$ & $(-1.405)$ & $(-1.067)$ & $(0.126)$ & $(-0.782)$ \\
\hline \multirow[t]{2}{*}{ Profitability } & 0.000 & 0.000 & -0.000 & -0.000 & 0.000 \\
\hline & $(0.126)$ & $(0.094)$ & $(-0.446)$ & $(-0.509)$ & $(0.417)$ \\
\hline \multirow{2}{*}{ Leverage } & 0.001 & 0.001 & 0.001 & 0.000 & 0.005 \\
\hline & $(0.526)$ & $(0.548)$ & $(0.772)$ & $(0.573)$ & $(0.700)$ \\
\hline \multirow[t]{2}{*}{ Age } & -0.025 & -0.026 & $-0.020^{\star \star}$ & -0.011 & -0.059 \\
\hline & $(-1.164)$ & $(-1.212)$ & $(-1.978)$ & $(-1.353)$ & $(-1.142)$ \\
\hline \multirow[t]{2}{*}{ Big4 } & 0.029 & 0.027 & 0.018 & 0.012 & 0.030 \\
\hline & $(0.772)$ & (0.708) & (0.998) & (0.795) & $(0.308)$ \\
\hline \multirow[t]{2}{*}{ AmountTotalCapitalis Lag } & $0.281^{\star \star \star}$ & $0.284^{\star \star \star}$ & $0.169^{\star \star \star}$ & $0.084^{\star \star \star}$ & 0.204 \\
\hline & (3.729) & $(3.756)$ & $(4.636)$ & $(2.711)$ & (1.299) \\
\hline \multirow[t]{2}{*}{ Enforcement } & -0.005 & -0.005 & -0.006 & -0.007 & -0.017 \\
\hline & $(-0.604)$ & $(-0.143)$ & $(-0.361)$ & $(-0.516)$ & $(-0.307)$ \\
\hline \multirow[t]{2}{*}{ Corruption } & 0.002 & 0.002 & 0.001 & 0.001 & 0.004 \\
\hline & $(0.380)$ & $(0.207)$ & $(0.351)$ & $(0.302)$ & $(0.268)$ \\
\hline \multirow[t]{2}{*}{ InvProtect } & 0.150 & 0.182 & 0.243 & 0.307 & -0.658 \\
\hline & $(0.948)$ & (0.139) & $(0.386)$ & $(0.609)$ & $(-0.191)$ \\
\hline \multirow[t]{2}{*}{ CivicLaw } & 0.182 & 0.165 & 0.141 & 0.134 & 0.142 \\
\hline & (1.414) & $(0.256)$ & $(0.453)$ & $(0.537)$ & $(0.107)$ \\
\hline \multirow[t]{2}{*}{ MiningVsOil } & -0.028 & -0.027 & $-0.040^{\star \star}$ & $-0.038^{\star \star}$ & -0.048 \\
\hline & $(-0.734)$ & $(-0.685)$ & $(-2.119)$ & $(-2.520)$ & $(-0.511)$ \\
\hline \multirow[t]{2}{*}{ Australia } & & -0.083 & -0.009 & 0.069 & 0.055 \\
\hline & & $(-0.149)$ & $(-0.034)$ & $(0.322)$ & $(0.057)$ \\
\hline \multirow[t]{2}{*}{ Canada } & & -0.034 & 0.050 & 0.123 & -0.002 \\
\hline & & $(-0.049)$ & (0.150) & $(0.460)$ & $(-0.002)$ \\
\hline \multirow[t]{2}{*}{ UK } & & -0.038 & 0.002 & 0.038 & 0.320 \\
\hline & & $(-0.071)$ & $(0.007)$ & (0.184) & $(0.278)$ \\
\hline \multirow[t]{2}{*}{ DExpenseAll } & 0.041 & 0.051 & 0.030 & 0.012 & 0.257 \\
\hline & $(0.400)$ & (0.501) & $(0.612)$ & $(0.295)$ & $(0.749)$ \\
\hline \multirow[t]{2}{*}{ SuccessEffort } & 0.072 & 0.078 & 0.053 & 0.037 & 0.201 \\
\hline & $(0.743)$ & $(0.797)$ & $(1.132)$ & $(0.979)$ & $(0.644)$ \\
\hline \multirow[t]{2}{*}{ Arealnterest } & 0.100 & 0.137 & $0.093^{*}$ & 0.061 & 0.226 \\
\hline & $(1.023)$ & $(1.300)$ & $(1.830)$ & (1.497) & $(0.692)$ \\
\hline \multirow[t]{2}{*}{ Constant } & $0.534^{\star}$ & 0.530 & 0.341 & 0.202 & 2.225 \\
\hline & $(1.845)$ & (0.659) & $(0.881)$ & $(0.652)$ & $(0.842)$ \\
\hline Observations & 944 & 944 & 944 & 920 & 346 \\
\hline R-squared & 0.087 & 0.088 & 0.154 & 0.112 & 0.167 \\
\hline
\end{tabular}



SMALLER AMOUNTS OF E\&E ASSETS

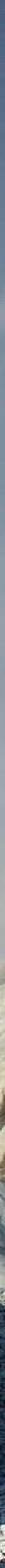
a 1.7. W. t.t. 


\section{Conclusion}

\subsection{Conclusions and recommendations}

In this research, we have focused on the accounting treatment of E\&E expenditure by companies in the El, with particular attention to the related amounts that companies capitalise, impair and expense. This research is motivated by three significant factors. First, the IASB is collecting information to help it make a decision on whether to start a project to replace or amend IFRS 6. Second, while there is scant literature on El firms, what there is concentrates on the accounting policies used for the treatment of these expenditures. Research on the amounts involved, and hence recognised, expensed and impaired, is absent. Furthermore, there is an absence of evidence on the characteristics of firms that capitalise and impair such expenditure. Third, there has been increasing concern and debate about whether intangible assets more broadly are reflected in companies' financial statements, given the current accounting standards and that the gap between book and market values is widening over time owing to the increasing importance of intangibles.

The accounting for E\&E costs can be viewed as an extension of the debate on the recognition of intangible assets versus the level of accounting conservatism. Hence, the overall objective of this research is to shed light on the accounting treatment of E\&E expenditure along with the related amounts that companies capitalise, impair and expense and, in consequence, complement the IASB (2020b) staff paper by providing a more holistic view of the significance of the amounts involved and the complexities facing users of the financial statements.

This project has involved archival and manual data collection as well as univariate and multivariate analyses. The analysis focuses on the reporting practices of 1,096 firms from eight world-leading countries, with a significant presence of firms in the El sector for the financial year 2018. These firms are analysed in aggregate but also disaggregated across 12 sub-sectors, oil and gas, and mining industry groups as well as junior explorers, producers and developers. This analysis reflects three main research aims of the project:

1. to understand the factors that are associated with the decision to capitalise E\&E expenditure and the corresponding amounts capitalised

2. to identify the factors that are associated with the accounting policy chosen by firms, and

3. to investigate factors that are associated with an impairment of E\&E capitalised expenditure and the corresponding amounts of impairment recognised.

In a nutshell, we find a general tendency of companies to capitalise and recognise significant amounts of internally generated E\&E expenditure. We also find that impairments are significant and commonly occur, with the mean value of E\&E costs impairment accounting for a large proportion of the previous year's non-current assets. This suggests that the basic capitalisation and impairment model seems to be working in the El. This is contrasted to the relative lack of capitalisation of development costs of new products and processes under IAS 38. Nonetheless, very different methods are applied and related disclosures are either absent or unclear in many instances. This results in lack of comparability between firms. There is a clear country effect in that Australian firms are restricted to using the Area of Interest method. Outside Australia, Successful Efforts is the most frequently used method, followed by what we label as Expense All (similar to the recognition model in IAS 38), with very few companies using the Full Cost method.

Given the large presence of mining firms in Australia, there is great heterogeneity among methods followed within this industry, compared with oil and gas firms, which mostly follow the Successful Efforts method. Finally, consistent with the classification of the Area of Interest method as a less conservative approach, we find that firms that follow this method report higher values of total E\&E capitalised and internally generated E\&E asset capitalised than firms following the Successful Efforts method. 
Nevertheless, given the variation on how companies define and employ the unit of account under both methods, the impairment in relation to E\&E assets are of similar magnitude among firms using these two methods.

The findings of this research give rise to policy implications and recommendations that can be outlined across the following three themes:

a. Revision/amendment of IFRS 6 into a single standard for El firms. Such a standard should not lead to the prevalence of expensing and a lack of capitalisation of E\&E expenditure as is the case under the current IAS 38 for other internally generated intangible assets.

b. This standard should give clear definitions of the permitted accounting policies and should include a list of disclosure requirements that would allow users of the financial statements to understand the way companies implement these definitions in practice and how they conduct the impairment testing of the E\&E assets capitalised.

c. It appears that there would be very little appetite for including the Full Cost method as one of the methods permitted in such a revised standard. This is the least applied in our sample (less than 3\%). Further, the inclusion of the method we label as Expense All would be encouraged only on the basis of maintaining internal consistency between IFRS 6 and the current requirements in IAS 38.

IN A NUTSHELL, WE FIND A GENERAL TENDENCY OF COMPANIES TO CAPITALISE AND RECOGNISE SIGNIFICANT AMOUNTS OF INTERNALLY GENERATED E\&E EXPENDITURE.

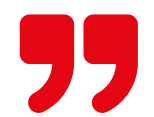

\subsection{Limitations and directions for future research}

The results reported above are subject to a number of common limitations and caveats. First, as we have acknowledged, it was inevitable that we needed to exercise judgement when categorising firms across the four methods of accounting treatment of E\&E expenditure. Most companies either do not name the accounting policy they choose or the label they use is not in line with the criteria we have followed (see section 4.2). Second, we rely on econometric techniques to identify the factors associated with the decision to capitalise internally generated E\&E assets, the magnitude of the corresponding amounts, the likelihood of recognising an impairment of E\&E assets and the magnitude of the corresponding amounts. There is a lack of previous research in the area. Thus, for the tests relating to the factors associated with the decision to capitalise internally generated E\&E assets and the magnitude of the corresponding amounts, we informed the selection of the potential factors from the corresponding literature that examines R\&D active firms. For the tests relating to the likelihood of recognising an impairment of E\&E assets and the magnitude of the corresponding amounts, we were informed in our selection of the potential factors by the corresponding literature that focuses on goodwill impairments. While we have also considered the characteristics of the firms in the El, we recognise we may not have included all pertinent factors.

Future research could examine the convergence in policy choices building on earlier literature, which either examines this question in the early year of IFRS adoption (Abdo 2016; Power et al. 2017) or more recent years (Stadler and Nobes 2020; IASB 2020b). Little is known about the period in between and, more importantly, whether the amounts of E\&E capitalised and expensed were affected by any change during such a convergence/divergence in practices. Finally, we would encourage qualitative research that examines the relevance and usefulness of accounting policies currently applied by El firms. This could reflect the views of a number of stakeholder groups, such as preparers, auditors and analysts. 
19.

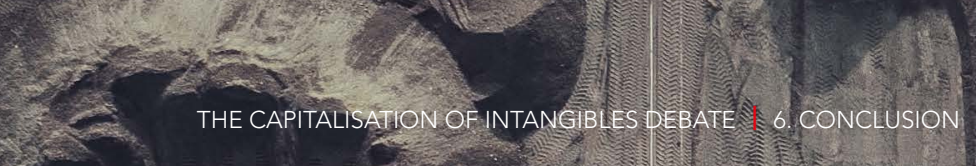

$$
\text { (3) }
$$
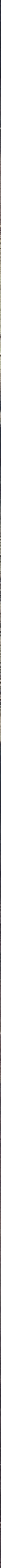


\section{About the authors}

\section{Dr Anna Fani Constantatos, Deree-The American College of Greece}

Anna is a lecturer in accounting at Deree -The American College of Greece. Anna holds a BSc in Accounting and Finance from the same institution, an MBA in Finance and Investments from the City University of New York (Baruch College) and a PhD in Accounting and Finance from the University of Stirling. Anna has been teaching various courses in the area of accounting and finance including Financial Accounting, Intermediate Financial Accounting, Managerial Accounting, Foundations of Corporate Finance, and Corporate Governance and Accountability. Her research interests include international accounting, corporate governance and earnings management. She has participated in a number of conferences.

\section{Dr Dionysia Dionysiou, University of Stirling} Dionysia is a senior lecturer in Accounting and Finance at the University of Stirling. Before that, Dionysia was a researcher within the INTACCT network, where she was working on the implications of the mandatory implementation of IFRS in European countries. Dionysia's main areas of research interest are in corporate finance and corporate distress, as well as financial reporting and market-based accounting. She has published in internationally acclaimed journals in these areas and, for her practice-relevant research, she has received research grants from the Institute of Chartered Accountants of Scotland (ICAS) and ACCA.
Dr Richard Slack, Durham University

Richard is a professor in accounting at Durham University Business School. Richard joined Durham University in 2012, having previously been professor in accounting at Newcastle Business School, Northumbria University. Before his academic career, Richard, a graduate of St Andrews University, worked at Price Waterhouse and is a qualified chartered accountant. Richard's research encompasses areas of accounting information, and its use by, and usefulness to, capital market users. Further, Richard is interested in the way information is presented by companies and whether narrative disclosure is decision-useful to stakeholder groups.

\section{Dr Ioannis Tsalavoutas, University of Glasgow} loannis is a professor of accounting at the University of Glasgow. His main area of expertise is financial accounting and reporting, in particular, investigating companies' reporting practices under IFRS across different jurisdictions, along with any economic consequences that may arise from divergence in practice. loannis' work experience includes positions as an accounting assistant (in Greece) and as a financial accounting and reporting analyst at Company Reporting Ltd in Edinburgh. Before joining the University of Glasgow in January 2015, loannis was a lecturer in accounting at the University of Stirling.

\section{Dr Fanis Tsoligkas, University of Bath}

Fanis is a lecturer in accounting at the University of Bath. His main research interests lie in the fields of financial reporting discretion and the adoption of International Financial Reporting Standards. They also include the capital market effects of accounting information and the effect of trading behaviour of corporate executives and directors. Before joining academia, Fanis practised accountancy in Greece. 


\section{References}

Abdo, H. (2016), 'Accounting for Extractive Industries: Has IFRS 6 Harmonised Accounting Practices by Extractive Industries?', Australian Accounting Review, 26(4): 346-59.

AASB A(ustralian Accounting Standards Board) (1989b:), AAS 7: Accounting for the Extractive Industries. Downloadable from <https://www.aasb.gov.au/admin/file/content102/c3/AAS07_1189.pdf>, accessed 3 December 2020.

AASB (Australian Accounting Standards Board) (1989a), AASB 1022: Accounting for the extractive industries, Melbourne, Australia: Australian Accounting Standard Board.

AASB (Australian Accounting Standards Board) (2004), AASB 6: Exploration for and evaluation of mineral resources, Melbourne, Australia: Australian Accounting Standard Board.

BDO (Binder Dijker Otte) (2013), IFRS in Practice: An Overview of IFRS 6 Exploration for and Evaluation of Mineral Resources, $\mathrm{BDO}$, London.

Bernanke, B.S. (2011), 'Promoting Research and Development: The Government's Role'. Speech given at the conference on 'New Building Blocks for Jobs and Economic Growth', Washington, D.C., 16 May. Downloadable from: <https://www.federalreserve. gov/newsevents/speech/bernanke20110516a.htm>, accessed 7 November 2018.

Berry, K. T. and Wright, J. W. (2001), 'The Value Relevance of Oil and Gas Disclosures: An Assessment of the Market's Perception of Firms' Effort and Ability to Discover Reserves', Journal of Business Finance \& Accounting, 28 (5\&6): 741-69.

Brown, P., Preiato, J., and Tarca, A. (2014). 'Measuring Country Differences in Enforcement of Accounting Standards: An Audit and Enforcement Proxy', Journal of Business Finance \& Accounting, 41(1-2): 1-52.

Bryant, L. (2003), 'Relative Value Relevance of the Successful Efforts and Full Cost Accounting Methods in the Oil and Gas Industry', Review of Accounting Studies, 8: 5-28.

Cazavan-Jeny, A., Jeanjean, T. and Joos, P. (2011), 'Accounting Choice and Future Performance: The Case of R\&D Accounting in France', Journal of Accounting and Public Policy, 30 (2): 145-65.

Chen, X., Wright, S, and Wu, H. (2018), 'Exploration Intensity, Analysts' Private Information Development and their Forecast Performance', Accounting and Business Research, 48 (1): 77-107.

Cortese, C., Irvine, H. and Kaidonis, M. (2009), 'Extractive Industries Accounting and Economic Consequences: Past, Present and Future', Accounting Forum, 33 (1): 27-37.

Cortese, C., Irvine, H. and Kaidonis, M. (2010), 'Powerful Players: How Constituents Captured the Setting of IFRS 6, an Accounting Standard for the Extractive Industries', Accounting Forum, 34 (1): 76-88.

Curle, J.H. (1905), The Gold Mines of the World, 3rd edn. Routledge and Sons, London.

Deloitte Touche Tohmatsu (2001), IASC's Extractive Industries Issues Paper Summary and Analysis for the Mining Industry. Downloadable from: <https://www.iasplus.com/en/news/2001/ March/news191>, accessed 4 December 2020.
Dinh, T., Kang, H. and Schultze, W. (2016), Capitalizing research \& Development: Signaling or Earnings Management?, European Accounting Review, 25 (2):1-29.

Djankov, S., La Porta, R., Lopez-De-Silanes, F., and Shleifer, A. (2008), 'The Law and Economics of Self-dealing', Journal of Financial Economics, 88: 430-65.

EFRAG TEG-CFSS (European Financial Reporting Advisory Group Technical Expert Group Consultative Forum of Standard Setters) (2020), Extractive Activities: Issues Paper.

European Financial Reporting Advisory Group (EFRAG), 2018 , 'Feedback Statement - Research Agenda Consultation', Downloadable from: <https://www.efrag.org/News/Project-324/ Feedback-Statement---2018-EFRAG-Research-AgendaConsultation>, accessed 21 November 2018.

FASB (1977), SFAS 19, Financial Accounting and Reporting by Oil and Gas Producing Companies, Financial Accounting Standards Board, Norwalk, CT.

Gray, S., Hellman, N. and Ivanova, M. (2019), 'Extractive Industries Reporting: A Review of Accounting Challenges and the Research Literature', Abacus, 55(1): 42-91.

Haskel, J., and Westlake, S. (2017), Capitalism without Capital: The Rise of the Intangible Economy (Princeton: Princeton University Press).

IASB (2004a), IFRS 6: Exploration for and Evaluation of Mineral Resources, IFRS Foundation, London.

IASB (2004b), IASB Documents Published to Accompany IFRS Standard 6 (Basis for conclusions), IFRS Foundation, London.

IASB (2010), Discussion Paper: Extractive Activities, IASC Foundation, London. <https://www.ifrs.org/projects/2016/ extractive-activities-2010/>, accessed 17/12/2020.

IASB (2016a), Agenda Consultation 2015, IFRS Foundation, London.

IASB (2016b), IASB Workplan, 2017-21; Feedback Statement on the 2015 Agenda Consultation, IFRS Foundation, London.

IASB (2016c), Agenda Consultation; Extractive Activities / Intangible Assets / Research and Development, May 2016, IFRS Foundation, London.

IASB (2019a) Extractive Activities, Feedback Summary, Staff paper, March 2019, IFRS Foundation, London. <https://cdn.ifrs. org/-/media/feature/meetings/2019/march/iasb/ap19-extractiveactivities.pdf>, accessed 17/12/2020.

IASB (2019b), Extractive Activities, Scope and Approach, Staff paper, September 2019, IFRS Foundation, London. <https://www. ifrs.org/-/media/feature/meetings/2019/september/iasb/ap19extractive-activities.pdf>, accessed 17/12/2020.

IASB (2020a), Extractive Activities, Academic literature review, Staff paper, July, IFRS Foundation, London. <https://cdn.ifrs. org/-/media/feature/meetings/2020/july/iasb/ap19b-extractiveactivities.pdf?la=en>, accessed 17/12/2020. 
IASB (2020b), Extractive Activities, Accounting policies developed applying IFRS 6, Staff paper, October 2020, IFRS Foundation, London. <https://cdn.ifrs.org/-/media/feature/ meetings/2020/october/iasb/ap19a-extractive-activities.pdf>, accessed 17/12/2020.

IASC (International Accounting Standards Committee) (2000), Extractive Industries Issues Paper, IASC Steering Committee on Extractive Industries, IASC, Geneva. <https://www.iasplus. com/en/binary/resource/0011extractsummary.pdf $>$, accessed $17 / 12 / 2020$

Karapinar, A., Zaif, F. and Torun, S. (2012), 'Accounting Policies in the Extractive Industry: A Global and a Turkish Perspective', Australian Accounting Review, 60 (1), 40-50.

Katz, L. C. (1985), 'Oil and Gas: A Compromise Method of Accounting', Journal of Accountancy, 159 (6): 116-24.

La Porta, R. L., Lopez-de-Silanes, F., Shleifer, A., \& Vishny, R. W. (1998). Law and finance. Journal of political economy, 106(6), 1113-1155.

Lev, B. (2018), 'The Deteriorating Usefulness of Financial Report Information and How to Reverse It.' Accounting and Business Research, 48 (5): 465-93.

Lev, B. and Gu, F. (2016), The End of Accounting and the Path Forward for Investors and Managers (New Jersey: John Wiley and Sons).

Luther, R. (1996), 'The Development of Accounting Regulation in the Extractive Industries'. The International Journal of Accounting, 31(1): 67-93.

Mazzi, F., Slack, R., Tsalavoutas, I. and Tsoligkas, F. (2019a), The Capitalisation Debate: RandD Expenditure, Disclosure Content and Quantity and Stakeholder Views, ACCA Research report.

Mazzi, F., Slack, R., Tsalavoutas, I. and Tsoligkas, F. (2019b). Country Level Corruption and Accounting Choice: Research \& Development Capitalization under IFRS, The British Accounting Review, 51(5): 1-25.

Misund, B. (2017), 'Accounting Method Choice and Market Valuation in the Extractive Industries', Cogent Economics and Finance, 5: 1-14.
Nobes, C. (2006), The Survival of International Differences under IFRS: Towards a Research Agenda. Accounting and Business Research, 36 (3): 233-45.

Nobes, C. and Stadler, C. (2020), 'Towards a Solution to the International Variety in the Accounting Practices of Extractive Firms Under IFRS', working paper available at SSRN < https:// papers.ssrn.com/sol3/papers.cfm?abstract_id=3624733>, accessed 8 December 2020.

OIAC SORP (2001), Accounting for Oil and Gas Exploration, Development, Production and Decommissioning Activities (London: Oil Industry Accounting Committee).

Power, S. B., Cleary, P. and Donnelly, R. (2017), 'Accounting in the London Stock Exchange's Extractive Industry: The Effect of Policy Diversity on the Value Relevance of Exploration-related Disclosures', British Accounting Review, 49(6): 545-59.

Smith, C. and Venter, E. (2020), 'Financial Statement Comparability in the Extractive Industry', Accounting Research Journal, 33(3): 523-41.

Stadler, C. and Nobes, C. (2020), 'Varied Practice in Accounting for Extractive Activities under IFRS', working paper <https:// papers.ssrn.com/sol3/papers.cfm?abstract_id=3627080>, accessed 8 December 2020

Trueman, J. (1975), 'Oil Company Accounts: Not So Comparable?' Accounting and Business Research, 5 (18): 127-132.

Vent, G. and Milne, R.A. (1989), "The Standardization of Mine Accounting', The Accounting Historians Journal, 16 (1): 57-74.

Wise, T., and Spear, N. (2002), 'Factors and Forces of the Extractive Industry Environment, and their Implications for Accounting Measurement and Financial Reporting', Petroleum Accounting and Financial Management Journal, 21(3): 1-28.

Worldwide Government Indicators (WGI) Project. The World Bank, Washington DC, USA (2010)

Zhou, T., Birt, J. and Rankin, M. (2015), 'Extractive Firms and the Value Relevance of Exploration and Evaluation Expenditures', Accounting Research Journal, 28(3): 228-50. 


\section{Appendix A:}

\section{Brief description of accounting policies for E\&E expenditure as defined in various accounting standards}

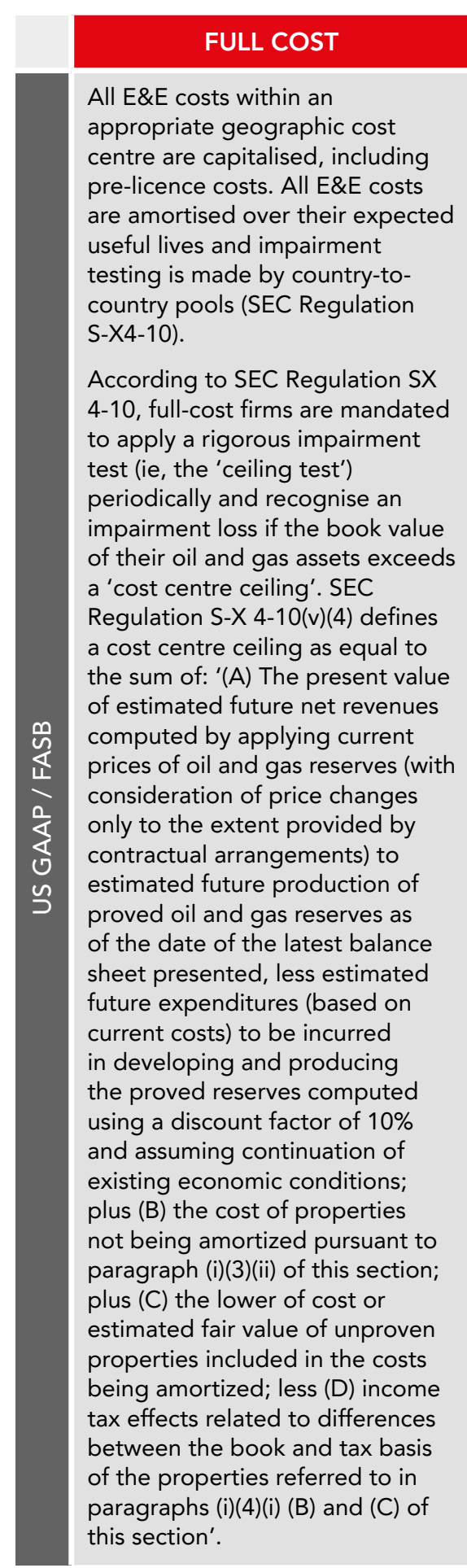

\section{SUCCESSFUL EFFORTS}

Exploration involves (a) identifying areas that may warrant examination and (b) examining specific areas that are considered to have prospects of containing oil and gas reserves, including drilling exploratory wells and exploratory-type stratigraphic test wells. Exploration costs may be incurred both before acquiring the related property (sometimes referred to in part as 'prospecting costs') and after acquiring the property.

Principal types of exploration cost, which include depreciation and applicable operating costs of support equipment and facilities (paragraph 26) and other costs of exploration activities, are:

a. Costs of topographical, geological, and geophysical studies, rights of access to properties to conduct those studies, and salaries and other expenses of geologists, geophysical crews, and others conducting those studies. Collectively, those are sometimes referred to as geological and geophysical or 'G\&G' costs.

b. Costs of carrying and retaining undeveloped properties, such as delay rentals, ad valorem taxes on the properties, legal costs for title defence, and the maintenance of land and lease records.

c. Dry hole contributions and bottom hole contributions.

d. Costs of drilling and equipping exploratory wells.

e. Costs of drilling exploratory-type stratigraphic test wells.

Geological and geophysical costs, costs of carrying and retaining undeveloped properties, and dry hole and bottom hole contributions shall be charged to expense when incurred.

The costs of drilling exploratory wells and the costs of drilling exploratory-type stratigraphic test wells shall be capitalised as part of the enterprise's uncompleted wells, equipment, and facilities pending determination of whether the well has found proved reserves. If the well has found proved reserves (paragraphs 31-34), the capitalised costs of drilling the well shall become part of the enterprise's wells and related equipment and facilities (even though the well may not be completed as a producing well); if, however, the well has not found proved reserves, the capitalised costs of drilling the well, net of any salvage value, shall be charged to expense. (FASB 19, 1977 para 16-19) 
All costs associated with exploring for or developing oil and gas reserves are capitalised, irrespective of the success or failure of specific parts of the overall exploration activity. Costs are accumulated in cost centres (known as 'cost pools'). The costs in each cost pool are generally written off against income arising from the production of the reserves attributable to that pool (OIAC SORP 2001: para 37)

Expenditure on pre-licence, licence acquisition, exploration, appraisal and development activities, including enhanced oil recovery and extended life projects should be capitalised pool (OIAC SORP 2001: para 41)

\section{SUCCESSFUL EFFORTS}

Exploration expenditure that is general in nature is charged directly to the profit and loss account and that which relates to unsuccessful drilling operations, though initially capitalised pending determination, is subsequently written off. Only costs that relate directly to the discovery and development of specific commercial oil and gas reserves will remain capitalised, to be depreciated over the lives of these reserves. The success or failure of each exploration effort will be judged on a well-by-well basis as each potentially hydrocarbonbearing structure is identified and tested (OIAC SORP 2001: para 36)

N/A

All pre-licence, licence acquisition, exploration, appraisal costs should initially be capitalised (including those costs that may fall to be written off in the same period, such as those costs referred to in paragraph 51) in well, field or general exploration costs centres as appropriate, pending determination. Expenditures incurred during the various exploration and development phases should then be written off unless commercial reserves have been established or the determination process has not been completed (OIAC SORP 2001: para 50)

\section{FULL COST}

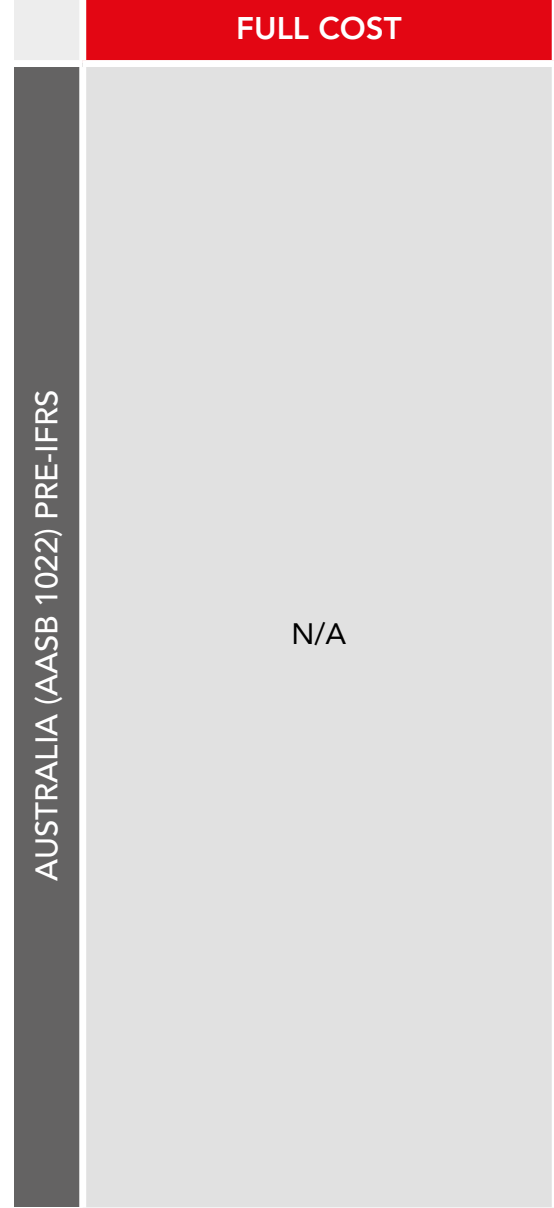

\section{SUCCESSFUL EFFORTS}

\section{AREA OF INTEREST}

'Area of interest' is defined as ' $[. .$.$] an$ individual geological area which is considered to constitute a favourable environment for the presence of a mineral deposit or an oil or natural gas field, or has been proved to contain such a deposit or field' (AASB1989a para. 06).

Each area of interest shall be considered separately when deciding whether, and to what extent, costs arising from exploration, evaluation and development are carried forward or written off. Costs arising from exploration and evaluation related to an area of interest shall be written off as incurred, except that they may be carried forward provided that rights to tenure of the area of interest are current and provided further that at least one of the following conditions is met: (a) such costs are expected to be recouped through successful development and exploitation of the area of interest, or alternatively, by its sale; and (b) exploration and evaluation activities in the area of interest have not at balance date reached a stage which permits a reasonable assessment of the existence or otherwise of economically recoverable reserves, and active and significant operations in, or in relation to, the area of interest are continuing. (AASB 1989a: para. 10 and 11, p 8). 


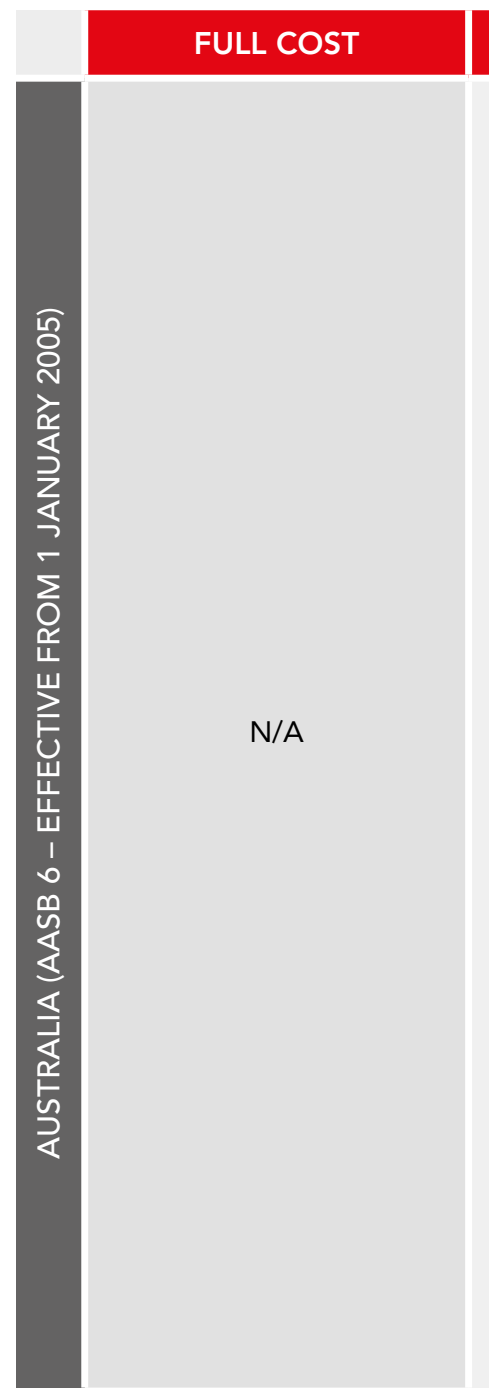

SUCCESSFUL EFFORTS

N/A
AREA OF INTEREST

Australian El firms shall use only the so-called 'Area of Interest method' (AASB 2004: para. 7.1). The 'Area of Interest' is defined as 'an individual geological area whereby the presence of a mineral deposit or an oil or natural gas field is considered favourable or has been proved to exist' (AASB 2004: para. 7.3).

An exploration and evaluation asset shall only be recognised in relation to an area of interest if the following conditions are satisfied: (a) the rights to tenure of the area of interest are current; and (b) at least one of the following conditions is also met: (i) the exploration and evaluation expenditures are expected to be recouped through successful development and exploitation of the area of interest, or alternatively, by its sale; and (ii) exploration and evaluation activities in the area of interest have not at the end of the reporting period reached a stage which permits a reasonable assessment of the existence or otherwise of economically recoverable reserves, and active and significant operations in, or in relation to, the area of interest are continuing (AASB 2004: para 7.2: 11).

An entity shall determine an accounting policy specifying which expenditures are recognised as exploration and evaluation assets and apply the policy consistently. In making this determination, an entity considers the degree to which the expenditure can be associated with finding specific mineral resources. The following are examples of expenditures that might be included in the initial measurement of exploration and evaluation assets (the list is not exhaustive): (a) acquisition of rights to explore; (b) topographical, geological, geochemical and geophysical studies; (c) exploratory drilling; (d) trenching; (e) sampling; and $(f)$ activities in relation to evaluating the technical feasibility and commercial viability of extracting a mineral resource (AASB 2004: para 9: 12).

\section{Comments/notes on IFRS 6}

- IFRS 6 states that 'A variety of accounting practices are followed by entities engaged in the exploration for and evaluation of mineral resources. These practices range from deferring on the balance sheet nearly all exploration and evaluation expenditure to recognising all such expenditure in profit or loss as incurred. The IFRS permits these various accounting practices to continue '(IASB 2004a: para BC 17).

- IFRS 6 allows firms to capitalise all exploration expenditures, such as a) acquisition of rights to explore; (b) topographical, geological, geochemical and geophysical studies; (c) exploratory drilling; (d) trenching; (e) sampling; and $(f)$ activities in relation to evaluating the technical feasibility and commercial viability of extracting a mineral resource (IASB 2004a: para 9). The IFRS clarifies that expenditures before the entity has obtained legal rights to explore in a specific area are not exploration and evaluation expenditures and are therefore outside the scope of the IFRS (IASB 2004a: para BC 1).

- For those policies that allow capitalisation, impairment testing should be carried out on those assets when facts and circumstances suggest that the carrying amount of the assets may exceed their recoverable amount (IASB 2004a: para IN 5b). E\&E assets are then allocated to cash-generating units (CGUs) or groups of CGUs for the purpose of impairment testing (IASB 2004a: para 21). Notably, IFRS 6 permits the use of a wider unit of account than the CGU, with regard to impairment testing of E\&E capitalised assets. Any resulting impairment loss should be disclosed in accordance with IAS 36 (IASB 2004a: para 18). 


\section{Appendix B:}

\section{Variable definition}

\section{VARIABLE NAME}

AccPolicyOrder

Age

Amortisation $^{\text {a }}$

AmountCapitalis Lag

AmountCapitalis ${ }^{a}$

AmountTotalCapitalis Lag ${ }^{\text {a }}$

Arealnterest

Australia

Big4

Canada

Capitalis

Capitalis Lag

CivicLaw

Corruption

DExpenseAll

E\&E Expense Max ${ }^{b}$

E\&E Expense ${ }^{a}$

E\&E Exter. Capitalis Lag ${ }^{a}$

E\&E Exter. Capitalis ${ }^{a}$

E\&E Impair Max ${ }^{b}$

\section{DEFINITION}

A categorical variable that takes values from 1 to 4 for the four accounting methods. AccPolicyOrder1 = 'Full Cost', AccPolicyOrder2 = 'Area of Interest', AccPolicyOrder3 = 'Successful Efforts' and AccPolicyOrder4 = 'Expense All'.

Firm age in years. In regressions, its natural logarithm is used.

Amortisation by total assets, at the end of year $t$.

This is the E\&E amount internally capitalised to total assets at the end of the previous year, ie E\&E Inter. Capitalis_t-1.

This is the E\&E amount internally capitalised to total assets, ie E\&E Inter. Capitalis.

This is the E\&E amount internally and externally capitalised to total assets at the end of the previous year, ie E\&E Inter. Capitalis_t-1.

A binary variable that takes the value of one (1) when a company chooses the Area of Interest as its E\&E accounting policy, and zero (0) otherwise.

Australia is a dummy variable that takes the value of one (1) if the company operates in Australia, and zero (1) otherwise.

A binary variable that takes the value of one (1) when a company has one of the Big Four international auditors (ie Deloitte Touche Tohmatsu, Ernst \& Young, KPMG or Pricewaterhouse Coopers) and zero (0) otherwise.

Canada is a dummy variable that takes the value of one (1) if the company operates in Canada, and zero (0) otherwise.

A binary variable that takes one (1) if the E\&E amount capitalised is higher than zero, and zero $(0)$ if there is zero E\&E amount capitalised.

A binary variable that takes one (1) if the E\&E amount capitalised at the end of the previous year is higher than zero, and zero ( 0 ) if there is zero E\&E amount capitalised at the of the previous year.

A dummy variable that takes zero (0) if common law and one (1) if civil law (La Porta et al. 1998).

Corruption is the percentile rank of control of corruption (Worldwide Governance Indicators (WGI) Project, 2010). The higher the value, the lower is the corruption in a country.

A binary variable that takes the value of one (1) when a company chooses to Expense All and zero $(0)$ otherwise.

E\&E Amount expensed by non-current assets at the end of year $t$, with a maximum value of $100 \%$.

E\&E Amount expensed by non-current assets at the end of the previous year $\mathrm{t}-1$.

E\&E Amount EXTERNALLY capitalised to total assets at the end of year $\mathrm{t}-1$.

E\&E Amount EXTERNALLY capitalised to total assets, at the end of year $t$.

E\&E Impairment charge by non-current assets at the end of the previous year $\mathrm{t}-1$, with a maximum value of $100 \%$. 


\section{VARIABLE NAME}

E\&E Impair
E\&E Intensity
E\&E Inter. Capitalis Lag
E\&E Inter. Capitalis
E\&E NBV
E\&E NBV

Enforcement

FirmSize
Impair
Impair amount_Max
Impair amount $<1$
Impair amount $>0$
Impair amounta
Impairment Reversal
InvProtect

Leverage

LowRevenueD

MiningVsOil

Profitability

RevenueT

SuccessEffort

Total Capitalis Lag

UK

\section{DEFINITION}

E\&E Impairment charge by non-current assets at the end of the previous year $\mathrm{t}-1$.

The sum of E\&E Inter. Capitalis, E\&E Exter.Capitalis and E\&E Expense, divided by total assets.

E\&E Amount INTERNALLY capitalised to total assets, at the end of year t-1.

E\&E Amount INTERNALLY capitalised to total assets, at the end of year $t$.

E\&E Net book value by total assets, at the end of year $t$.

E\&E Net book value by total assets, both at the end of the previous year $\mathrm{t}-1$.

Enforcement is an index capturing the quality of audit function and degree of accounting enforcement in each country measured in 2008, source Brown et al. (2014). The higher the value the higher the enforcement in a country.

Natural logarithm of total assets (TA).

A binary variable that takes the value of one (1) if the impairment charge at the end of the year is higher than zero $(0)$, and zero $(0)$ if there is zero impairment at the end of the year.

E\&E Impairment charge by non-current assets at the end of the previous year $\mathrm{t}-1$, with a maximum value of $100 \%$.

E\&E Impairment charge by non-current assets at the end of the previous year $\mathrm{t}-1$, excluding the firms with impairment value above $100 \%$.

E\&E Impairment charge by non-current assets at the end of the previous year $\mathrm{t}-1$, using only the firms with impairment value above zero (0).

E\&E Impairment charge by non-current assets at the end of the previous year t-1.

Amount of a reversal of impairment in year $t$, by TA at the end of year $t-1$.

A measure of legal protection of minority shareholders against expropriation by corporate insiders (anti self-dealing index): source Djankov et al. (2008). The higher the value, the higher the investor protection in a country.

Total debt to book value of equity at the end of year $t$.

A dummy variable that takes one (1) if the firm revenues are in the RevenueT category 1 ie, the lowest levels, and zero (0) otherwise.

A binary variable that takes the value of one (1) when a company belongs to one of the mining subsectors (ie aluminium; coal; copper; diamonds and gemstones; general mining; or gold) and zero $(0)$ when it belongs to one of the oil and gas subsectors (ie, alternative fuels; integrated oil and gas; offshore drill and services; oil: crude producers).

Return on Assets at the end of year $t$.

A categorical variable that divides the sample into three groups on the basis of their revenue. Firms with low revenue (including zero (0)) are in category 1 , medium revenue firms are in category 2 and high-revenue firms are in category 3.

A binary variable that takes the value of one (1) when a company chooses the Successful Efforts as its E\&E accounting policy, and zero (0) otherwise.

A binary variable that takes one (1) if the E\&E internal or external amount capitalised at the end of the previous year is higher than zero, and zero $(0)$ if there is zero E\&E internal and external amount capitalised at the of the previous year.

UK is a dummy variable that takes one (1) if the company operates in UK, and zero (0) otherwise.

a variable winsorised at the 1st and 99th percentile.

b variable winsorised at the 1 st percentile and capped to 1 . 


\section{Appendix C:}

Descriptive statistics after categorising our sample firms into total assets terciles (ie what we name as junior explorers, developers and producers)

\section{E\&E Expenditure}

\begin{tabular}{|c|c|c|c|c|c|c|c|c|c|}
\hline & $\begin{array}{l}\text { E\&E } \\
\text { NBV }\end{array}$ & $\begin{array}{c}\text { E\&E } \\
\text { NBV Lag }\end{array}$ & $\begin{array}{c}\text { E\&E } \\
\text { Inter. } \\
\text { Capitalis }\end{array}$ & $\begin{array}{c}\text { E\&E Inter. } \\
\text { Capitalis } \\
\text { Lag }\end{array}$ & $\begin{array}{c}\text { E\&E } \\
\text { Exter. } \\
\text { Capitalis }\end{array}$ & $\begin{array}{c}\text { E\&E Exter. } \\
\text { Capitalis } \\
\text { Lag }\end{array}$ & $\begin{array}{c}\text { E\&E } \\
\text { Expense }\end{array}$ & $\begin{array}{c}\text { E\&E } \\
\text { Expense } \\
\text { Max }\end{array}$ & $\begin{array}{c}\text { E\&E } \\
\text { Intensity }\end{array}$ \\
\hline \multicolumn{10}{|c|}{ JUNIOR EXPLORERS } \\
\hline$N$ & 360 & 360 & 360 & 360 & 356 & 356 & 312 & 312 & 360 \\
\hline $\mathrm{N}$-no zeros & 235 & 245 & 196 & 197 & 102 & 87 & 110 & 110 & 308 \\
\hline Mean & 0.396 & 0.415 & 0.121 & 0.103 & 0.051 & 0.064 & 3.106 & 0.196 & 1.491 \\
\hline Median & 0.317 & 0.381 & 0.009 & 0.010 & 0.000 & 0.000 & 0.000 & 0.000 & 0.182 \\
\hline StDev & 0.392 & 0.389 & 0.242 & 0.197 & 0.129 & 0.192 & 11.652 & 0.372 & 6.575 \\
\hline Min & 0.000 & 0.000 & 0.000 & 0.000 & 0.000 & 0.000 & 0.000 & 0.000 & 0.000 \\
\hline Max & 0.991 & 0.996 & 1.184 & 0.852 & 0.611 & 0.933 & 58.434 & 1.000 & 48.570 \\
\hline \multicolumn{10}{|c|}{ DEVELOPERS } \\
\hline N & 351 & 351 & 351 & 351 & 348 & 348 & 344 & 344 & 351 \\
\hline $\mathrm{N}$-no zeros & 301 & 303 & 266 & 268 & 89 & 84 & 113 & 113 & 332 \\
\hline Mean & 0.484 & 0.486 & 0.083 & 0.085 & 0.034 & 0.041 & 0.559 & 0.077 & 0.576 \\
\hline Median & 0.564 & 0.530 & 0.035 & 0.032 & 0.000 & 0.000 & 0.000 & 0.000 & 0.089 \\
\hline StDev & 0.372 & 0.370 & 0.127 & 0.128 & 0.109 & 0.147 & 4.685 & 0.227 & 4.468 \\
\hline Min & 0.000 & 0.000 & 0.000 & 0.000 & 0.000 & 0.000 & 0.000 & 0.000 & 0.000 \\
\hline Max & 0.991 & 0.996 & 1.184 & 0.852 & 0.611 & 0.933 & 58.434 & 1.000 & 48.570 \\
\hline \multicolumn{10}{|c|}{ PRODUCERS } \\
\hline$N$ & 291 & 291 & 291 & 291 & 289 & 289 & 288 & 288 & 291 \\
\hline $\mathrm{N}$-no zeros & 228 & 231 & 195 & 194 & 50 & 50 & 134 & 134 & 261 \\
\hline Mean & 0.144 & 0.156 & 0.020 & 0.025 & 0.004 & 0.010 & 0.017 & 0.017 & 0.367 \\
\hline Median & 0.040 & 0.047 & 0.002 & 0.002 & 0.000 & 0.000 & 0.000 & 0.000 & 0.011 \\
\hline StDev & 0.232 & 0.231 & 0.042 & 0.072 & 0.029 & 0.056 & 0.061 & 0.061 & 4.017 \\
\hline Min & 0.000 & 0.000 & 0.000 & 0.000 & 0.000 & 0.000 & 0.000 & 0.000 & 0.000 \\
\hline Max & 0.989 & 0.979 & 0.341 & 0.820 & 0.428 & 0.732 & 0.627 & 0.627 & 48.570 \\
\hline
\end{tabular}




\section{E\&E Impairment}

\begin{tabular}{|l|c|c|c|c|c|c|}
\hline \multirow{2}{*}{} & \multicolumn{2}{|c|}{ JUNIOR EXPLORERS } & \multicolumn{2}{c|}{ DEVELOPERS } \\
\cline { 2 - 6 } & $\begin{array}{c}\text { E\&E } \\
\text { IMPAIR }\end{array}$ & $\begin{array}{c}\text { E\&E } \\
\text { IMPAIR MAX }\end{array}$ & $\begin{array}{c}\text { E\&E } \\
\text { IMPAIR }\end{array}$ & $\begin{array}{c}\text { E\&E } \\
\text { IMPAIR MAX }\end{array}$ & $\begin{array}{c}\text { E\&E } \\
\text { IMPAIR }\end{array}$ \\
\hline IMPAIR MAX \\
\hline IM-no zeros & 121 & 312 & 344 & 344 & 288 & 288 \\
\hline Mean & 0.665 & 121 & 134 & 134 & 91 & 91 \\
\hline Median & 0.323 & 0.323 & 0.036 & 0.036 & 0.008 & 0.008 \\
\hline StDev & 0.943 & 0.409 & 0.614 & 0.259 & 0.065 & 0.065 \\
\hline Min & 0.000 & 0.000 & 0.000 & 0.000 & 0.000 & 0.000 \\
\hline Max & 3.838 & 1.000 & 3.838 & 1.000 & 0.344 & 0.344 \\
\hline
\end{tabular}




\section{Appendix D:}

\section{Examples of companies' disclosures}

This Appendix provides extracts from the financial statements of 20 firms. These firms have very high E\&E intensity and/or very large impairments of E\&E assets in the year. Thus, for these firms, E\&E expenditure is material and detailed and clear disclosures would be pertinent. These extracts demonstrate the variety of accounting methods that companies follow and how these are described. Presentation of the movements of E\&E assets and discussion of the large impairments recognised also vary a lot.

Cascadero Copper, Year-end: 30th November 2018

Pg 9-10

g) Exploration and evaluation assets

(i) Pre-license expenditures

Pre-license expenditures are costs incurred before the legal rights to explore a specific area have been obtained. These costs are expensed in the period in which they are incurred.

(ii) Exploration and evaluation expenditures

Once the legal right to explore has been acquired, costs directly associated with the exploration project are capitalized as either tangible or intangible exploration and evaluation assets according to the nature of the asset acquired. Such exploration and evaluation ("E\&E") costs may include undeveloped land acquisition, geological, geophysical and seismic, exploratory drilling and completion, testing, decommissioning and directly attributable internal costs. E\&E costs are not depleted and are carried forward until technical feasibility and commercial viability of extracting a mineral resource is considered to be determined. The technical feasibility and commercial viability of a mineral resource is considered to be established when proven and or probable mineral reserves are determined to exist. The Company has not established NI 43-101 compliant proven or probable reserves on any of its mineral properties which have been determined to be economically viable.

The Company may occasionally enter into farm-out arrangements, whereby the Company will transfer part of a mineral interest, as consideration, for an agreement by the transferee to meet certain exploration and evaluation expenditures which would have otherwise been undertaken by the Company. The Company does not record any expenditures made by the farmee on its behalf. Any cash consideration received from the agreement is credited against the costs previously capitalized to the mineral interest, with any excess cash accounted for as a gain on disposal.

Although the Company has taken steps to verify title to mineral properties in which it has an interest, these procedures do not guarantee the Company's title. Such properties may be subject to prior agreements or transfers and title may be affected by undetected defects.

(iii) Impairment

Exploration and evaluation assets are assessed for impairment at the each reporting period or when indicators and circumstances suggest that the carrying amount may exceed its recoverable amount. If any such indication exists, the recoverable amount of the asset is estimated in order to determine the extent of the impairment. Indication of impairment includes but is not limited to expiration of the right to explore, substantive expenditures in the specific area is neither budgeted nor planned, and exploration for and evaluation of mineral resources in the specific area have not led to the discovery of any commercially viable quantities of mineral resources.

Where an impairment loss subsequently reversed the carrying amount of the asset (or cash generating unit) is increased to the revised estimate of its recoverable amount, but to an amount that does not exceed the carrying amount that would have been determined had no impairment loss been recognized for the asset (or cash-generating unit) in prior years. A reversal of an impairment loss is recognized immediately as profit or loss. 


\section{Pg 17}

\section{EXPLORATION AND EVALUATION ASSETS}

\section{Toodoggone Property}

The Company had 49\% interest in the Toodoggone property located in BC. The Company has written off all of the capitalized exploration expenditures relating to the Toodoggone property in prior years leaving the property with a carrying value of \$nil because no significant expenditures were planned or budgeted, and the Company lacks the capital to continue spending on the property.

On June 7, 2017, the Company signed an option agreement (the "Option Agreement") with Amarc that enables Amarc to acquire a 100\% interest in the Company's $49 \%$ interest in the Toodoggone property. In order to exercise the option, Amarc is required to make staged cash payments to the Company in the aggregate amount of $\$ 1$ million and issuance of common shares of Amarc with the aggregated value of \$950,000 before October 31, 2018. During the year ended November 30, 2017, the Company received $\$ 400,000$ cash and 1,944,444 common shares of Amarc with the fair value of $\$ 281,044$ based on the Amarc's common shares' trading price at the date of issuance. During the year ended November 30, 2018, the Company received remaining proceeds consisting of $\$ 600,000$ cash and 3,333,334 common shares of Amarc with the fair value of $\$ 358,333$ based on the Amarc's common shares' trading price at the date of issuance (Note 4). The Company recognized a gain on disposal of the Toodoggone property of \$958,333 (2017 - \$681,944) during the year ended November 30, 2018.

\section{Argentina Mineral Properties}

The Company, through CMSA, SGSA and TSA holds certain mineral properties in Argentina (also see Note 5). The summary of exploration costs incurred directly by the Company for the years ended November 30, 2018 and 2017 are as follows. These expenditures have been written off as at November 30, 2018 and 2017 respectively because the Company had no budgeted or planned exploration for the next twelve months.

\begin{tabular}{lrr} 
& $\mathbf{2 0 1 8}$ & 2017 \\
& $\mathbf{\$}$ & $\$$ \\
\cline { 2 - 3 } Consulting & $\mathbf{5 0 , 0 9 5}$ & 170,862 \\
Geological and exploration & $\mathbf{-}$ & 503,466 \\
Food and lodging & $\mathbf{2 5 , 1 4 5}$ & 66,175 \\
Equipment and truck rental & $\mathbf{-}$ & 6,563 \\
Others & $\mathbf{1 4 , 4 2 4}$ & 39,950 \\
\hline & $\mathbf{8 9 , 6 6 4}$ & 787,016 \\
\hline
\end{tabular}

Halio Energy, Year-end: 31st July 2018

\section{Pg 10}

b) Exploration and evaluation assets

Pre-exploration costs

Costs incurred prior to acquiring the right to explore an area of interest are expensed as incurred.

\section{Exploration and evaluation expenditures}

Once the legal right to explore a property has been acquired, costs directly related to exploration and evaluation expenditures are recognized and capitalized, in addition to the acquisition costs. Costs capitalized include topographical, geological, geochemical and geophysical studies, exploration drilling, sampling and technical feasibility and commercial viability activities involving extracting an oil or gas resource. No amortization is recognized during the exploration and evaluation phase. Costs not directly attributable to exploration and evaluation activities, including general administrative overhead costs, are expensed as incurred.

When a project is deemed to no longer have commercially viable prospects to the Company, exploration and evaluation expenditures in respect of that project are deemed to be impaired. As a result, those exploration and evaluation expenditure costs, in excess of estimated recoveries, are written off to the statement of comprehensive loss.

The Company assesses exploration and evaluation assets for impairment when facts and circumstances suggest that the carrying amount of an asset may exceed its recoverable amount.

As the Company currently has no operational income, any incidental revenues earned in connection with exploration activities are applied as a reduction to capitalized exploration costs. 
$\operatorname{Pg} 17-18$

6. EXPLORATION AND EVALUATION ASSETS

Exploration and evaluation assets are comprised of:

July 31, 2017 Expenditures Impairment July 31, 2018

\begin{tabular}{lrrrr} 
& July 31,2017 & Expenditures & Impairment & July 31, 2018 \\
\hline $\begin{array}{l}\text { Western Idaho Basin - Oregon } \\
\text { Deferred exploration costs }\end{array}$ & $\$$ & $\$$ & $\$$ & \\
\hline Total & 572,560 & 344,473 & $(917,033)$ & - \\
\hline \hline & 572,560 & 344,473 & $(917,033)$ & - \\
\hline & July 31, 2016 & Expenditures & Impairment & July 31, 2017 \\
\hline & $\$$ & $\$$ & $\$$ & $\$$
\end{tabular}

Western Idaho Basin - Oregon

Deferred exploration costs

\begin{tabular}{lrrrr} 
Deferred exploration costs & - & 572,560 & - & 572,560 \\
\hline $\begin{array}{l}\text { Street Property - Sudbury, Ontario } \\
\text { Acquisition }\end{array}$ & - & 572,560 & - & 572,560 \\
\hline & - & 2,000 & $(2,000)$ & - \\
\hline Total & - & 2,000 & $(2,000)$ & - \\
\hline \hline
\end{tabular}

6. EXPLORATION AND EVALUATION ASSETS (continued)

Deferred exploration costs were as follows:

\begin{tabular}{lrrr}
\hline & $\begin{array}{r}\text { Western Idaho } \\
\text { Basin, Oregon }\end{array}$ & $\begin{array}{r}\text { Street Property } \\
\text { Sudbury, Ontario }\end{array}$ & Total \\
\hline & $\$$ & $\$$ & \$ \\
Balance, July 31, 2016 & - & - & $-229,160$ \\
\hline $\begin{array}{l}\text { Exploration: } \\
\text { Licensing } \\
\text { Geology and geophysics }\end{array}$ & 229,160 & - & 343,400 \\
\hline Balance, July 31, 2017 & 343,400 & - & 572,560 \\
\hline $\begin{array}{l}\text { Exploration: } \\
\text { Licensing }\end{array}$ & 572,560 & - & 343,055 \\
$\quad$ Geology and geophysics & & - & 344,473 \\
\hline & 343,055 & - & 917,033 \\
\hline Balance, July 31, 2018 & 1,418 & - & - \\
\hline
\end{tabular}

Oregon's Western Idaho Basin

On October 3, 2016, the Company signed a Farm-out Agreement with Trendwell West Inc. ("Trendwell") to drill several highpriority oil and gas prospects in Oregon's Western Idaho Basin. Subject to the Company completing a financing, the Company will have the option to earn a 50\% interest in the project by paying \$6 million USD in costs related to the development of the wells.

During the year ended July 31, 2018, the Company incurred $\$ 344,473(2017$ - $\$ 572,560)$ in costs related to the development of the well.

On April 16, 2018, Trendwell terminated the Farm-out Agreement after the Company failed to provide the evidence of sufficient financing to fulfil its obligation to expend the remaining cost of development. As a result, the Company wrote off the carrying value of the property. 
Frontline Gold, Year-end 31st December 2018

\section{$\operatorname{Pg} 7$}

(d) Exploration and Evaluation Assets

Exploration and evaluation expenditures include the costs of acquiring licenses, costs associated with exploration and evaluation activities, and the fair value (at acquisition date) of exploration and evaluation assets acquired in a business combination. Exploration and evaluation expenditures are capitalized as incurred as intangible assets. Costs incurred before the Company has obtained the legal rights to explore an area are recognized in profit or loss.

Once the technical feasibility and commercial viability of the extraction of mineral resources in an area of interest are demonstrable, which management has determined to be indicated by a feasibility study and a decision to proceed with development, exploration and evaluation assets attributable to that area of interest are first tested for impairment and then reclassified to resource property in property, plant and equipment.

An impairment review of exploration and evaluation assets is performed, either individually or at the cash generating unit level, when there are indicators that the carrying amount of the assets may exceed their recoverable amounts. To the extent this occurs, the excess is fully provided against the carrying amount, in the period in which this is determined. Exploration and evaluation assets are assessed on a regular basis and these costs are carried forward provided at least one of the following conditions is met:

- such costs are expected to be recovered through successful exploration and development and of the area of interest or by its sale; or

- exploration and evaluation activities in the area have not yet reached a stage that permits reasonable assessment of the existence or otherwise of economically recoverable reserves, and active and significant operations in relation to the area are continuing, or planned in the future.

Pg 15

6. Exploration and Evaluation Assets

The change in exploration and evaluation ("E\&E") assets in the period are as follows:

\begin{tabular}{|c|c|c|c|c|c|c|c|c|c|c|}
\hline & & $\begin{array}{c}\text { As at } \\
\text { December } \\
31,2017 \\
\end{array}$ & & $\begin{array}{l}\text { Acquisition } \\
\text { Costs }\end{array}$ & & $\begin{array}{c}\text { Exploration } \\
\text { Expenditures }\end{array}$ & & $\begin{array}{l}\text { Option } \\
\text { Proceeds } \\
\text { Received } \\
\end{array}$ & & $\begin{array}{c}\text { As at } \\
\text { December } \\
31,2018 \\
\end{array}$ \\
\hline Niaouleni Gold Project & $\$$ & 33,424 & $\$$ & - & $\$$ & - & $\$$ & - & $\$$ & 33,424 \\
\hline Red Lake - Birch Lake & & 24,500 & & 26,000 & & - & & $(50,500)$ & & - \\
\hline Whitehorse Property & & - & & - & & 115 & & - & & 115 \\
\hline Rainy River Property & & 74,500 & & 2,500 & & - & & - & & 77,000 \\
\hline Kambertepe Property & & 167,018 & & - & & 1,623 & & - & & 168,641 \\
\hline Keban Property & & 200,517 & & - & & - & & - & & 200,517 \\
\hline Giresun Property & & 21,000 & & - & & - & & _ & & 21,000 \\
\hline Rex Lake Property & & - & & 8,000 & & 2,301 & & - & & 10,301 \\
\hline Jubilee Lake Property & & - & & 2,000 & & 7,140 & & - & & 9,140 \\
\hline Gullrock Property & & _ & & 75,000 & & & & _ & & 75,000 \\
\hline \multirow[t]{3}{*}{ Other Ontario Property } & & 28,990 & & - & & 1,277 & & - & & 30,267 \\
\hline & $\$$ & 549,949 & $\$$ & 113,500 & $\$$ & 12,456 & $\$$ & $(50,500)$ & $\$$ & 625,405 \\
\hline & & $\begin{array}{c}\text { As at } \\
\text { December } 31 \text {, } \\
2016 \\
\end{array}$ & & $\begin{array}{c}\text { Acquisition } \\
\text { Costs }\end{array}$ & & $\begin{array}{l}\text { Exploration } \\
\text { Expenditures }\end{array}$ & & $\begin{array}{l}\text { Option } \\
\text { Proceeds } \\
\text { Received } \\
\end{array}$ & & $\begin{array}{c}\text { As at } \\
\text { December 31, } \\
2017 \\
\end{array}$ \\
\hline Niaouleni Gold Project & $\$$ & - & $\$$ & - & $\$$ & 33,424 & $\$$ & - & $\$$ & 33,424 \\
\hline Red Lake - Birch Lake & & 52,113 & & 24,500 & & - & & $(52,113)$ & & 24,500 \\
\hline Chukuni Property & & 18,900 & & 15,000 & & 3,200 & & $(37,100)$ & & - \\
\hline Whitehorse Property & & 2,112 & & - & & - & & $(2,112)$ & & - \\
\hline Rainy River Property & & 33,000 & & 32,500 & & 9,000 & & - & & 74,500 \\
\hline Kambertepe Property & & 167,018 & & - & & - & & - & & 167,018 \\
\hline Keban Property & & 200,517 & & - & & - & & - & & 200,517 \\
\hline Giresun Property & & 21,000 & & - & & - & & - & & 21,000 \\
\hline Other Ontario Property & & 6,000 & & 1.575 & & 21,415 & & _ & & 28,990 \\
\hline & $\$$ & 500,660 & $\$$ & 73,575 & $\$$ & 67,039 & $\$$ & $(91,325)$ & $\$$ & 549,949 \\
\hline
\end{tabular}


Argentina Lithium \& Energy Corp, Year-end: 31st December 2018

\section{Pg 7}

Exploration, Evaluation and Development Expenditure

Exploration and evaluation expenditures are expensed as incurred, until the property reaches development stage. The development stage begins once the technical feasibility and commercial viability of the extraction of mineral resources in an area of interest are demonstrable. All direct costs related to the acquisition of resource property interests are capitalized. Development expenditures incurred subsequent to a development decision, which increase or extend the life of existing production, are capitalized and will be amortized on the unit-of-production method based upon estimated proven and probable reserves.

Mineral property acquisition costs include cash costs and the fair market value of common shares, based on the trading price of the shares issued for mineral property interests, pursuant to the terms of the related property agreements. Payments related to a property acquired under an option or joint venture agreement are made at the sole discretion of the Company, and are recorded as mineral property acquisition costs upon payment.

Exploration and evaluation assets are classified as intangible assets

Pg 13-14

\section{EXPLORATION AND EVALUATION ASSETS}

The schedules below summarize the acquisition costs and all exploration expenditures incurred to date for each exploration and evaluation asset that the Company holds title to as at December 31, 2018 and 2017:

\section{Acquisition Costs}

\begin{tabular}{|c|c|c|c|c|c|}
\hline & \multirow[b]{2}{*}{$\begin{array}{c}\text { Arizaro } \\
\mathbf{S}\end{array}$} & \multicolumn{4}{|c|}{ Argentina } \\
\hline & & $\begin{array}{c}\text { Incahuasi } \\
\mathbf{S}\end{array}$ & $\begin{array}{l}\text { Antofalla } \\
\$\end{array}$ & $\begin{array}{c}\text { Fierro } \\
\mathbf{S}\end{array}$ & $\begin{array}{c}\text { Total } \\
\mathbf{S}\end{array}$ \\
\hline Balance - December 31, 2016 & $1,526,490$ & - & - & 1 & $1,526,491$ \\
\hline \multicolumn{6}{|l|}{ Additions } \\
\hline $\begin{array}{l}\text { Option payments, staking costs, land payments } \\
\text { and acquisition costs }\end{array}$ & $1,763,775$ & 77,799 & - & - & $1,841,574$ \\
\hline Impairment of exploration and evaluation assets & - & - & - & (1) & $(1)$ \\
\hline Balance-December 31, 2017 & $3,290,265$ & 77,799 & - & - & $3,368,064$ \\
\hline \multicolumn{6}{|l|}{ Additions } \\
\hline $\begin{array}{l}\text { Option payments, staking costs, land payments } \\
\text { and acquisition costs }\end{array}$ & 37,455 & - & 279,126 & - & 316,581 \\
\hline Impairment of exploration and evaluation assets & $(3,327,720)$ & - & $(257,580)$ & - & $(3,585,300)$ \\
\hline Balance-December 31, 2018 & - & 77,799 & 21,546 & - & 99,345 \\
\hline
\end{tabular}


5. EXPLORATION AND EVALUATION ASSETS (continued)

Exploration Expenditures

\begin{tabular}{lrrrrr}
\hline & \multicolumn{5}{c}{ Argentina } \\
\cline { 2 - 7 } & $\begin{array}{r}\text { Antofalla } \\
\text { S }\end{array}$ & $\begin{array}{r}\text { Arizaro } \\
\text { S }\end{array}$ & $\begin{array}{c}\text { Incahuasi } \\
\text { O Other }\end{array}$ & Total \\
\hline Cumulative exploration expenses & & & & $\mathbf{S}$ & \multicolumn{1}{c}{$\mathbf{S}$} \\
December 31, 2017 & - & $1,607,044$ & 157,207 & - & $1,764,251$ \\
\hline Expenditures during the year: & & & & & \\
Assays & - & - & 41,885 & - & 41,885 \\
Drilling & - & - & 657,717 & - & 657,717 \\
Geophysics & 1,623 & 89,942 & 26,338 & - & 117,903 \\
Metallurgy and mineralogy & 1,160 & - & - & 16,706 & 17,866 \\
Office & 2,902 & 8,848 & 73,690 & - & 85,440 \\
Professional fees & 1,849 & 17,262 & 76,974 & 1,569 & 97,654 \\
Property maintenance payments & 2,987 & 7,526 & 38,547 & 6,358 & 55,418 \\
Salaries and contractors & 621 & 58,884 & 231,519 & - & 291,024 \\
Social and community & 4,238 & 4,343 & 50,477 & - & 59,058 \\
Supplies and equipment & 7,014 & 48,623 & 524,579 & - & 580,216 \\
Transportation & 277 & 26,957 & 212,841 & - & 240,075 \\
Statutory taxes & 3,495 & 40,451 & 298,246 & 3,798 & 345,990 \\
\hline Cumulative exploration expenses & 26,166 & 302,836 & $2,232,813$ & 28,431 & $2,590,246$ \\
\hline December 31, 2018 & & & & & \\
\hline
\end{tabular}

\begin{tabular}{lrrr}
\hline & \multicolumn{3}{c}{ Argentina } \\
\cline { 2 - 4 } & $\begin{array}{r}\text { Arizaro } \\
\mathbf{S}\end{array}$ & $\begin{array}{r}\text { Incahuasi } \\
\mathbf{S}\end{array}$ & $\begin{array}{c}\text { Total } \\
\mathbf{S}\end{array}$ \\
\hline Cumulative exploration expenses & & & 113,710 \\
December 31, 2016 & 113,710 & & \\
\hline Expenditures during the year: & 27,593 & 12,380 & 39,973 \\
Assays & 434,548 & - & 434,548 \\
Drilling & 26,443 & 30,319 & 56,762 \\
Geophysics & 58,957 & 7,449 & 66,406 \\
Office & 90,877 & 4,777 & 95,654 \\
Professional fees & 25,146 & 18,536 & 43,682 \\
Property maintenance payments & 357,882 & 29,988 & 387,870 \\
Salaries and contractors & 22,683 & 732 & 23,415 \\
Social and community & 174,971 & 6,046 & 181,017 \\
Supplies and equipment & 86,360 & 27,202 & 113,562 \\
Transportation & 187,874 & 19,778 & 207,652 \\
Statutory taxes & $1,493,334$ & 157,207 & $1,650,541$ \\
\hline Cumulative exploration expenses & & & \\
December 31, 2017 & $1,607,044$ & 157,207 & $1,764,251$ \\
\hline
\end{tabular}


Revelo Resources Corp, Year-end: 31st January 2018

\section{Pg 11}

\section{Exploration and Evaluation Assets}

Upon acquiring legal title to explore, the acquisition of mineral property interests are initially measured at cost. Mineral property acquisition costs include the cash consideration and the fair market value of shares issued for mineral property interests pursuant to the terms of the relevant agreements.

Mineral property acquisition costs and development expenditures incurred subsequent to the determination of the feasibility of mining operations and approval of development by the Company are capitalized until the property to which they relate is placed into production, sold or allowed to lapse. These costs will be amortized over the estimated life of the mineral property following commencement of commercial production, or written off if the property is sold, allowed to lapse, or when an impairment of value has been determined to have occurred.

Exploration and evaluation costs incurred prior to determination of the feasibility of mining operations are expensed as incurred. Reimbursements of current period exploration and evaluation costs are recognized as a recovery. Reimbursements of previously expensed exploration and evaluation costs are recognized in profit or loss.

When there is little prospect of further work on a property being carried out by the Company or its partners, when a property is abandoned, or when the capitalized costs are no longer considered recoverable, the related property costs are written down to management's estimate of their net recoverable amount.

\section{$\operatorname{Pg} 19$}

\section{EXPLORATION AND EVALUATION ASSETS}

\begin{tabular}{|c|c|c|c|c|}
\hline & \multicolumn{2}{|c|}{ January 31, 2018} & \multicolumn{2}{|c|}{ January 31, 2017} \\
\hline Las Pampas, Chile & $\$$ & 651,722 & $\$$ & 651,722 \\
\hline Cerro Blanco, Chile & & 100,000 & & 100,000 \\
\hline Cerro Buenos Aires, Chile & & 100,000 & & 100,000 \\
\hline Magallanes, Chile & & 1 & & 1 \\
\hline T4, Chile & & 11,836 & & 11,836 \\
\hline San Guillermo, Chile & & - & & 89,949 \\
\hline Morros Blancos, Chile & & 70,030 & & 70,030 \\
\hline Altamira, Chile & & 10,000 & & 10,000 \\
\hline Calvario, Chile & & 120,041 & & 120,041 \\
\hline Mirador, Chile & & 120,042 & & 120,042 \\
\hline Colla Kananchiari (formerly Bronce Weste), Chile & & 1 & & 1 \\
\hline San Valentino, Chile & & 120,041 & & 120,041 \\
\hline Reina Hija, Chile & & - & & 40,014 \\
\hline Montezuma, Chile & & 1 & & - \\
\hline Los Azules, Chile & & 327,545 & & 452,555 \\
\hline Block 2, Chile & & 75,000 & & 75,000 \\
\hline Redondo-Veronica, Chile & & 25,000 & & 25,000 \\
\hline Block 3, Chile & & 800,975 & & 800,975 \\
\hline Block 4, Chile & & 121,842 & & 121,842 \\
\hline Limbo, Chile & & 1 & & 1 \\
\hline Las Animas, Chile & & 75,426 & & 75,426 \\
\hline Loro, Chile & & 6,550 & & 31,550 \\
\hline Victoria Sur, Chile & & 1 & & - \\
\hline Orca (formerly Morsas), Chile & & 183,838 & & 183,838 \\
\hline Reprado, Chile & & - & & 104,995 \\
\hline & $\$$ & $2,919,893$ & $\$$ & $3,304,859$ \\
\hline
\end{tabular}




\section{Pg 23}

\section{EXPLORATION EXPENDITURES}

During the year ended January 31,2018 , the Company incurred the following exploration expenditures, including regional exploration and property investigation costs, which were expensed as incurred:

\begin{tabular}{|c|c|c|c|c|c|c|c|c|c|c|c|c|c|c|c|c|c|c|c|}
\hline & & Calvario & & $\begin{array}{l}\text { Morros } \\
\text { Blancos }\end{array}$ & & Loro & & ontezuma & $\begin{array}{l}\text { Redondo- } \\
\text { Veronica }\end{array}$ & Victoria Sur & & $\begin{array}{l}\text { Block } 4 \text { - } \\
\text { naconda }\end{array}$ & & s Pampas & Las Animas & & $\begin{array}{l}\text { egional } \\
\text { project } \\
\text { elopment }\end{array}$ & & Total \\
\hline Exploration field costs & $\$$ & - & $\$$ & - & $\$$ & 210,519 & $\$$ & 127,509 & $\$$ & $\$$ & $\$$ & - & $\$$ & - & $\$$ & $\$$ & 1,796 & $\$$ & 339,824 \\
\hline Legal and accounting & & 6,800 & & 2,287 & & 17,727 & & 34,785 & 4,169 & 2,993 & & 3,202 & & - & 2,788 & & 120,362 & & 195,113 \\
\hline Office and administration & & 10,704 & & 5,952 & & 4,942 & & 53,519 & 8,512 & 7,789 & & 6,538 & & 265 & 9,571 & & 63,293 & & 171,085 \\
\hline Property maintenance & & 94,197 & & 53,875 & & 28,256 & & 274,296 & 76,148 & 70,496 & & 58,488 & & 230,581 & 63,358 & & 456,976 & & $1,406,671$ \\
\hline Salaries and benefits & & 36,291 & & 20,181 & & 148,640 & & 176,561 & 28,860 & 26,406 & & 22,167 & & - & 24,600 & & 213,021 & & 696,727 \\
\hline Travel & & 391 & & 217 & & 67,225 & & 55,240 & 311 & 284 & & 239 & & - & 265 & & 15,672 & & 139,844 \\
\hline Total Expenditures & & 148,383 & & 82,512 & & 477,309 & & 721,910 & 118,000 & 107,968 & & 90,634 & & 230,846 & 100,582 & & 871,120 & & $2,949,264$ \\
\hline Recoveries & & - & & - & & $(408,800)$ & & $(24,322)$ & - & - & & - & & - & - & & - & & $(433,122)$ \\
\hline Operat & & - & & - & & $(46,684)$ & & - & - & - & & - & & - & - & & - & & $(46,684)$ \\
\hline Net Expenditures & $?$ & 148,383 & $\$$ & 82,512 & 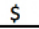 & 21,825 & 8 & 697,588 & $\$ 118,000$ & $\$ 107,968$ & 5 & 90,634 & 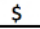 & 230,846 & $\$ 100,582$ & 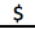 & 871,120 & $\$$ & $2,469,458$ \\
\hline
\end{tabular}

During the year ended January 31, 2017, the Company incurred the following exploration expenditures, including regional exploration and property investigation costs, which were expensed as incurred:

\begin{tabular}{|c|c|c|c|c|c|c|c|c|c|c|c|c|c|c|}
\hline & Las & Pampas & & $\begin{array}{l}\text { lorros } \\
\text { lancos }\end{array}$ & Morsas & Montezuma & $\begin{array}{l}\text { Redondo- } \\
\text { Veronica }\end{array}$ & $\begin{array}{l}\text { Block } 3 \text { - } \\
\text { Culebra }\end{array}$ & $\begin{array}{l}\text { Block } 4 \text { - } \\
\text { Anaconda }\end{array}$ & Culebra & & s Animas & $\begin{array}{c}\text { Regional } \\
\text { project } \\
\text { development }\end{array}$ & Total \\
\hline Exploration field costs & $\$$ & 12,663 & $\$$ & 59,297 & 7,434 & 22,321 & $\$$ & $\$$ & 1,636 & $\$$ & $\$$ & 14,748 & 38,542 & 156,641 \\
\hline Legal and accounting & & 4,556 & & 6,103 & 5,461 & 49,088 & 5,421 & 4,414 & 2,886 & 4,460 & & 3,084 & 81,065 & 166,538 \\
\hline Office and administration & & 717 & & 15,810 & 15,948 & 7,561 & 16,332 & 13,298 & 8,208 & 13,436 & & 9,292 & 78,974 & 179,576 \\
\hline Property maintenance & & 217,641 & & 66,834 & 112,678 & 10,232 & 122,713 & 99,920 & 61,514 & 100,959 & & 65,152 & 412,254 & $1,269,897$ \\
\hline Salaries and benefits & & 289 & & 64,856 & 65,421 & 31,016 & 66,996 & 54,552 & 33,672 & 55,119 & & 38,117 & 294,491 & 704,529 \\
\hline Travel & & - & & 6,326 & 7,231 & 409 & 883 & 719 & 444 & 726 & & 3,414 & 65,194 & 85,346 \\
\hline
\end{tabular}

Net Expenditures

$\begin{array}{lllllllllllllllllll}\$ 235,866 & \$ 219,226 & \$ 214,173 & \$ & 120,627 & \$ & 212,345 & \$ & 172,903 & \$ & 108,360 & \$ & 174,700 & \$ & 133,807 & \$ & 970,520 & \$ 2,562,527 \\ \end{array}$

Included in property maintenance costs for regional project development is US\$50,000 $(\$ 65,460)$ related to a payment made to Tombstone Aruba A.V.V pursuant to a mutual release and termination agreement related to a NSR royalty agreement dated as of April 4, 2008 respecting the Vaquillas property and certain other properties in Chile. 
Palladium One Mining, Year-end: 31st December 2018

\section{$\operatorname{Pg} 9$}

Mineral exploration and evaluation expenditures

Pre-exploration costs are expensed in the year they are incurred. All direct and indirect costs pertaining to exploration and evaluation of mineral properties are expensed in the period in which they are incurred. These direct exploration and evaluation expenditures include such costs as acquisition costs, materials used, surveying costs, drilling costs and payments made to contractors. Costs not directly attributable to exploration \& evaluation activities are expensed in the period in which they occur under another classification.

Once the technical feasibility and commercial viability of extracting the mineral resource has been determined, the property is considered to be a mine under development and is classified as 'mines under construction'.

As the Company currently has no operational income, any incidental revenues earned in connection with exploration activities are recorded in profit or loss.

\section{Pg 17}

\section{Exploration and evaluation expenditures}

The Company performed the following work on their properties during the year:

\begin{tabular}{|c|c|c|c|c|}
\hline & \multicolumn{2}{|c|}{$\begin{array}{r}\text { December } 31, \\
2018 \\
\end{array}$} & \multicolumn{2}{|c|}{$\begin{array}{r}\text { December } 31, \\
2017 \\
\end{array}$} \\
\hline \multicolumn{5}{|l|}{ Manitouwadge: } \\
\hline Assays and surveying & $\$$ & - & $\$$ & 820 \\
\hline Claims & & 1,122 & & 26,833 \\
\hline Field costs & & - & & 15,194 \\
\hline Geological consulting & & - & & 7,000 \\
\hline \multirow[t]{2}{*}{ Mobilization/ demobilization } & & - & & 19,095 \\
\hline & & 1,122 & & 68,942 \\
\hline \multicolumn{5}{|l|}{ LK Project: } \\
\hline Acquisition costs & & 526,516 & & - \\
\hline Report & & 1,837 & & 62,286 \\
\hline \multirow[t]{3}{*}{ Travel and support } & & - & & 4,964 \\
\hline & & 528,353 & & 67,250 \\
\hline & $\$$ & 529,475 & S & 136,192 \\
\hline
\end{tabular}

\section{Manitouwadge}

The Company conducts exploration and evaluation expenditures on a property located in Northwestern Ontario and held $100 \%$ by the Company. As at December 31, 2018, a number of claims were forfeited, and the Company had no further obligation with respect to those claims.

\section{LK Project}

The Company holds a 100\% interest in the LK project located in North-central Finland. The LK project was acquired on February 2018 as part of the acquisition of Nortec (Note 4). As at December 31, 2018, a number of claims were in application stage and the Company would continue with the application and further obligation with respect to those claims. 
Alliance Mining Corp, Year-end: 31st December 2018

\section{$\operatorname{Pg} 9$}

c) Exploration and Evaluation Assets

Expenditures related to the acquisition, exploration, and development of exploration and evaluation assets are expensed and charged to earnings in the period in which they are incurred. Any option payments received by the Company from third parties or tax credits refunded to the Company are charged against exploration expenses in the statement of comprehensive loss.

Although the Company has taken steps to verify the title to mineral properties in which it has an interest in accordance with general industry standards, these procedures do not guarantee the Company's title. Such properties may be subject to prior agreements or transfers and, as such, title may be affected.

\section{Pg 14-15}

\section{NOTE 7 - EXPLORATION AND EVALUATION ASSET}

In January 2017, the Company signed an option agreement (the "Agreement") with Tiberius Gold Corp. ("Tiberius") a private company, under which the Company may acquire 100\% of the Red Rice Lake property (the "Property") located in the Bissett Gold Mine Camp in Manitoba (the "Transaction"). Under the terms of the Agreement, the Company may earn-in a 100\% interest in the Property by making certain staged cash payments and/or share payments of common shares of the Company to Tiberius over a four-year period as follows:

\section{NOTE 7 - EXPLORATION AND EVALUATION ASSET (Continued)}

On or before 90 days of the TSX Venture Exchange's approval of the Transaction

On November 21, 2017 the Transaction was approved by the TSX Venture Exchange. Pursuant to the terms of the Agreement, the Company issued 500,000 common shares with a value of \$25,000 to an arm's length party as finder's fee.

The Company made the first payment by issuing 5,000,000 common shares to Tiberius on February 09, 2018. The fair value recognized of $\$ 200,000$ was based on the closing quoted market price of the Company's share at the date of issuance.

In March 2018, the Company entered into three agreements to acquire the net smelter rights (NSR) regarding the Red Rice Lake property. Pursuant to the terms of the agreements, the Company issued a total of 600,000 common shares valued at $\$ 30,000$ and made two cash payments totaling $\$ 50,000$.

In August 2018, the Company signed a Letter of Intent ("LOI") with Jadestone Energy LLC to acquire a 100\% interest in Jadestone's Tonopah Uranium project. The Tonopah Uranium project is located in the Tonopah Mining district in Nye County and Esmerelda Country, Nevada. The project consists of 160 contiguous Bureau of Land Management claims covering an area of 3,200 acres.

Pursuant to the terms of the LOI with Jadestone Energy LLC, the Company may earn-in a 100\% interest in the property by making a cash payment of US $\$ 25,000$ on signing of the LOI (paid), and certain staged cash payments and share payments of common shares in the capital of the Company to Jadestone over a four year period from the date of the signing of the Definitive Agreement as follows: (i) US $\$ 300,000$ in cash; and (ii) US $\$ 1,700,000$ in common shares. The Company must also expend a minimum of US $\$ 600,000$ of exploration expenditures on the property over a four-year period. As of the Auditors' Report date, a Definitive Agreement has not yet been signed. 
Emerald Oil \& Gas Corp, Year-end: 30th June 2018

\section{Pg 35}

(j) Exploration and evaluation expenditure

The exploration and evaluation expenditure accounting policy is to expense expenditure as incurred other than for the capitalisation of acquisition costs.

\section{$\operatorname{Pg}$ 44-45}

\begin{tabular}{|llrr|}
\hline & & \multicolumn{2}{r|}{ Consolidated } \\
& & 2018 & 2017 \\
\hline 12 & Exploration \& Evaluation Expenditure & $\$$ & \\
(a) $\quad$ Non-current & & \\
& Opening balance & & \\
& Exploration and evaluation expenditure incurred & $37,900,933$ & - \\
& Exploration and evaluation expenditure expensed & $5,957,923$ & $7,449,887$ \\
& Acquired on acquisition (Note 28) & $(5,957,923)$ & $(7,449,887)$ \\
& Exploration and feasibility acquisition costs expensed & - & $37,900,933$ \\
& Total non-current exploration and evaluation expenditure & $(4,300,000)$ & - \\
& & $33,600,933$ & $37,900,933$ \\
\hline
\end{tabular}

(b) Recoverability of capitalised acquisition costs

The value of the group's capitalised acquisition costs is dependent upon:

- The continuance of the groups rights to tenure of the areas of interest;

- The results of future exploration and evaluation; and

- The recoupment of costs through successful development and exploitation of the areas of interest, or alternatively, by their sale.

During the year the Company recognised an impairment of $\$ 4,300,000$ relating to the $O^{\prime}$ Chhung exploration license acquisition costs. The Company's intends to recommence activities on this licence however the Company's current short to mid-term focus is the development of the Okvau Gold Project and exploration activities on its other tenure recently acquired under Earn-In/ Joint Venture Agreements and through exploration licence applications. The Company believes it appropriate to recognise an impairment in relation to this licence given there are no current planned exploration programs. 
Lindian Resources, Year-end: 30 June 2018

\section{$\operatorname{Pg} 34$}

(h) Deferred Exploration and Evaluation Expenditure

Exploration and evaluation expenditure incurred by or on behalf of the Group is accumulated separately for each area of interest. Such expenditure comprises net direct costs and an appropriate portion of related overhead expenditure, but does not include general overheads or administrative expenditure not having a specific nexus with a particular area of interest.

Each area of interest is limited to a size related to a known or probable mineral resource capable of supporting a mining operation.

Exploration and evaluation expenditure for each area of interest is carried forward as an asset provided that one of the following conditions is met:

- such costs are expected to be recouped through successful development and exploitation of the area of interest or, alternatively, by its sale; or

- exploration and evaluation activities in the area of interest have not yet reached a stage which permits a reasonable assessment of the existence or otherwise of economically recoverable reserves, and active and significant operations in relation to the area are continuing.

Expenditure which fails to meet the conditions outlined above is written off. Furthermore, the Directors regularly review the carrying value of exploration and evaluation expenditure and make write downs if the values are not expected to be recoverable.

Identifiable exploration assets acquired are recognised as assets at their cost of acquisition, as determined by the requirements of AASB 6 Exploration for and Evaluation of Mineral Resources. Exploration assets acquired are reassessed on a regular basis and these costs are carried forward provided that at least one of the conditions referred to in AASB 6 is met.

Exploration and evaluation expenditure incurred subsequent to acquisition in respect of an exploration asset acquired, is accounted for in accordance with the policy outlined above for exploration expenditure incurred by or on behalf of the entity.

Acquired exploration assets are not written down below acquisition cost until such time as the acquisition cost is not expected to be recovered.

When an area of interest is abandoned, any expenditure carried forward in respect of that area is written off.

Expenditure is not carried forward in respect of any area of interest/mineral resource unless the Group's rights of tenure to that area of interest are current.

Pg 42-43

Consolidated

\section{Deferred Exploration and Evaluation Expenditure}

\section{Exploration and evaluation phase - at cost}

At beginning of the period

$2,164,251$

Exploration expenditure during the year

Acquisition of exploration assets

Impairment expense (i)

$(2,295,954)$

Total exploration and evaluation

(i) The Company elected to impair its capitalised exploration expenditure during the year in relation to its gold assets in Tanzania. The Company is of the view that it is unlikely that substantive expenditure on exploration and evaluation of mineral resources is expected to be incurred on the tenements in the near term while the Company focuses on its bauxite interests in Tanzania and rare earths interests in Malawi. The Company will continue to review its gold assets to achieve the best outcome for shareholders. The recoupment of costs carried forward in relation to areas of interest in the exploration and evaluation phase is dependent on the successful development and commercial exploitation or sale of the respective areas. 
Diamond Fields International, Year-end: 30th June 2018 (extracts from pages 12, 18, and 19 of the annual report)

\section{Pg 12}

(f) Mineral properties

The Company's properties are all currently in the Exploration and Evaluation ("E\&E") stage.

Acquisition and E\&E expenditures incurred prior to the date of a positive economic analysis on the property are expensed as incurred. Direct costs incurred for the development of mineral properties, net of cost recoveries, are capitalized once the technical feasibility and commercial viability of extracting the mineral resource has been determined.

On the commencement of commercial production, the net capitalized costs are charged to operations on a unit-of-production basis, by property, using the estimated proven and probable reserves as the depletion base.

\section{Pg 18}

\section{EXPLORATION EXPENSES}

Atlantis II Red Sea project

South Africa Phosphate project

Namibian Diamond project

Beravina project

Other projects

\begin{tabular}{rr} 
June 30, 2018 & June 30, 2017 \\
$\mathbf{\$}$ & $\$$ \\
$\mathbf{2 , 1 3 0}$ & - \\
$\mathbf{1 3 , 9 6 7}$ & 20,425 \\
$\mathbf{2 3 5 , 0 9 7}$ & 169,270 \\
$\mathbf{1 3 5 , 9 1 8}$ & - \\
$\mathbf{4 , 5 9 5}$ & 10,888 \\
\hline $\mathbf{3 9 1 , 7 0 7}$ & 200,583 \\
\hline
\end{tabular}

Exploration expenses by nature of expenditure are summarized below:

\begin{tabular}{lrr} 
& June 30, 2018 & June 30, 2017 \\
Consulting & $\mathbf{S}$ & $\$$ \\
Travel & $\mathbf{2 2 5 , 3 2 3}$ & 185,680 \\
Sample testing & $\mathbf{5 5 , 8 4 4}$ & 10,538 \\
Licenses & $\mathbf{1 0 9 , 3 2 1}$ & - \\
& $\mathbf{1 , 2 1 9}$ & 4,365 \\
\hline
\end{tabular}

BC Iron, Year-end: 30 June 2018

Pg 40-41

\section{NOTE 9 - EXPLORATION AND EVALUATION}

\begin{tabular}{lr}
$r$ & 2017 \\
& $S 000$ 's \\
\hline Opening balance & 4,600 \\
Exploration earn-in & 1,000 \\
Exploration tenements acquisition & 500 \\
Unsuccessful exploration expenditure derecognised & 9,000 \\
\hline Net carrying amount & $(100)$ \\
\hline
\end{tabular}

Key judgement - Capitalisation of exploration and evaluation expenditure

The Company has capitalised acquired exploration and evaluation expenditure and earn-in expenditure on the basis that either it is expected to be recouped through future successful development (or alternatively sale) of the areas of interest concerned or on the basis that it is not yet possible to assess whether it be recouped. The future recoverability of capitalised exploration and evaluation expenditure is dependent on a number of factors, including whether the Company decides to exploit the related lease itself, or, if not, whether it successfully recovers the related exploration and evaluation asset through sale.

$\mathrm{BCl}$ acquired a number of prospective and underexplored West Pilbara tenements (Kumina and Cane River) from Mineralogy Pty Ltd in September 2017. Consideration for the acquisition was $\$ 9.0 \mathrm{M}$..... These tenements are located within economic trucking distance from BCl's Cape Preston East Port and have the potential to host iron ore deposits which could support an increase in throughput of the Buckland Project to 15Mtpa and enhance the value and marketability of the proposed "Buckland Blend". 
Orosur Mining, Year-end: 31 May 2018

\section{Pg 11-12}

The recoverability of amounts shown for E\&E costs is dependent upon the discovery of economically recoverable reserves. The exploration assets are reassessed on a regular basis for impairment. An impairment of an exploration asset occurs when at least one the following conditions are met:

- the Company's right to explore in an area of interest has expired or will expire in the near future and is not expected to be renewed;

- the Company has strategically decided to discontinue activities in the area of interest;

- substantive exploration expenditure on further exploration in the area of interest is neither budgeted nor planned in the near future and no negotiations to sell the project or farm it out are planned or considerably advanced;

- sufficient work has been performed to indicate that the carrying amount of the expenditure carried forward as an asset will not be fully recovered, even though a viable mine has been discovered.

The capitalized E\&E related to the project is written off in the period it is considered impaired under the criteria outlined above.

$\operatorname{Pg} 25$

\begin{tabular}{lrrrr}
\hline & Uruguay & Chile & Colombia & Total \\
\hline May 31, 2016 & $\mathbf{4 , 4 1 8}$ & $\mathbf{6 , 4 0 7}$ & $\mathbf{6 , 4 2 6}$ & $\mathbf{1 7 , 2 5 1}$ \\
Cash expenditure & 1,576 & 318 & 710 & 2,604 \\
Foreign exchange movement & - & - & 94 & 94 \\
Other & $(68)$ & - & 25 & $(43)$ \\
Transfer to depreciable assets & $(2,098)$ & - & - & $(2,098)$ \\
Written-off & $(131)$ & - & - & $(131)$ \\
\hline May 31, 2017 & 3,697 & 6,725 & $\mathbf{7 , 2 5 5}$ & $\mathbf{1 7 , 6 7 7}$ \\
Cash expenditure & 2,550 & 176 & 2,457 & 5,183 \\
Foreign exchange movement & - & - & 43 & 43 \\
Other & 487 & $(559)$ & - & $(72)$ \\
Transfer to depreciable assets & $(735)$ & - & - & $(735)$ \\
Reclassification of asset held for sale & - & $(120)$ & - & $(120)$ \\
Written-off & $(5,999)$ & $(6,222)$ & $-(12,221)$ \\
\hline May 31, 2018 & - & - & $\mathbf{9 , 7 5 5}$ & $\mathbf{9 , 7 5 5}$ \\
\hline
\end{tabular}

(b) Impairment of exploration projects, exploration projects evaluation and resource definition work

Management determined based on the results of drilling activity completed during the year that the carrying value of certain capitalized exploration expenditures attributed to specific projects was impaired as substantive expenditure or further exploration and evaluation activities in those areas is neither budgeted nor planned in the foreseeable future. As a result, an impairment of \$12,221 (2017 - \$131) was recognized as explained in Note 10. 


\section{Millenium Minerals, Year-end: 31st December 2018}

Pg 43-44

\section{G. Key accounting estimates, judgements and assumptions}

\section{...}

Impairment of exploration assets

The recoverable amount of the Company's exploration and evaluation assets are reviewed at each reporting period to determine if there is any indication of impairment.

Exploration and evaluation assets are tested for impairment if:

(i) sufficient data exists to determine technical feasibility and commercial viability is unlikely, or

(ii) facts and circumstances suggest the carrying value exceeds the recoverable amount. The application of this policy requires management to make certain estimates and assumptions about future events or circumstances, in particular, whether an economically viable extraction operation can be established.

These estimates and assumptions may change as new information becomes available and could have a material impact on the carrying value of exploration and evaluation assets. If, after expenditure is capitalised, information becomes available suggesting that the recovery of expenditure is unlikely, the relevant capitalised amount is tested for impairment in the period when the new information becomes available.

\section{$\operatorname{Pg} 52$}

\begin{tabular}{lrr} 
& 2018 & 2017 \\
$\$ \prime 000$ \\
\hline Opening balance at 1 January & $\$ 2000$ & 20,120 \\
Expenditure capitalised for the year & 25,574 & 23,308 \\
Acquisition of tenements (i) & 61 & 15 \\
Reclassification to mine development & $(16,665)$ & $(9,913)$ \\
Impairment (ii) & $(1,463)$ & $(1,143)$ \\
\hline Closing balance at 31 December & $\mathbf{3 9 , 8 9 4}$ & $\mathbf{3 2 , 3 8 7}$ \\
\hline
\end{tabular}

(ii) Impairment

The impairment relates to the relinquishment of tenements in areas of interest where no future exploration and evaluation activities are expected, and the carrying amount of the exploration expenditure relating to these areas was written down to $\$ 0$. 
SDX Energy, Year-end: 31 December 2018

Pg 60

Exploration and evaluation expenditures ...

Exploration and evaluation expenditures, including the costs of acquiring licences and directly attributable general and administrative costs, geological and geophysical costs, acquisition of mineral and surface rights, technical studies, other direct costs of exploration (drilling, trenching, sampling, and evaluating the technical feasibility and commercial viability of extraction) and appraisal are accumulated and capitalized as intangible exploration and evaluation ("E\&E") assets.

...

\section{$\operatorname{Pg} 72$}

10. Exploration and evaluation assets

US\$000s

Balance at December 31, 2016

\begin{tabular}{lr} 
Additions & 4,608 \\
\hline
\end{tabular}

\begin{tabular}{ll} 
Balance at December 31, 2017 & 15,231 \\
\hline
\end{tabular}

$\begin{array}{ll}\text { Additions } & 29,000\end{array}$

Exploration and evaluation expense $\quad(5,103)$

\begin{tabular}{ll}
\hline Balance at December 31, 2018 & 39,128
\end{tabular}

During the twelve months ended December 31, 2018, E\&E additions amounted to US\$29.0 million.

Of this, US\$8.5 million was invested at South Disouq for the drilling of the Ibn Yunus-1X, Kelvin-1X, SD-4X, and SD-3X wells. Following the interpretation of well logs, Kelvin-1X was deemed non-commercial and the associated costs (US\$1.6 million) were expensed to the Consolidated Statement of Comprehensive Income. A further US\$2.1 million was capitalized, representing the costs of the 3D seismic acquisition that began in Q4 2018.

Additions in Morocco relate to the drilling of the ELQ-1, KSS-2, LNB-1, and LMS-1 wells (US\$9.4 million) and US\$6.4 million for the current 3D seismic campaign. Following sub-commercial results at the ELQ-1 and KSS-2 wells, the full costs of these two wells (US\$3.5 million) were expensed.

US\$2.6 million of costs relating to the South Ramadan SRM-3 well were incurred during the year. 
Wentworth Resources, Year-end: 31 December 2018

\section{Pg77}

\section{E\&E exploration assets} $\ldots$

E\&E assets are assessed for impairment if (i) sufficient data exists to determine technical feasibility and commercial viability, and (ii) facts and circumstances suggest that the carrying amount exceeds the recoverable amount.

The technical feasibility and commercial viability of extracting a resource is generally considered to be determinable when proven and/or probable reserves are determined to exist. A review of each exploration licence or field is carried out, at least annually, to ascertain whether it is technically feasible and commercially viable. Upon determination of technical feasibility and commercial viability, intangible E\&E assets attributable to those reserves are first tested for impairment with the unimpaired amounts reclassified from E\&E assets to a separate category within tangible assets within PP\&E referred to as oil and gas interests.

\section{$\operatorname{Pg} 94$}

\begin{tabular}{lrrr} 
& Tanzania & Mozambique & Total \\
\$000 & & & $\begin{array}{r}\text { \$000 } \\
\text { Cost }\end{array}$ \\
\hline Balance at 31 December 2016 & 8.129 & 37.409 & 45.538 \\
\hline Additions & - & 2.383 & 2.383 \\
\hline Balance at 31 December 2017 & 8.129 & 39.792 & 47.921 \\
\hline Additions & - & 1.806 & 1,806 \\
Impairment loss & - & $(41.598)$ & $(41.598)$ \\
\hline Balance at 31 December 2018 & 8,129 & - & 8,129 \\
\hline
\end{tabular}

The Company performed a technical and commercial review of the Mozambique E\&E asset portfolio and determined that Tembo licence did not provide the Company with suitable monetisation solutions in keeping with Company material growth mandate. At 31 December 2017, all Mozambique E\&E assets of \$41.6 million were impaired.

Tanzania E\&E assets were $\$ 8.1$ million (31 December 2017 - \$8.1 million). The Mnazi Bay Concession agreement expires in 2031. The Mnazi Bay joint venture partners have identified several prospects within the concession area but outside of the area covering discovered gas reserves and therefore has concluded that an impairment test is not required for the Tanzanian asset 
Echo Energy, Year-end: 31st December 2018

$\mathrm{Pg} 47$

(g) Other intangible assets - exploration and evaluation costs

Exploration and evaluation ("E\&E") expenditure comprises costs which are directly attributable to researching and analysing exploration data. It also includes the costs incurred in acquiring mineral rights, the entry premiums paid to gain access to areas of interest and amounts payable to third parties to acquire interests in existing projects. When it has been established that a mineral deposit has development potential, all costs (direct and applicable overhead) incurred in connection with the exploration and development of the mineral deposits are capitalised until either production commences or the project is not considered economically viable. In the event of production commencing, the capitalised costs are amortised over the expected life of the mineral reserves on a unit of production basis. Other pre-trading expenses are written off as incurred. Where a project is abandoned or is considered to be of no further interest, the related costs are written off.

\section{(h) Impairment of tangible and intangible assets excluding goodwill}

At each balance sheet date, the Group reviews the carrying amounts of its tangible and intangible assets to determine whether there is any indication that those assets have suffered an impairment loss. If any such indication exists, the recoverable amount of the asset is estimated in order to determine the extent of the impairment loss (if any). Where it is not possible to estimate the recoverable amount of an individual asset, the Group estimates the recoverable amount of the cash-generating unit ("CGU") to which the asset belongs.

The recoverable amount is the higher of fair value less costs to sell or value in use. In assessing value in use, the estimated future cash flows are discounted to their present value using a pre-tax discount rate that reflects the current market assessments of the time value of money and the risks specific to the asset. If the recoverable amount of an asset (or CGU) is estimated to be less than its carrying amount, the carrying amount of the asset is reduced to its recoverable amount. An impairment loss is recognised immediately in profit or loss, unless the relevant asset is carried at a revalued amount, in which case the impairment loss is treated as a revaluation decrease.

Where an impairment loss subsequently reverses, the carrying amount of the asset is increased to the revised estimate of its recoverable amount, but so that the increased carrying amount does not exceed the carrying amount that would have been determined had no impairment loss been recognised for the asset (CGU) in prior years. A reversal of an impairment loss is recognised immediately in profit or loss, unless the relevant asset is carried at a re-valued amount, in which case the reversal of the impairment loss is treated as a revaluation increase.

Pg 59

\section{Other Intangible Assets (Group)}

\section{Exploration and Evaluation}

$\begin{array}{rrr}\text { Argentina } & \text { Ksar Hadada } & \\ \text { Exploration \& } & \text { Exploration } & \\ \text { Evaluation } & \text { Acreage } & \text { Tota } \\ \text { US\$ } & \text { US\$ } & \text { US\$ }\end{array}$

\begin{tabular}{|c|c|c|c|}
\hline 31 DECEMBER 2018 & & & \\
\hline \multicolumn{4}{|l|}{ Cost } \\
\hline 1 January 2018 & $2,500,000$ & $2,043,429$ & $4,543,429$ \\
\hline Additions & $14,479,134$ & - & $14,479,134$ \\
\hline Transfer to PP\&E & $(1,270,832)$ & - & $(1,270,832)$ \\
\hline 31 December 2018 & $15,708,302$ & $2,043,429$ & $17,751,731$ \\
\hline \multicolumn{4}{|l|}{ Impairment } \\
\hline 1 January 2018 & - & $2,043,429$ & $2,043,429$ \\
\hline Impairment charge for the year & $14,148,371$ & - & $14,148,371$ \\
\hline 31 December 2018 & $14,148,371$ & $2,043,429$ & $16,191,800$ \\
\hline \multicolumn{4}{|l|}{ Carrying amount } \\
\hline 31 December 2018 & $1,559,931$ & - & $1,559,931$ \\
\hline 31 December 2017 & $2,500,000$ & - & $2,500,000$ \\
\hline
\end{tabular}




\begin{tabular}{|c|c|c|c|}
\hline 31 DECEMBER 2017 & & & \\
\hline \multicolumn{4}{|l|}{ Cost } \\
\hline 1 January 2017 & - & $1,866,235$ & $1,866,235$ \\
\hline Exchange arising on retranslation & - & 177,194 & 177,194 \\
\hline Additions & $2,500,000$ & - & $2,500,000$ \\
\hline 31 December 2017 & $2,500,000$ & $2,043,429$ & $4,543,429$ \\
\hline \multicolumn{4}{|l|}{ Impairment } \\
\hline 1 January 2017 & - & $1,332,889$ & $1,332,889$ \\
\hline Impairment charge for the year & - & 556,999 & 556,999 \\
\hline Exchange & - & 153,541 & 153,541 \\
\hline 31 December 2017 & - & $2,043,429$ & $2,043,429$ \\
\hline \multicolumn{4}{|l|}{ Carrying amount } \\
\hline 31 December 2017 & $2,500,000$ & - & $2,500,000$ \\
\hline 31 December 2016 & - & 533,346 & 533,346 \\
\hline
\end{tabular}

Physical property, plant and equipment acquired as part of the acquisition of the producing assets in Fraccion C, D and Laguna De Los Capones were transferred from intangible assets and depleted on a unit of production basis during the year. A decision was made to impair the CDL assets following the results of the drilling campaign carried out during 2018 .

\section{GTI Resources, Year-end: 31 December 2018}

\section{Pg 29}

Exploration and evaluation expenditure

Exploration, evaluation and development expenditure incurred accumulated in respect of each identifiable area of interest. These costs are carried forward only if they relate to an area of interest for which rights of tenure are current and in respect of which:

(i) such costs are expected to be recouped through successful development and exploitation or from sale of the area; or

(j) exploration and evaluation activities in the area have not, at balance date, reached a stage which permits a reasonable assessment of the existence or otherwise of economically recoverable reserves, and active operations in, or relating to, the area are continuing.

Accumulated costs in respect of areas of interest which are abandoned are written off in full against profit in the period in which the decision to abandon the area is made. A regular review is undertaken of each area of interest to determine the appropriateness of continuing to carry forward costs in relation to that area of interest.

Notwithstanding the fact that a decision not to abandon an area of interest has been made, based on the above, the exploration and evaluation expenditure in relation to an area may still be written off if considered appropriate to do so.

\section{$\operatorname{Pg} 35$}

\section{Exploration and Evaluation Expenditure}

Balance at beginning of year

Capitalized during the year

Incurred during the year

67,585

Impaired during the year

$(67,585)$

\begin{tabular}{rr}
\hline 2018 & 2017 \\
$\$$ & $\$$ \\
\hline & \\
- & - \\
- & - \\
67,585 & 183,880 \\
$(67,585)$ & $(183,880)$ \\
- & - \\
\hline- & - \\
\hline
\end{tabular}


Carbon Minerals, Year-end: 31 December 2018

Pg 32

Critical accounting estimates and assumptions

$\ldots$

Exploration and evaluation expenditure

Certain exploration and evaluation expenditure is capitalised where it is considered likely that the expenditure will be recovered by future exploitation or sale, or where activities have not reached a stage which permits a reasonable assessment of the existence of commercially recoverable reserves. This process necessarily requires management to make certain estimates and assumptions as to future events and circumstances, in particular, whether economically viable extraction operations can be established. Any such estimates and assumptions may change as new information becomes available. If, after having capitalised expenditure under this policy it is concluded unlikely that the expenditure will be recovered by future exploitation or sale, the relevant amount capitalised is written off to the income statement. The Group's accounting policy for exploration and evaluation is set out in Note 1 (I).

\section{Pg 36}

\section{Note 13: $\quad$ Non-current assets - exploration and evaluation expenditure}

$\begin{array}{cc}2018 & 2017 \\ \$ & \$\end{array}$

Cost brought forward

Expenditure incurred during the year

Less impairment

\begin{tabular}{rr}
$\mathbf{7 , 5 0 3 , 0 9 0}$ & $7,294,318$ \\
$\mathbf{2 0 4 , 7 7 9}$ & 208,772 \\
\hline $\mathbf{7 , 7 0 7 , 8 6 9}$ & $7,503,090$ \\
$\mathbf{( 7 , 7 0 7 , 8 6 9 )}$ & $(7,503,090)$ \\
\hline
\end{tabular}

Net exploration and evaluation expenditure carried forward

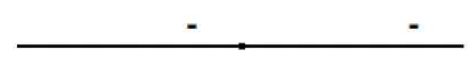

The carrying amounts of the Group's exploration and evaluation assets are reviewed at each reporting date to determine whether there is any indication of impairment. The impairment charge of $\$ 7.708 \mathrm{M}$ noted above primarily results from the ongoing low prices for oil/gas. Where an indicator of impairment exists, a formal estimate of the recoverable amount is made. The recoverable amount of the Group's exploration and evaluation assets are based on its fair value less costs of disposal. The recoverable amount of the Group's exploration and evaluation assets is nil.

Pursuit Minerals, Year-end: 30 June 2018

Pg 34-35

b) Significant management judgement in applying accounting policies and estimate uncertainty ...

\section{Exploration and evaluation expenditure}

The application of the Consolidated Entity's accounting policy for exploration and evaluation expenditure requires judgement in determining whether it is likely that future economic benefits are likely either from future exploitation or sale or where activities have not reached a stage which permits a reasonable assessment of the existence of reserves. The determination of a Joint Ore Reserves Committee (JORC) resource is itself an estimation process that requires varying degrees of uncertainty depending on sub-classification and these estimates directly impact the point of deferral policy requires management to make certain estimates and assumptions about future events or circumstances, in particular whether an economically viable extraction operation can be established. Estimates and assumptions made may change if new information becomes available. 
Ora Gold (previous name THUNDELARRA LIMITED), Year-end: 30 September 2018

\section{Pg 63}

\section{Exploration expenditure}

(i) Exploration, development and joint venture expenditure carried forward represents an accumulation of net costs incurred in relation to separate areas of interest for which rights of tenure are current and in respect of which:

(a) such costs are expected to be recouped through successful development and exploitation of the area, or alternatively by its sale, or

(b) exploration and/or evaluation activities in the area have not yet reached a stage which permits a reasonable assessment of the existence or otherwise of economically recoverable reserves, and active and significant operations in, or in relation to the areas are continuing.

Accumulated costs in respect of areas of interest, which are abandoned, are written off in the income statement in the year in which the area is abandoned.

\section{Pg 73}

\section{EXPLORATION EXPENDITURE (NON-CURRENT)}

\section{Exploration and evaluation}

At 1 October 2017
Expenditure incurred during the year
Expenditure provided or written off during the year (note 4(d))
At 30 September 2018

\begin{tabular}{rr}
$4,177,164$ & $3,041,985$ \\
$(4,177,164)$ & $(3,041,985)$ \\
\hline
\end{tabular}

For those areas of interest which are still in the exploration phase, the ultimate recoupment of the stated costs is dependent upon the successful development and commercial exploitation, or alternatively sale of the respective areas of interest (refer to note 24).

Some of the Consolidated entity's exploration properties are subject to claim(s) under native title. As a result, exploration properties or areas within the tenements may be subject to exploration and/or mining restrictions.

\section{$\operatorname{Pg} 70$}

4. REVENUE AND EXPENSES

\begin{tabular}{|cc|}
\hline \multicolumn{2}{|c|}{ Consolidated } \\
2018 & 2017 \\
$\$$ & $\$$ \\
\hline
\end{tabular}

(d) Exploration Expenditure Written Off

Exploration expenditure written-off or impaired

$(4,177,164)$ $(3,041,985)$ 
International Battery Metals, Year-end: 31 January 2018

\section{Pg 2}

\section{Exploration and evaluation properties}

Exploration and evaluation expenditures include the costs of acquiring licenses, costs associated with exploration and evaluation activity, and the fair value (at acquisition date) of exploration and evaluation assets acquired in a business combination. Exploration and evaluation expenditures are capitalized. Costs incurred before the Company has obtained the legal rights to explore an area, are recognized in profit or loss.

Option payments received are treated as a reduction of the carrying value of the related exploration and evaluation properties and deferred costs until the receipts are in excess of costs incurred, at which time they are credited to income. Option payments are at the discretion of the optionee, and accordingly, are recorded on a cash basis.

Exploration and evaluation assets are assessed for impairment if (i) sufficient data exists to determine technical feasibility and commercial viability, and (ii) facts and circumstances suggest that the carrying amount exceeds the recoverable amount. The recoverable amount is the higher of fair value less costs to sell and value in use at that time.

Once the technical feasibility and commercial viability of the extraction of mineral resources in an area of interest are demonstrable, exploration and evaluation assets attributable to that area of interest are first tested for impairment and then reclassified to mining property and development assets within property, plant and equipment.

Recoverability of the carrying amount of any exploration and evaluation assets is dependent on successful development and commercial exploitation, or alternatively, sale of the respective areas of interest.

\section{Pg 12-13}

\section{Exploration and Evaluation Properties}

The Company's exploration and evaluation properties expenditures for the year ended 31 January 2018 were as follows:

\begin{tabular}{lrrrr} 
& $\begin{array}{r}\text { Bygoo Tin } \\
\text { Property }\end{array}$ & $\begin{array}{r}\text { Woodbury } \\
\text { Property }\end{array}$ & $\begin{array}{r}\text { Pattullo } \\
\text { Property }\end{array}$ & Total \\
\hline ACQUISITION COSTS & $\$$ & $\$$ & $\$$ & $\$$ \\
Balance, 31 January 2017 & & & - & - \\
Additions & - & 100 & - & 389,674 \\
Impairment write-down & 389,574 & $(100)$ & - & $(389,674)$ \\
\hline Balance, 31 January 2018 & $(389,574)$ & - & - & - \\
\hline
\end{tabular}

\section{EXPLORATION AND EVALUATION COSTS}

Balance, 31 January 2017

Additions

Impairment write-down

10,700

$(10,700)$

Total 


\section{Exploration and Evaluation Properties (Continued)}

The Company's exploration and evaluation properties expenditures for the year ended 31 January 2017 were as follows:

\begin{tabular}{lrrrr} 
& $\begin{array}{r}\text { Bygoo Tin } \\
\text { Property }\end{array}$ & $\begin{array}{r}\text { Woodbury } \\
\text { Property }\end{array}$ & $\begin{array}{r}\text { Pattullo } \\
\text { Property }\end{array}$ & Total \\
\hline ACQUISITION COSTS & $\$$ & $\$$ & $\$$ & $\$$ \\
Balance, 31 January 2016 & - & - & - & - \\
Additions & - & - & 1,500 & 1,500 \\
Impairment write-down & - & - & $(1,500)$ & $(1,500)$ \\
\hline Balance, 31 January 2017 & - & - & - & - \\
\hline
\end{tabular}

\section{EXPLORATION AND EVALUATION \\ COSTS}

Balance, 31 January 2016

Impairment write-down

Balance, 31 January 2017

\section{Total}

\section{Bygoo Tin Property}

On May 24, 2017 the Company entered an option agreement (the "Sub-Option Agreement"), subsequently amended, with BeiSur OstBarat Agency Ltd. ("BOAL"). BOAL holds an option to earn a 51\% undivided interest, with an option to acquire up to a further 25\% interest in the Bygoo Tin Project (the "Property"), located in New South Wales, Australia. BOAL's interest in the Property is subject to an underlying agreement between BOAL and Riverston Tin Pty Ltd. ("Riverston").

During the year ended January 31, 2018, the Company paid $\$ 230,780$ (AUD $\$ 228,000$ ), reimbursed expenses of $\$ 108,974$, and issued 150,970 shares valued at $\$ 49,820$ as option payments.

During the year ended January 31, 2018, the Company defaulted on its option on this property. Accordingly, the property was written down to \$nil. 


\section{PI-INTANGIBLES-E\&E-EI}

ACCA The Adelphi 1/11 John Adam Street London WC2N 6AU United Kingdom / +44 (0)20 70595000 / www.accaglobal.com 